\title{
Skeletal muscle lipid metabolism: a magnetic resonance spectroscopy study
}

Citation for published version (APA):

Schrauwen-Hinderling, V. B. (2006). Skeletal muscle lipid metabolism: a magnetic resonance spectroscopy study. [Doctoral Thesis, Maastricht University]. Datawyse. https://doi.org/10.26481/dis.20060524vs

Document status and date:

Published: 01/01/2006

DOI:

10.26481/dis.20060524vs

Document Version:

Publisher's PDF, also known as Version of record

\section{Please check the document version of this publication:}

- A submitted manuscript is the version of the article upon submission and before peer-review. There can be important differences between the submitted version and the official published version of record.

People interested in the research are advised to contact the author for the final version of the publication, or visit the DOI to the publisher's website.

- The final author version and the galley proof are versions of the publication after peer review.

- The final published version features the final layout of the paper including the volume, issue and page numbers.

Link to publication

\footnotetext{
General rights rights.

- You may freely distribute the URL identifying the publication in the public portal. please follow below link for the End User Agreement:

www.umlib.nl/taverne-license

Take down policy

If you believe that this document breaches copyright please contact us at:

repository@maastrichtuniversity.nl

providing details and we will investigate your claim.
}

Copyright and moral rights for the publications made accessible in the public portal are retained by the authors and/or other copyright owners and it is a condition of accessing publications that users recognise and abide by the legal requirements associated with these

- Users may download and print one copy of any publication from the public portal for the purpose of private study or research.

- You may not further distribute the material or use it for any profit-making activity or commercial gain

If the publication is distributed under the terms of Article $25 \mathrm{fa}$ of the Dutch Copyright Act, indicated by the "Taverne" license above, 
SKELETAL MUSCLE LIPID METABOLISM:

A MAGNETIC RESONANCE SPECTROSCOPY STUDY 


\section{nutim}

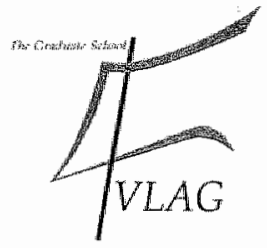

The study presented in this thesis was performed at the Nutrition and Toxicology Research Institute Maastricht (NUTRIM) which participates in the Graduate School VLAG (Food Technology, Agrobiotechnology, Nutrition and Health Sciences), accredited by the Royal Netherlands Academy of Arts and Sciences

Cover design: Vera Schrauwen-Hinderling and Annet Gericke, Datawyse Lay-out: Ine Kengen

Printed by: Datawyse

ISBN-10: 9052785244

ISBN-13: 9789052785240

Copyright (C) Vera Schrauwen-Hinderling, Maastricht 2006.

Financial support for publication of this thesis was generously provided by: Philips Medical Systems and Kodak 
SKELETAL MUSCLE LIPID METABOLISM:

A MAGNETIC RESONANCE SPECTROSCOPY STUDY

\section{Proefschrift}

ter verkrijging van de graad van doctor aan de Universiteit Maastricht, op gezag van Rector Magnificus

Prof. mr. G.P.M.F. Mols, volgens het besluit van het College van Decanen, in het openbaar te verdedigen op woensdag 24 mei 2006 om 16.00 uur

door

Vera Bettina Schrauwen-Hinderling

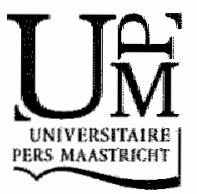


Promotores:

Prof. dr. J.M.A. van Engelshoven

Prof. dr. K. Nicolay (Technische Universiteit Eindhoven)

\section{Copromotor:}

Dr. M.E. Kooi

Dr. P. Schrauwen

\section{Beoordelingscommissie}

Prof. dr. G.J. van der Vusse (voorzitter)

Dr. E.E. Blaak

Prof. dr. A. Heerschap (Radboud Universiteit Nijmegen)

Prof. dr. H. Kuipers

Prof. dr. A.M. Schols 


\section{CONTENTS}

$\begin{array}{lll}\text { Chapter 1: } & \text { General introduction } & 8\end{array}$

$\begin{array}{lll}\text { Chapter 2: } & \text { Techniques } & 18\end{array}$

Chapter 3: $\quad$ The increase in intramyocellular lipid content is a very early response to training

Chapter 4: The accumulation of intramyocellular lipids (IMCL) with short-term training is accompanied by a down regulation of $\mathrm{ACC} 2 \mathrm{mRNA}$ in skeletal muscle

Chapter 5: Intramyocellular lipid content and molecular adaptations in response to a one-week high-fat diet

Chapter 6: Influence of prolonged endurance cycling and recovery diet on intramuscular triglyceride content in trained males

Chapter 7: Intramyocellular lipid content is increased after exercise in non-exercising human skeletal muscle

Chapter 8: Intramyocellular lipid content and in vivo mitochondrial function of patients with type 2 diabetes mellitus and BMI matched controls

Chapter 9: $\quad$ General discussion

Nederlandse samenvatting $\quad 148$

Dankwoord 154

Curriculum vitae and publications $\quad 158$ 



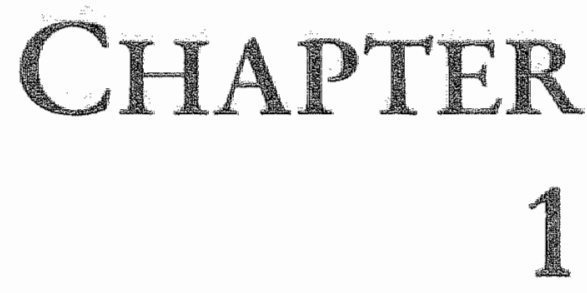

GENERAL INTRODUCTION 


\section{Introduction}

Although most fat in the human body is stored in adipose tissue, a small fraction is located inside skeletal muscle cells in the form of lipid droplets in the sarcoplasm (intramyocellular lipid, IMCL). This thesis focuses on the investigation of intramyocellular lipid content of skeletal muscle under various circumstances as measured by proton Magnetic Resonance Spectroscopy (H-MRS). In this chapter, the relation between IMCL content, insulin resistance, and oxidative capacity is shortly discussed. Then, the background for the determination of oxidative capacity is given, as well as the outline of the thesis.

\section{IMCL, insulin resistance and oxidative capacity}

Initially, much data on the function of IMCL came from studies using electron microscopy and revealed that these lipid droplets in the sarcoplasm are very often in close contact with mitochondria. Since mitochondria are energy producing organelles, this may suggest that the lipid droplets may serve as an important fuel for oxidation during physical exercise. In line with the use of IMCL during exercise, an increased IMCL content is found in endurance trained subjects $(1,2)$, who rely more heavily on fat oxidation during exercise than untrained subjects. Also, oxidative muscle fibre types (type 1 muscle fibres) are characterized by a higher fat content compared to glycolytic fibre types (type 2 muscle fibres) (3).

Interestingly, IMCL content is also increased in type 2 diabetes mellitus (T2DM) patients $(2,4)$ and subjects with insulin resistance (5) and moreover, correlations between insulin resistance and IMCL content have been reported $(6,7)$. Insulin resistance is a condition where cells no longer respond adequately to insulin. In the healthy state, insulin is interacting with the insulin receptor and through a cascade of intracellular signalling, vesicles with glucose transporters subtype 4 (GLUT4) are translocated to the plasma membrane, causing glucose uptake into the cell. The correlation of IMCL content with insulin resistance has been suggested to be due to increased IMCL levels interfering with insulin signalling. However, endurance trained athletes are very insulin sensitive and are, as mentioned characterized by a high IMCL content. This paradox might be explained by the fact that in obesity and insulin resistance, next to triglyceride, also lipid metabolites may accumulate. When IMCLs are incompletely metabolised, fatty acid acyl-CoA, DAG and ceramides are formed as intermediates and can accumulate in myocytes. These intermediates can interfere with insulin sensitivity (8) leading to decreased translocation of GLUT4 protein to the plasma membrane (see Figure 1.1). On the other hand, these metabolites probably do not accumulate if IMCL can be efficiently directed to oxidation, as is the case in the trained state. Therefore, as the accumulation of lipid metabolites 
may be due to a mismatch between fat oxidative capacity and the availability of fat, it has been suggested that the oxidative capacity might also be important in determining insulin sensitivity $(2,9)$. Interestingly, trained arhletes are characterized by a high IMCL content together with a high oxidative capacity and the latter might explain their high insulin sensitivity: when fat oxidative capacity is high, the potentially hazardous fat metabolites will be rapidly diverted to oxidation and therefore, cytosolic concentration will stay low, not interfering with insulin signalling.

Insight in the oxidative capacity of skeletal muscle can be gained by investigating phosphocreatine (PCr) kinetics during recovery immediately after exercise as will be explained in the next paragraph.

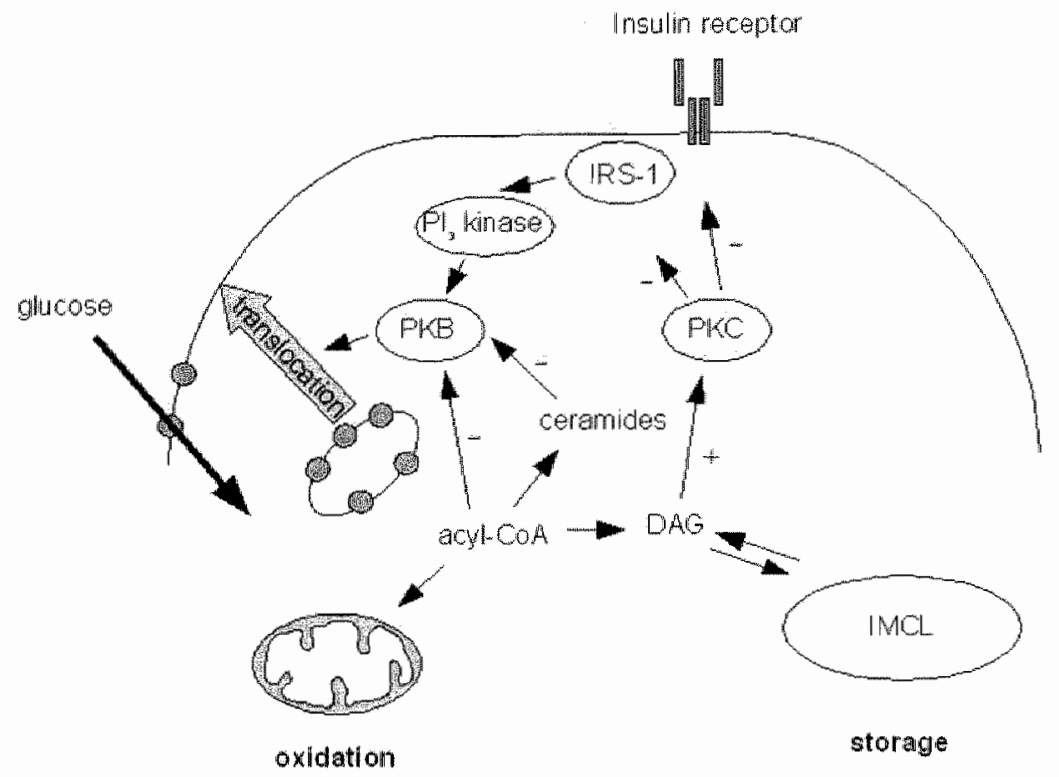

Figure 1.1: Schematic representation of possible interactions between IMCL, lipid metabolites and insulin signalling, with + representing enhancing, and representing inhibitory interactions. The small grey circles represent GLUT4 protein. $\mathrm{PKB}=$ protein kinase $\mathrm{B}, \mathrm{PKC}=$ protein kinase $\mathrm{C}, \mathrm{IRS}-1=$ insulin receptor substrate $1, D A G=$ Diacylglycerol, acyl-CoA $=$ acyl-coenzymeA

\section{Oxidative capacity and PCr kinetics}

Many energy-consuming processes are driven by ATP hydrolysis, including the contraction of skeletal muscle (see Equation 1.3.1).

$$
\mathrm{ATP}+\mathrm{H}_{2} \mathrm{O} \stackrel{\mathrm{ADP}}{\longrightarrow} \mathrm{Pi}+\mathrm{H}^{+}+\operatorname{energy}(1.1)
$$

Because ATP concentration in muscle is low, ATP needs to be regenerated continuously in order to make sustained contraction possible. The oxidative 
capacity is the capacity to synthesize ATP by fully oxidizing substrate (mainly fat and glucose) to carbon dioxide $\left(\mathrm{CO}_{2}\right)$ and water $\left(\mathrm{H}_{2} \mathrm{O}\right)$ (see Table 1.1 full aerobic oxidation of glucose and oxidation of fatty acids). Oxygen $\left(\mathrm{O}_{2}\right)$ is required as electron acceptor in this process.

The transmission of electrons to $\mathrm{O}_{2}$ and the coupled formation of ATP take place in mitochondria. Therefore, oxidative capacity is also named mitochondrial capacity or mitochondrial function (see Figure 1.2).

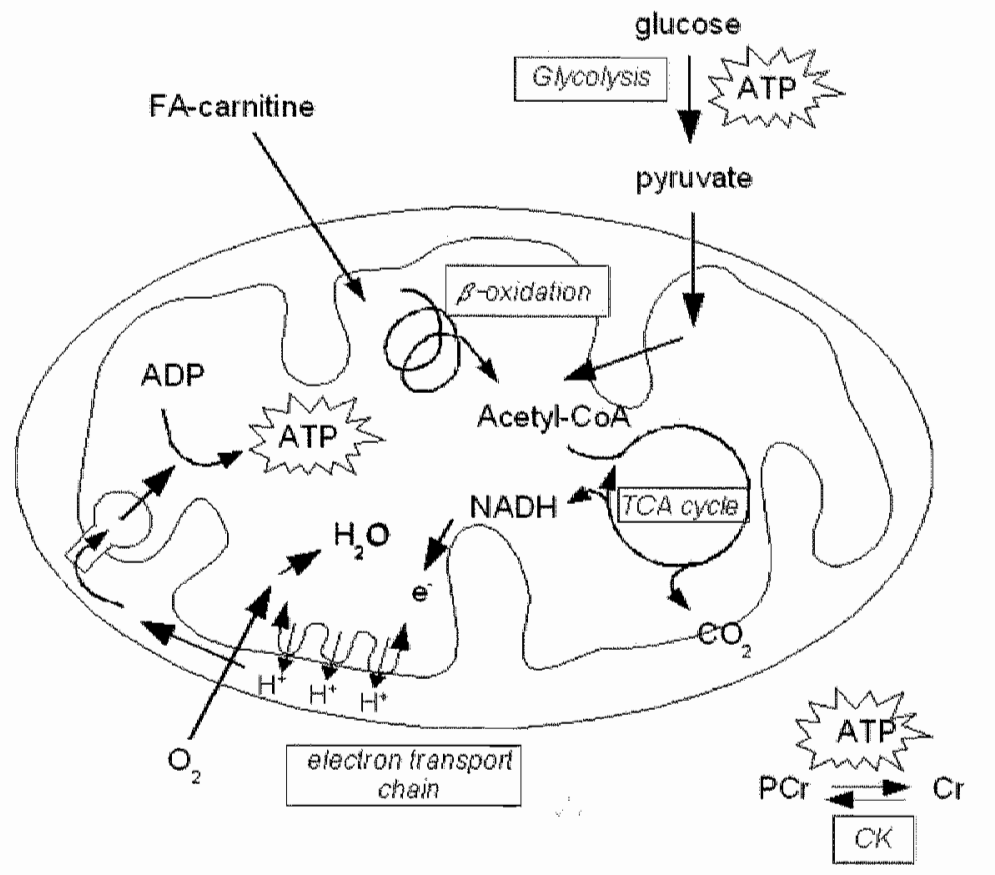

Figure 1.2 Schematic depiction of the oxidative generation of ATP int the mitochondria and the anaerobic ATP generation (glycolysis) in the cytosol. FA = fatry acid, Aceryl-CoA = Acetyl-CoenzymeA, TCA cycle = Tricarboxylic acid cycle, NADH nicotinamide adenine dinucleoride (reduced form), CK = creatine kinase.

The mitochondria are not the only site of ATP formation, although the most important one. The partial breakdown of glucose to pyruvate (which can be transformed to lactate) does not require oxygen and already furnishes ATP. This process is called anaerobic glycolysis (see Table 1.1 and Figure 1.2). Furthermore, the high-energy phosphate metabolite $\mathrm{PCr}$ can donate a phosphate group to ADP to form ATP, a reaction that is catalysed by the enzyme creatine kinase (see Table 1.1 and Figure 1.2).

Although ATP is continuously used during exercise, the ATP concentration barely changes, indicating that these well-regulated mechanisms indeed ensure the maintenance of ATP stores. 
Table 1.1: ATP producing partways that are engaged to keep the ATP concentration constant.

\begin{tabular}{|c|c|c|}
\hline $\begin{array}{l}\text { ATP producing } \\
\text { pathway }\end{array}$ & & ATP yield \\
\hline $\begin{array}{l}\text { Full aerobic } \\
\text { oxidation of glucose }\end{array}$ & glucose $+6 \mathrm{O}_{2} \longrightarrow 6 \mathrm{CO}_{2}+6 \mathrm{H} \mathrm{O}$ & $-38 \mathrm{ATP}$ \\
\hline $\begin{array}{l}\text { Oxidation of fatty } \\
\text { acids (palmitic acid) }\end{array}$ & palmitic acid $+23 \mathrm{O}_{2} \longrightarrow 16 \mathrm{CO}_{2}+16 \mathrm{H}_{2} \mathrm{O}$ & $\sim 130 \mathrm{ATP}$ \\
\hline Anaerobic glycolysis & glucose $\longrightarrow 2$ pyruwate $+2 \mathrm{H}^{+}+2 \mathrm{H}_{2} \mathrm{O}$ & $2 \mathrm{ATP}$ \\
\hline Hydrolysis of $\mathrm{PCr}$ & $\mathrm{PCr}+\mathrm{H}^{+} \longrightarrow \mathrm{Cr}+\mathrm{Pi}$ & $1 \mathrm{ATP}$ \\
\hline
\end{tabular}

At the beginning of exercise, the splitting of $\mathrm{PCr}$ is an important tool to regenerate ATP and thereby making continued contraction possible. In line with this, the concentration of $\mathrm{PCr}$ decreases at the beginning of exercise. At submaximal exercise intensities, the $\mathrm{PCr}$ concentration stabilizes and a steady state is reached when other ways to generate ATP (full aerobic oxidation of carbohydrate and fat and anaerobic glycolysis) are activated.

After exercise, $\mathrm{PCr}$ is rapidly resynthesized; a process requiring ATP. Interestingly, the A T P-generation for resynthesis of $\mathrm{PCr}$ after exercise is not driven by anaerobic glycolysis, but almost exclusively by full aerobic oxidation $(10,11)$. Therelore, the recovery period after exercise is an interesting setting to study the capacity of aerobic ATP generation (oxidative capacity). A fast recovery reflects an excellent oxidative capacity, while delayed recovery kinetics may indicate mitochondrial malfunctioning or a change in mitochondrial phenotype.

One should however keep in mind that a slow PCr recovery can have various causes. It can be caused by mitochondrial malfunctioning, but also by e.g. impaired perfusion. Similarly, one cannot differentiate between slow $\mathrm{PCr}$ recovery due to a decreased number of mitochondria, malfunctioning of mitochondria or a change in mitochondrial phenotype.

\section{Outline of the thesis}

In the present thesis, IMCL content and oxidative capacity were investigated by MRS. "The techniques of IMCL and PCr quantification are discussed in Chapter 2. "To this end, the different techniques that can be employed to quantify IMCL content are described and the background of magnetic resonance spectroscopy in general, and more specifically, the quantification of MMCL and PCr by MRS are discussed. 
As stated earlier, the correlation between insulin resistance and IMCL content might suggest a causal role of IMCL content in the pathogenesis of insulin resistance and type 2 diabetes mellitus. However, because not only insulin resistant subjects, but also trained athletes who are very insulin sensitive are characterized by a high IMCL content, it has been suggested that the IMCL content per se cannot be the culprit in hampering insulin resistance. Yet, the fact that $\mathrm{MMCL}$ content is increased in trained, insulin sensitive subjects does not definitively rule out a causal role of $\mathrm{MMCL}$ content in insulin resistance. Long. term endurance training is accompanied by many adaptive responses such as increased perfusion and a shift in fibre types. All these adaptations can have positive effects on insulin sensitivity. Therefore, it might be possible that the unfavourable influence of IMCL content in a trained individual is overcompensated by other long-term training adaptations, which have a positive influence on insulin sensitivity. To investigate this possibility, we conducted a short-term training study, in which we investigated the change in IMCL content and insulin sensitivity. In this setting it can be assumed that the earlier mentioned long-term training effects can be excluded. In addition, we examined whether IMCL indeed serves as an important energy source during exercise and if so, whether the use of IMCL is affected by two weeks of endurance training (Chapter 3).

To characterize molecular adaptations that accompany the increase in IMCL content with training, we investigated $\mathrm{mRNA}$ and protein concentrations of markers of fat- and carbohydrate metabolism before and after endurance training (Chapter 4).

Although the use of IMCL during exercise, as well as the higher levels after endurance training may indicate an important role for IMCL as an energy source during physical activity, it has also been reported that IMCL can be increased by the consumption of a high-fat diet (12-16). In Chapter 5, we investigated the acute effect of the consumption of a one-week high-fat diet on IMCL content as well as the accompanying changes in mRNA and protein expression of skeletal muscle markers of fat- and carbohydrate metabolism. In this way, dietary and training-induced effects on IMCL and molecular markers could be compared.

The effect of a high fat diet does not necessarily imply an unfavourable situation, as long as the increased level of IMCL is used during subsequent periods of physical activity. In that respect, an increased IMCL content might even be an advantage for performance during prolonged exercise. Therefore, we investigated whether a high-fat diet can accelerate the recovery of IMCL stores in the engaged muscle after exercise. The results of this study are reported in Chapter 6.

Based on decreases in IMCL content in the active muscle during a marathon run, Boesch et al estimated that $11-26 \%$ of fat oxidation originates from the oxidation of IMCL. Although IMCL oxidation contributes substantially to fat oxidation during exercise, the largest contribution is thought to come from plasma free fatty acids (FFA). During prolonged endurance exercise, adipose tissue lipolysis is 
stimulated to provide FA to the working muscle and therefore plasma FFA rise during exercise. The major part of the liberated FA from adipose tissue is oxidized by the working muscle. However, the release of FA by lipolysis exceeds the fat oxidation capacity of the working muscle and the remaining part of FA could be reesterified in adipose tissue, liver and exercising or non-exercising skeletal muscle. In the exercising muscle, muscle contraction strongly increases the percentage of FA that is directed towards oxidation. Therefore, one would expect a net decrease in muscle triglyceride content during exercise in the active muscle. In non-contracting muscle, however, the abundance of plasma FFA during exercise could lead to an increase in muscle triglycerides. In Chapter 7 , we investigated the IMCL content of an (almost) inactive biceps brachii muscle of the arm before and after a cycling protocol and compared it to the IMCL content of the vastus lateralis muscle that was used during cycling exercise.

As stated in paragraph 1.2, the oxidative capacity may be an important player in the determination of the negative effects of IMCL content on insulin sensitivity. In order to get more insight in the possible role of skeletal muscle oxidative capacity in modulating the effect of IMCL content on insulin resistance, we determined IMCL content, skeletal muscle oxidative capacity and insulin resistance in a group of type 2 diabetic patients and healthy controls, matched for body weight (Chapter 8).

In the general discussion (Chapter 9) the obtained results and the physiological function of IMCL will be discussed. 


\section{References}

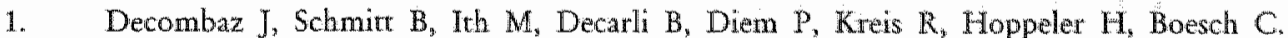
Postexercise fat intake repletes intramyocellular lipids but no faster in trained dhan in sedentary subjects. Am J Plysiol Regw Integr Comp Pbysiol. 2001; 281: R760-9.

2. Goodpaster BH, He J, Watkins $S$, Kelley DE. Skeletal muscle lipid content and insulin resistance: evidence for a paradox in endurance-trained athletes. $/$ Clin Endocrinol Metab. 2001; 86: 5755-61.

3. van Loon LJ, Schrauwen-Hinderling VB, Koopman R, Wagenmakers AJ, Hesselink MK, Schaart $G$, Kooi ME, Saris WH. Influence of prolonged endurance cycling and recovery dier on intramuscular triglyceride content in trained males. Am I Physiol Endocrinot Metab. 2003; 285: E804-11.

4. Falholt $\mathbb{K}$, Jensen I, Lindkaer Jensen S, Montensen $H$, Volund A, Heding $L G$, Noerskov Petersen P, Falholt W. Carbohydrate and lipid metabolism of skeletal muscle in type 2 diabetic patients. Diabet Med. $1988 ; 5: 27-31$.

5. Jacob S, Machann J, Rett K, Brechtel K, Volk A, Renn W, Maerker E, Matthaei S, Schick $\mathrm{F}$, Claussen $\mathrm{CD}$, Haring HU. Association of increased intramyocellular lipid content with insulin resistance in lean nondiabetic offspring of type 2 diaberic subjects. Diabetes. 1999; 48: 1113-9.

6. Pan DA, Lillioja S, Kriketos AD, Miner MR, Baur LA, Bogardus C, Jenkins AB, Storlien LH. Skeletal muscle triglyceride levels are inversely related to insulin action. Diabetes. 1997; 46: 9:83-8.

7. Krssak M, Fallk Petersen K, Dresner A, DiPietro L, Vogel SM, Rothman DL, Roden M, Shulman GI. Intramyocellular lipid concentrations are correlated with insulin sensitivity in humans: a 1H NMR spectroscopy study. Diabetologia. 1999; 42: 113-6.

8. Itani SI, Ruderman NB, Schmieder F, Boden G. Lipid-induced insulin resistance in human muscle is associated with changes in diacylglycerol, protein kinase $C_{n}$ and lkappaBalpha. Diabetes. 2002; 51: 2005-11.

9. Bruce $\mathrm{CR}$, Anderson MJ, Carey AL, Newman DG, Bonen A, Kriketos AD, Conney GJ, Hawley JA. Muscle oxidative capacity is a better predictor of insulin sensitivity than lipid status. J Clin Endacrinol Metab. 2003; 88: 5444.51.

10. Quistorff $B$, Johansen $L$, Sahlin $\mathrm{K}$. Absence of phosphocreatine resynthesis in human calf muscle during ischaemic recovery. Biochen J. 1993; 291 (Pt 3): 681-6.

11. Taylor DJ, Bore PJ, Styles P, Gadian DG, Radda GK. Bioenergetics of intact human muscle. A. 31P nuclear magnetic resonance study. Mol Biol Med. 1983; 1:77-94.

12. Helge JW, Watt PW, Richter EA, Rennie MJ, Kiens B. Fat utilization during exercise: adaptation to a fat-rich diet increases urilization of plasma fatry acids and very low density lipoprotein-triacylglycerol in humans. f Physiol. 2001; 537: 1009-20.

13. Bachmann $O P$, Dahl $D B$, Brechtel $K$, Machann $J$, Haap $M$, Maier ' $T$ ', Loviscach $M$, Stumvoll M, Claussen CD, Schick F, Haring ITU, Jacob S. Effects of intravenous and dietary lipid challenge on intramyocellular lipid content and the relation with insulin sensitivity in humans. Diabetes. 2001; 50:2579-84.

14. Johnson NA, Stannard SR, Mehalski K, Trenell MI, Sachinwalla T, Thompson CH, Thompson MW. Intramyocellular triacylglycerol in prolonged cycling with high and lowcarbohydrate availability. I Appl Physiol. 2003; 94: 1365-1372.

15. Zderic TW, Davidson CJ, Schenk S, Byerley LO, Coyle EF. Fligh-Fat Diet Elevates Resting Intramuscular Triglyceride Concentration and Whole-Body Lipolysis During Exercise. Am JPbysiol Endocrinol Metab. 2003;

16. Vogt M, Puntschart A, Howald H, Mueller B, Mannhart C, Gfeller-Tuescher L, Mullis P, Hoppeler $\mathrm{H}$. Effects of dietary fat on muscle substrates, metabolism, and performance in athletes. Med Sci Sports Exerc. 2003; 35: 952-60. 


\section{CHAPTER}

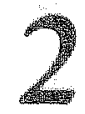

\section{TECHNIQUES}

Part of this chapter will be published in the perspective article: Intramyocellular lipid (IMCL) content in human skeletal muscle

VB Schrauwen-Hinderling, MKC Hesselink, P Schrauwen, and ME Kooi Obesity Research 2006, in press 


\section{Quantification of IMCL}

Several methods can be employed to quantify IMCL content in skeletal muscle. A problem that is encountered when quantifying IMCL content, is that besides fat droplets in the sarcoplasm (IMCL), fat in skeletal muscle is also present as adipose tissue between muscle fibre bundles and muscle groups (Extramyocellular lipids, EMCL). The contamination of the quantification of IMCL by EMCL is a problem for some of the IMCL quantification methods. Hereafter follows a discussion of the most commonly used methods.

\section{Quantification of IMCL by biochemical analysis of biopsies}

Biochemical analysis of biopsy samples has been used extensively to quantify IMCL content. When using this method, muscle biopsy samples are freed from any visible fat, specimens are freeze-dried and a chloroform-methanol extraction is used to isolate lipids. The triacylglycerols are hydrolyzed and the final concentration is calculated from the amount of glycerol or free fatty acids (FFA) released in solution. Although all visible adipose tissue is removed from the samples, small quantities of residual adipose tissue can have a large effect on the outcome, usually resulting in a high variability of the data and an inter-biopsy variation of $23 \%$ has been reported (1) which renders this method unsuitable for the detection of small changes. In well-trained subjects, who tend to have very little adipose tissue, the biochemical quantification is more reliable and a coefficient of variation of $12.3 \%$ has been reported (2). The method can be refined by microdisection of the muscle specimens (3) or by mechanically isolating the individual muscle fibers from freeze-dried samples using a binocular.

\section{Quantification of IMCL by electron microscopy}

Another approach, in which contamination of adipose tissue is not a problem, is the morphometric analysis of muscle biopsy slices with electron microscopy (EM) (see Figure 2.1). With a magnification of $20.000-30.000 \mathrm{x}$, the volume density of lipid droplets inside myocytes can be analyzed in ultrathin slices (50-100 nm) of biopsy samples (4-6). A disadvantage of this method is that it is limited to a very small muscle volume and many measurements need to be done to obtain a reliable quantitative measure of whole muscle IMCL content making the analysis of data very elaborate. An advantage of EM however is that it yields a lot of other morphological information such as the localization relative to mitochondria, the contact area between lipid droplets and mitochondria and the intracellular localization of the droplets (subsarcolemmal versus intramyofibrilar). Furthermore, differences in cytoarchitecture ( $z$-line thickness) (7) can be used to identify fiber type. 


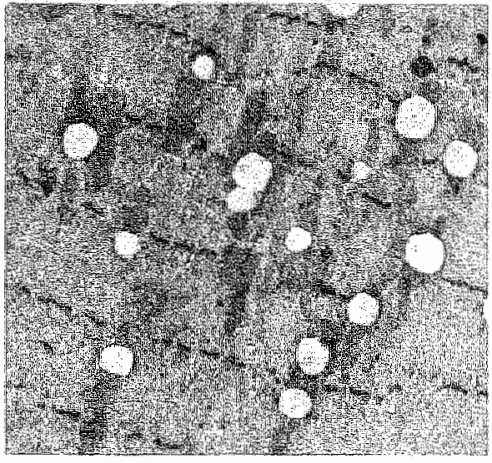

Figure 2.1: Quantification of IMCL by electron microscopy. The figure shows an ultrathin section of rat tibialis anterior muscle with lipid droplets (IMCL) (in white).

\section{Quantification of IMCL by Histochemistry}

Alternatively, thin cross-sectional slices $( \pm 5 \mu \mathrm{m}$ ) of biopsy specimens can be treated with $O$ il red $O$, which visualizes the lipid droplets with an orange-red tint under the light microscope. Oil red $O$ has long been used in light microscopy as a neutral lipid dye (8), but only recently this dye was employed for truly quantitative analysis of IMCL (9). Digital capturing of images and subsequent quantitative image analysis yield a percentage of the total cell area occupied by lipids. Interestingly, the Oil red $O$ dye is fluorescent and therefore IMCL can also be analyzed under a fluorescence microscope and quantified with dedicated software (10). This also allows one to simultaneously perform immuno-histochemical stainings on the same slices (10), e.g. to determine fiber type or proteins involved in fatty acid handling.

\section{Quantification of IMCL by ${ }^{\prime} H-M R S$}

With the demonstration that IMCL can be quantified by proton magnetic resonance spectroscopy ( $\mathrm{H}$-MRS) with a standard clinical whole body scanner $(11,12)$, it became possible to determine the IMCL content non-invasively and repeated measurements in the same muscle volume could be done. In contrast to EM or the oil red $O$ method, where lipids can be visualized within single muscle fibers, ${ }^{1} \mathrm{H}-\mathrm{MRS}$ measures lipid content over a larger muscle area. The different magnetic properties of IMCL and EMCL result in a slightly different resonance frequency, which allows quantifying two separated peaks in a 'H-MR spectrum (see paragraphs "The principles of Magnetic Resonance Spectroscopy" and "The principles of IMCL-quantification by ' $\mathrm{H}$-MRS").

\section{Quantification of IMCL by Computed Tomograpby and MRI}

Other non-invasive techniques, namely Computed Tomography (CT) and Magnetic Resonance Imaging (MRI) are also used to quantify fat content in skeletal muscle. With these imaging techniques, the fat content of muscle is determined based on different signal intensities of fat and lean muscle tissue. A drawback of these imaging techniques is however that they cannot distinguish between a pixel containing muscle tissue with a high MCL content and a pixel 
with muscle tissue with low IMCL content, but partially filled with adipose tissue (EMCL) as both pixels can have the same signal intensity (this phenomenon is called 'partial volume effect'). The reproducibility of CT measurements is very high and coefficients of variation of $0.51 \%$ to $0.85 \%$ have been reported (13).

Table 2.1: Comparison of the most commonly used methods to quantify IMCL

\begin{tabular}{|c|c|c|}
\hline Method & advantage & disadvantage \\
\hline \multirow[t]{2}{*}{ Electronmicroscopy } & $\begin{array}{l}\text { 1. Depicting additional structures } \\
\text { (e.g. mitochondria) }\end{array}$ & 1. Invasive (biopsy specimen) \\
\hline & 2. Not biased by EMCL & $\begin{array}{l}\text { 2. Very small area investigated, } \\
\text { Laborious }\end{array}$ \\
\hline $\begin{array}{l}\text { Histochemistry } \\
\text { (Oil red O) }\end{array}$ & $\begin{array}{l}\text { 1. Possibility of other } \\
\text { (immunofluorescent) stainings } \\
\text { 2. Not biased by EMCL }\end{array}$ & 1. Invasive (biopsy specimen) \\
\hline \multirow[t]{3}{*}{ MRS } & 1. Non-inwasive & $\begin{array}{l}\text { 1. Partial overlap of } \mathrm{IMCL} \text { and } \\
\text { EMCL peak }\end{array}$ \\
\hline & $\begin{array}{l}\text { 2. Repeated measurements in identical } \\
\text { volume }\end{array}$ & $\begin{array}{l}\text { 2. Absolute quantification is laborious, } \\
\text { Usually relative measures presented }\end{array}$ \\
\hline & 3. Relatively large wolume investigated. & \\
\hline \multirow[t]{2}{*}{ Biochemical andysis } & 1. Extensiwely used in literature & 1. Invasive (biopsy specimen) \\
\hline & (lots of relerence data) & $\begin{array}{l}\text { 2. Large variation, contamination by } \\
\text { adipose tissue likely }\end{array}$ \\
\hline \multirow[t]{3}{*}{$\mathrm{C}^{\prime} \mathrm{T}$} & 1. Non-invasive & $\begin{array}{l}\text { 1. No true separation of IMCL } \\
\text { and EMCL }\end{array}$ \\
\hline & $\begin{array}{l}\text { 2. Repeated measurements in identical } \\
\text { volume }\end{array}$ & 2. Exposure to ionizing radiation \\
\hline & 3. Large volume investigated & \\
\hline \multirow[t]{3}{*}{ MRI } & 1. Non-invasive & $\begin{array}{l}\text { 1. No true separation of IMCL } \\
\text { and EMCL }\end{array}$ \\
\hline & $\begin{array}{l}\text { 2. Repeated measurements in identical } \\
\text { volume }\end{array}$ & \\
\hline & 3. Large wolume investigated & \\
\hline
\end{tabular}

\section{Comparison of metbods}

When comparing the different methods, it has been shown that ${ }^{1}$ H-MRS data correlate closely with EM data (6) and a good correlation between ${ }^{1} \mathrm{H}-\mathrm{MRS}$ data and Oil red $O$ staining was reported as well (14). However, the correlation of chemical analysis with 'H-MRS and EM was poor (6), probably due to the high variability of the chemical analysis, as discussed above.

Therefore, 'H-MRS, EM and Oil red $O$ stainings are all valuable methods to quantify IMCL content while biochemical methods should only be used if refinements to diminish contamination of adipose tissue are applied. ${ }^{1} \mathrm{H}-\mathrm{MRS}$ has the advantage of being non-invasive. Other non-invasive methods, namely CT and MRI cannot truly separate IMCL and EMCL. For an overview of the different 
methods, see Table 2.1. Due to the true separation of $\mathbb{M M C L}$ and EMCL with ${ }^{1} \mathrm{H}-\mathrm{MRS}$, and due to the non-invasiveness of the method, ${ }^{1} \mathrm{H}-\mathrm{MRS}$ has been employed in the current study to quantify IMCL.

\section{The principles of Magnetic Resonance Spectroscopy}

In the present study, MRS was used to quantify IMCL and Phosphocreatine (PCr) content of skeletal muscle. MRS is a non-invasive technique based on the magnetic properties of atomic nuclei. Here, the principles of MRS are outlined shortly.

\section{The basics of MRS}

Atomic nuclei posses a property known as spin, which can be visualized in a classical description as a spinning motion around the axis of the nucleus (see Figure 2.2). The spin is described by spin quantum number I. Nuclei with nonzero spin have a magnetic moment.

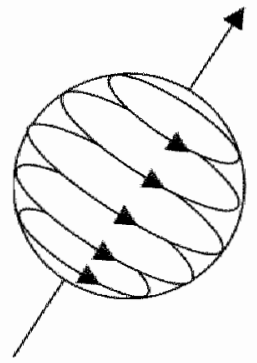

Figure 2.2: A spin can be visualized as a spinning motion of the nucleus about its own axis.

To perform MRS the nuclei are positioned in an external magnetic field $\mathrm{B}$ o. Spins of atomic nuclei with spin quantum number of $\mathbb{I}=1 / 2$ (such as ${ }^{31}$-phosphorus nuclei and protons) can thave two orientations in $\mathrm{B}_{0}$ : parallel (spin up) or anti-parallel (spin down) with respect to the magnetic field. These two orientations correspond to different energy levels with an energy difference $\Delta \mathrm{E}$. The magnitude of $\Delta \mathrm{E}$ depends on the magnitude of $B$ o and the gyromagnetic ratio $\gamma$ (Equation 2.1). The gyromagnetic ratio is characteristic for the kind of atom under investigation (see also Figure 2.3):

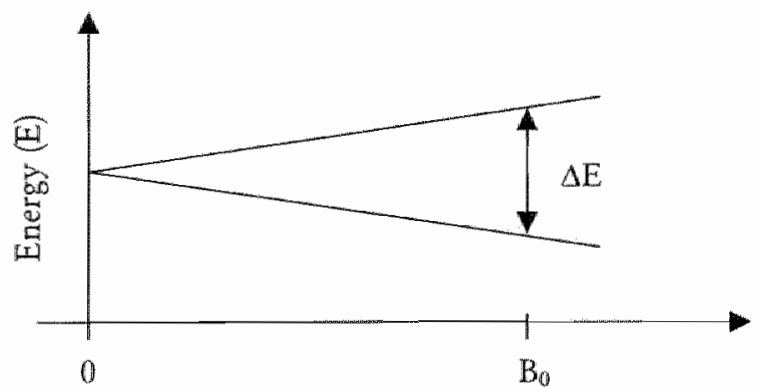

Figure 2.3: Schematic representation of the two possible energy levels of the spins (parallell and antiparallel to the static magnetic field $\mathrm{Bo}$ ), as a function of the external magnetic field $\mathrm{Bo}$. 
$\Delta E=\gamma \frac{h}{2 \pi} B_{0}$

where $\gamma$ is the gyromagnetic ratio and h the Planck constant.

The spin up state has a slightly higher probability (due to the lower energy level) than the spin down state. Transitions between the two energy levels can occur by absorption or emission of a quantum of radiation carrying the energy:

$\Delta E=h v_{0}(2.2)$

with h Planck constant and $v_{0}$ frequency.

Combining equation (2.1) and (2.2) gives the frequency of this quantum of radiation, which is the resonance frequency vo:

$$
v_{11}=\frac{\gamma}{2 \pi} B_{0} v_{i n}=\frac{\gamma}{2 \pi} B_{0}
$$

For an isolated nucleus in a magnetic field, the resonance frequency thus depends on the field strength $\left(B_{0}\right)$ and the gyromagnetic ratio of the nucleus (Equation 2.3). Different nuclei have different gyromagnetic ratios and therefore e.g. ${ }^{31} \mathrm{P}$-nuclei resonate at a different frequency $\left(v_{0}\right)$ than protons.

Additionally, in vivo, non-isolated nuclei are studied and their resonance frequency (v) varies slightly: The electron-density in the direct environment of a nucleus shields it from the static magnetic field, which causes a slight shift in resonance frequency. A lower electron density therefore makes the resonance frequency of a nucleus higher. The electrons that surround a nucleus experience a certain attraction also from the neighbouring nuclei in a molecule, which can further modify the electron-density at the nucleus under investigation. Hence, the field experienced by the nucleus in its chemical surrounding $\left(\mathrm{B}_{\mathrm{erf}}\right)$ differs from $\mathrm{B}_{0}$ :

$$
B_{e g}=B v(1-\sigma)(2.4)
$$

with $\sigma$ shielding constant. "The magnitude of $\sigma$ is thus dependent on the electronic environment of the nucleus, and therefore nuclei in different chemical environments give rise to signals at different frequencies. Hence, the resonance frequency of a nucleus is characteristic for a certain chemical environment. The resonance frequency of a non-isolated nucleus can thus be written as:

$$
v=\frac{\gamma}{2 \Pi} B 0(1-\sigma)
$$


The shift of the resonance frequency of a nucleus relative to a reference compound is referred to as the chemical shift ( $\delta)$ and is expressed as parts per million (ppm).

The chemical shift is defined as:

$\delta=\frac{v_{0}-V_{\text {ref }}}{W_{\text {erf }}} \times 10^{6}(2.6)$

Detection of MR signals

The transition from the spin up to the spin down state is referred to as excitation. Excitation is achieved by applying for a time period of at the most a few milliseconds, an oscillating current through a transmitter radio-frequency (RF) coil (RF pulse), and thereby generating an additional magnetic field $\mathrm{Br}$ oscillating with the resonance frequency. $\mathrm{B}_{1}$ is applied in the plane perpendicular to the direction of $\mathrm{B}$. The bandwidth (i.e. spread in frequency) of this pulse is sufficiently large to excite all nuclei within the required frequency range; it covers all the resonance frequencies of interest.

Thus, for excitation, the RF pulse is only applied for a few milliseconds. Due to the RF pulse, the spins resonate coherently (in phase); this induces an oscillating current in the RF coil. When the RF pulse is turned off, relaxation of the spins will occur. In its most simple form, the signal is a time-decaying sinusoidal function containing all the resonance frequencies present in the sample (free induction decay). An example of a free induction decay (FD) is shown in Figure 2.4.

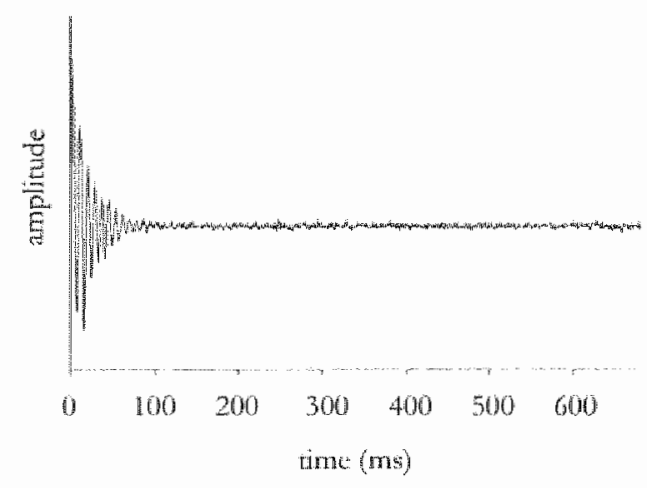

Figure 2.4: An example of a free induction decay (FID) of a "P-MRS measurement of muscle tissue at 1.5 'Tesla.

Although an FID signal contains all the different resonance frequencies, the information is not readily available. Fourier transformation of the FID signal gives a Magnetic Resonance Spectrum (as shown in Figure 2.5), which can be interpreted more easily. 


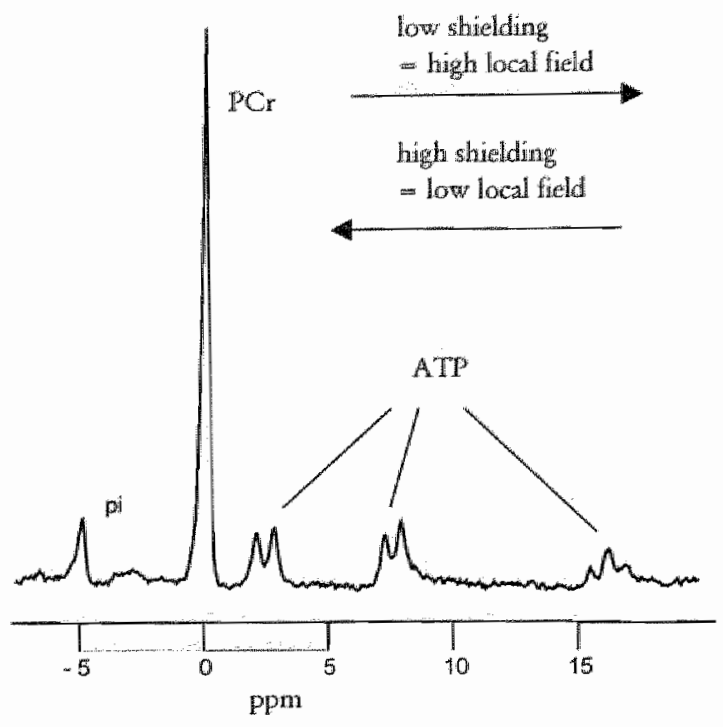

Figure 2.5: A typical in vivo Phosphorus Magnetic Resonance Spectroscopy ('P-MRS) spectrum of sheletal muscle is shown with the phosphate peak (Pi), phosphocreatine peak $(\mathrm{PCr})$ and the three peaks from adenosinetriphosphate (ATP). The three ATP peaks are split in multiplets because of a phenomenon known as spin-spin interaction (neighbouring spins influencing the resonance frequency, for explanation of this phenomenon see, (15) Chapter 6.2).

On the $\mathrm{x}$-axes of the spectrum, the chemical shift is depicted, while the intensity is depicted on the $y$-axes.

The area under a peak is proportional to the number of nuclei with corresponding resonance frequency in the sample of interest. Therefore, the spectra can be analysed to determine the relative concentration of the compounds of interest.

\section{Investigation of $P C Y$ recovery kinetics after exercise by ${ }^{37} P-M R S$}

As stated in the general introduction, the $\mathrm{PCr}$ recovery after exercise can be used to investigate oxidative capacity. The recovery of $\mathrm{PCr}$ after exercise can be approximated by a mono-exponential time-course if no substantial acidification occurred during exercise (16). Therefore, under these conditions, the time-course during recovery can be fully described by a few variables (see Figure 2.6):

$$
\operatorname{PCr}(t)=\operatorname{PCr}(t o)+D\left(1-e^{t(i-\text { tat }}\right)
$$

with: $\mathrm{PCr}=$ Phosphocreatine concentration, $\mathrm{D}=$ difference between $\mathrm{PCr}$ concentration in steady state and after recovery, $\mathrm{k}=$ time constant of recovery, $\mathrm{tO}=$ end-time of exercise

From the time constant of recovery the half-time $1 / 2$ can be calculated:

$t_{1 / 2}=\frac{0.693}{k}$ 


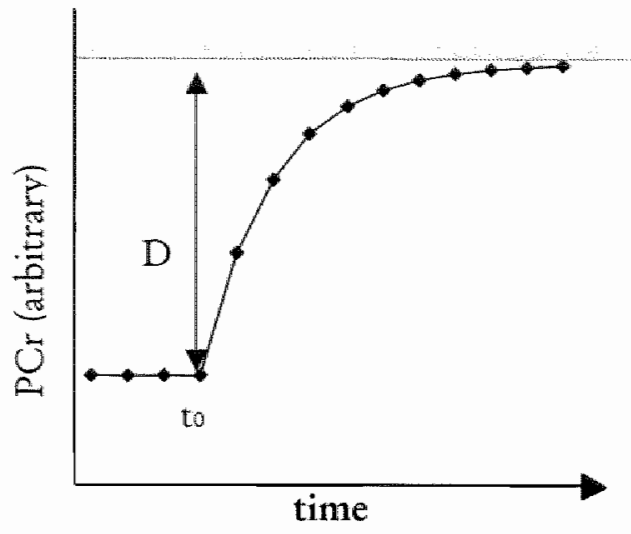

Figure 2.6: A mono-exponential time-course, schematicaly depicting the PCr concentration in steady state during exercise until to and recovery of $\mathrm{PCr}^{\circ}$ concentration after exercise. $\mathrm{PCr}=$ Phosphowereatine concentration, $\mathrm{D}=$ difference between $\mathrm{PCr}$ concentration in steady state and after recovery, to $=$ end-time of exercise

The exercise intensity is also influencing the rate with which $\mathrm{PCr}$ increases $\left((\mathrm{dPCr} / \mathrm{dt})_{\mathrm{r}}\right)$ immediately after exercise; a high intensity together with a large decrease in PCr leads to a fast increase in PCr concentration immediately after exercise. According to models describing PCr kinetics $(16,17)$ the half-time $\left(\mathrm{t}_{1 / 2}\right)$ of $\mathrm{PCr}$ recovery should however be independent of the intensity of the moderate-intensity exercise performed and therefore $t / 2$ (or analogously the time constant $k$ ) is described as a robust parameter of oxidative capacity, which has been confirmed experimentally $(18,19)$.

To determine the half-time of $\mathrm{PCr}$ recovery with ${ }^{31} \mathrm{P}-\mathrm{MRS}$, exercise has to be performed inside the MR scanner and the $\mathrm{PCr}$ concentration has to be measured with a high temporal resolution immediately after exercise. To this end, dynamical measurements with acquisition of a spectrum e.g. every 4 seconds can be performed. These spectra usually have a relatively low signal/noise ratio but still allow the quantification of $\mathrm{PCr}$, which represents the largest metabolite peak. To quantify PCr more accurately and also ATP, Pi and PDE, a measurement in the resting muscle can be performed with longer acquisition time (see Figure 2.5).

To perform exercise in the scanner an MR-compatible exercise device has to be used. Depending on the muscle under investigation, possible exercise forms are e.g. plantar flexion, knee extension or bulb squeezing, each of these possibilities require a dedicated exercise device. Alternatively, electrical stimulation can be used.

\section{The principles of IMCL-quantification by ${ }^{1} \mathrm{H}-\mathrm{MRS}$}

With MRS, one can distinguish atoms at different chemical positions (due to a difference in shielding by electrons, as outlined above) and therefore one can distinguish different chemical compounds. The chemical composition of lipids in fat droplets inside myocytes and lipids in adipose tissue is not likely to be 
different. Still, two separate peaks are measured for the methylene groups of the fatty acids (FA) in IMCL and EMCL in skeletal muscle. This separation is caused by the Bulk Magnetic Susceptibility (BMS) shift, which will be explained below. The local field that is experienced by a nucleus is not only influenced by the shielding effect of electrons but also by the magnetic susceptibility of the bulk medium. Whenever matter is placed in a magnetic field, electromagnetic interactions "disperse" or "concentrate" magnetic field lines leading to an additional shift in resonance frequency called the Bulk Magnetic Susceptibility (BMS) shift. That shift is determined by the magnetic induction (B) inside a compartment and outside the compartment (the external magnetic field ( $\mathrm{B} 0)$ ) (20).

The magnetic induction of small lipid droplets in a cytosolic environment (IMCL) can be calculated by approximating them as small lipid spheres in an aqueous environment. The susceptibility of small lipid droplets in an aqueous environment is exclusively defined by the magnetic susceptibility of water and is independent of the relative orientation to the static magnetic field.

The magnetic induction of adipose tissue distributed along muscle fibres (EMCL) can be calculated by approximating EMCL by macroscopic cylinders of oil in an aqueous environment. The induction of such a cylinder depends on the magnetic susceptibility of water as well as that of lipids and the orientation of the cylinder with respect to the static magnetic field. Therefore, the BMS shift of lipid in cylinders oriented parallel to the static magnetic field differs from that in cylinders with a perpendicular orientation. With these approximations (IMCL as lipid spheres and EMCL as lipid cylinders), the calculated maximal BMS shift between the two compartments amounts to $0.2 \mathrm{ppm}$ and occurs when the cylinders are positioned parallel to $\mathrm{B}$. These calculations have been confirmed by measurements with small lipid droplets and a cylindrical lipid phantom (20). Indeed, the largest separation of EMCL and IMCL with a frequency shift of 0.2 ppm is found when the muscle fibres (and the adipose tissue aligned with it) run parallel to Bo. This is the case if the fibres of the muscle under investigation run parallel to an extremity and the extremity is positioned parallel to the long axis of the magnet. A typical 'H-MRS spectrum of skeletal muscle with EMCL and IMCL peaks is presented in Figure 2.7.

To determine the IMCL content from a distinct area of muscle, localization methods are employed. Therefore, repeated measurements in the same muscle volume can be done. Importantly, all muscle groups of the upper and lower leg and/or arm can be investigated. Single voxel (volume selective) methods acquire signal from a defined volume of interest, and typically determine IMCL content in a volume of one to three milliliters $(\mathrm{ml})$. Alternatively, spectroscopic imaging (SI) can be employed to determine IMCL content simultaneously in a matrix of many voxels. The volume of one voxel is typically smaller for SI (0.1 to $1.5 \mathrm{ml})$ and different muscle groups can be investigated in a single measurement. 


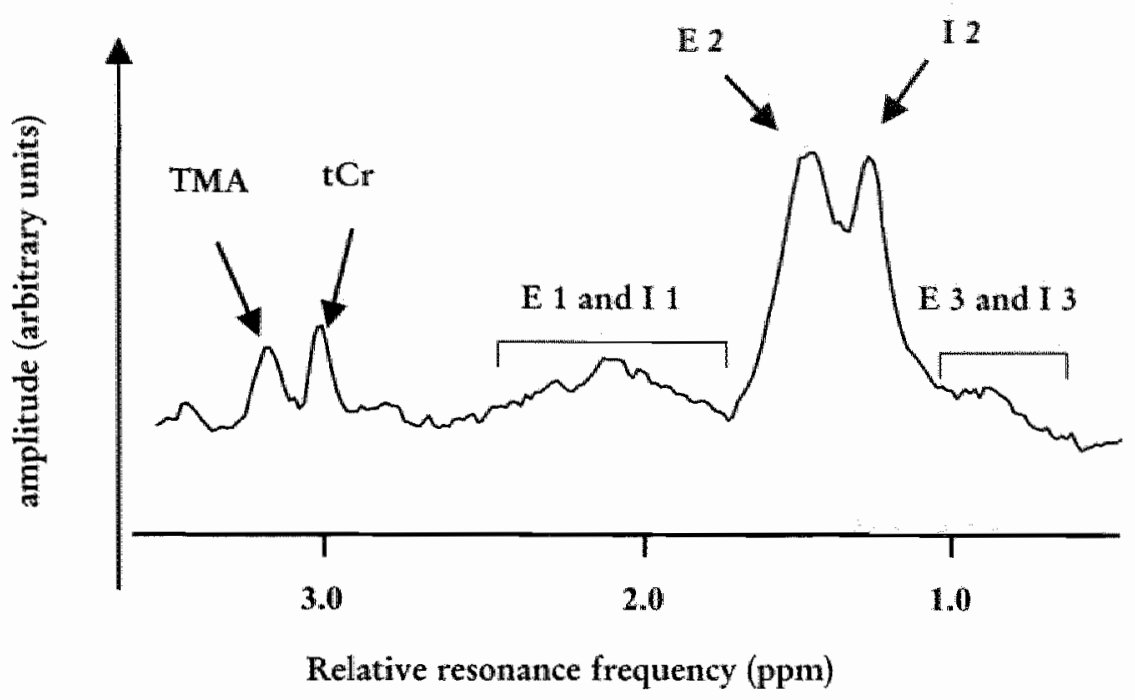

Figure 2.7: Quantification of IMCL by Magnetic Resonance Spectroscopy. The figure shows a 'H-MRS spectrum from a human wastus lateralis muscle. TMA = trimethylammonium compounds, $\mathrm{Cr}=$ total creatine, $\mathrm{E} 1$ and $\mathbb{I} 1=$ broad peaks of various, chemically different methylene protons of EMCL and IMCL in esters and adjacent to unsaturated bonds of fatry acids, $\mathrm{E} 2$ and I $2=\mathrm{CH}_{2}$ peak of EMCL and MCL respectively, E 3 and I 3 = methyl protons of EMCL and $I M C L$ respectively.

The coefficients of variation of repeated quantification of IMCL by MRS measurements typically lie around 6 to $14 \%(12,21-25)$.

The main drawback of ${ }^{1} \mathrm{H}-\mathrm{MRS}$ is that although two separate peaks are detectable, the IMCL and the EMCL peak do partially overlap and sophisticated peak fitting software is needed to quantify the two peaks separately. Especially in obese subjects, the high amount of EMCL makes it difficult to position the voxel in an area with little EMCL and a large EMCL peak will overlap more severely with the $\mathrm{MCL}$ peak. As the measurement can ensure the repeated investigation of identical muscle volumes in a non-invasive way, the method is especially interesting to longitudinally monitor the effect of interventions in individual patients. 


\section{References}

1. Wendling $\mathbb{P S}$, Peters SJ, Heigenhauser GJ, Spriet LI. Variability of triacylglycerol content in human skeletal muscle biopsy samples. J Appl Physiol. 1996; 81:1150-5.

2. Watt MJ, Heigenhauser GJ, Spriet LL. Intramuscular triacylglycerol utilization in human skeletal muscle during exercise: is there a controversy? J Appl Pbystol. 2002; 93: 1185-95.

3. Guo Z, Mishra P. Macura S. Sampling the intramyocellular triglycerides from skeletal muscle. J Lipid Res. 2001; 42: 1041-8.

4. Hoppeler $\mathrm{H}$, Luthi $\mathrm{P}$, Claassen $\mathrm{H}$, Weibel ER, Howald H. The ultrastructure of the normal human skeletal muscle. $\mathbb{A}$ morphometric analysis on untrained men, women and welltrained orienteers. P/lwgers Arch. 1973; 344:217\%32.

5. Jerusalem $F$, Engel AG, Peterson HA. Human muscle fiber fine structure: morphometric data on controls. Neurology. $1975 ; 25: 127-34$.

6. Howald H, Boesch C, Kreis R, Matter S, Billeter R, Essen-Gustavsson B, Hoppeler H. Content of intramyocellular lipids derived by electron microscopy, biochemical assays, and (1)H-MR spectroscopy. / Appl Physiol. 2002; 92: 2264-72.

7. Thornell LE, Carlsson E, Kugelberg E, Grove BK. Myofibrillar M-band structure and composition of physiologically defined rat motor units. A m J Physiol. 1987; 253: C456-68.

8. Bayliss-High O. Theory and Practice of histological techniques. 1977, Edinburgh: Churchill Livingstone 168-185.

9. Goodpaster BH, Theriault $R$, Watkins $S C$, Kelley DE. Intramuscular lipid content is increased in obesity and decreased by weight lloss. Metabolism. 2000; 49: 467-72.

10. Koopman $R$, Schart $G$, Hesselink MK. Optimisation of oil red $O$ staining permits combination with immunofluorescence and automated quantification of lipids. Histochem Cell Biol. 2001; 116:63-8.

11. Schick F, Eismann B, Jung WI, Bongers $H$, Bunse M, Lutz O. Comparison of localized proton NMR signals of skeletal muscle and fat tissue in viwo: two lipid compartments in muscle tissue. Magn Reson Med. 1993; 29: 158-67.

12. Boesch C, Slotboom J, Hoppeler H, Kreis R. In vivo determination of intra-myocellular lipids in human muscle by means of localized 1H-MR-spectroscopy. Magn Reson Med. 1997; 37: 484.93.

13. Goodpaster BH, Kelley DE, Thaete FL, He J, Ross $\mathbb{R}$. Skeletal muscle attemation determined by computed tomography is associated with skeletal muscle lipid content. J Appl Physiol. 2000; 89: 104-10.

14. Van Loon LJ, Schrauwen-Hinderling VB, Koopman R, Wagenmakers AJ, Hesselink MK, Schaart G, Kooi ME, Saris WH. Influence of prolonged endurance cycling and recovery diet on intramuscular triglyceride content in trained males. Am J Physiol Endocrinol Metab. 2003; 285: E804-11.

15. Gadian DG. NMR and its applications to living systems. 1995, Oxford: Oxford University Press

16. Kemp GJ, Radda GK. Quantitative interpretation of bioenergetic data from 31P and $1 \mathrm{H}$ magnetic resonance spectroscopic studies of skeletal muscle: an analytical review. Magra Reson Q. 1994; 10: 43-63.

17. Meyer RA. A linear model of muscle respiration explains monoexponential phosphocreatine changes. Am J Ploysiol. 1988; 254: C548-53.

18. Paganini AT, Foley JM, Meyer RA. Linear dependence of muscle phosphocreatine kinetics on oxidative capacity. Am J Pbysiol. 1997; 272: C501-10.

19. Lodi $\mathbb{R}$, Kemp $G$ J, Totti S, Radda GK, Barbiroli B. Influence of cytosolic $\mathrm{pH}$ on in vivo assessment of human muscle mitochondrial respiration by phosphorus magnetic resonance spectroscopy. Magmat. 1997; 5: 165-71.

20. Szczepaniak LS, Dobbins RL, Stein DT, MoGarry JD. Bulk magnetic susceptibility effects on the assessment of intraw and extramyocellular lipids in vivo. Magn Reson Med. 2002; 47: $607 \times 10$. 


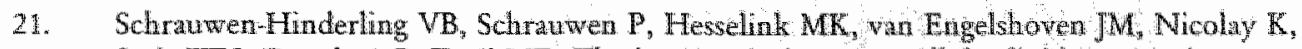
Saris WH, Kessels $A G, \mathbb{K}$ ooi ME. The increase in intramyocellular lipid content is a very early response to training. / Clin Endocrinol Motal, 2003, 88: 1610-6.

22. Rico-Sanz J, Hajnal JV, Thomas EL, Mierisowa S, Ala Korpela M, Bell JD. Intracellular and extracellular skeletal muscle triglyceride metabolism during alternating intensity exercise in humans. J Plysiol (Lond) 1998; 510: 615-22.

23. Szczepaniak LS, Babcock EE, Schick F, Dobbins RE, Gurg A, Burns DK, McGary JD, Stein DT. Measurement of intracellular triglyceride stores by $\mathrm{H}$ spectroscopy: validation in vivo. Am J Plyysiol. 1999; 276: E977-89.

24. Brechtel K, Machann ], Jacob S, Strempler A, Schick F, Haring HU, Claussen CD. [Inwivo IH-MR spectroscopy: the determination of the intra- and extramyocellular lipid content depending on the insulin effect in the direct offspring of type-2 diabetics]. Rofo Fontsch Geb Rontgenstr Newen Bildgeb Verfabr. 1999; 171:113-20.

25. Arrowsmith FE, Ward J, Rooney K, Kriketos AD, Baur LA, Thompson CH. Body famess, insulin sensitivity and muscle oxygen supply in adolescents. Clin Sci (Lond). 2002; 103: 391.6. 


\section{CHAPTER}

3

THE INCREASE IN INTRAMYOCELLULAR LIPID CONTENT IS A VERY EARLY RESPONSE TO TRAINING

V.B. Schrauwen-Hinderling, P. Schrauwen, M.K.C. Hesselink, J.M.A. van Engelshoven, K. Nicolay, W.H.M. Saris, A.G.H. Kessels, M.E. Kooi

J Clin Endocrinol Metab. 2003 Apr;88(4):1610-6. 


\section{Abstract}

The present study investigated the influences of a two-week training program on intramyocellular lipid (IMCL) content, $\mathrm{MMCL}$ decrease during exercise, fat oxidation and insulin sensitivity.

Nine untrained men (age: $23.3 \pm 3.2 \mathrm{y} ; \mathrm{BMI}: 22.6 \pm 2.6 \mathrm{~kg} / \mathrm{m}^{2}$; maximal power output (W/max): $3.8 \pm 0.6 \mathrm{~W} / \mathrm{kg}$ body weight) trained for two weeks. Before and after training, subjects cycled for three hours, while substrate oxidation was measured. IMCL content in the m. vastus lateralis was determined before and after cycling by proton magnetic resonance spectroscopy ('H-MRS). Before and after training, insulin sensitivity was assessed by an insulin tolerance test.

The training period resulted in a significant increase in IMCL content by $42 \pm 14 \%$. IMCL content decreased significantly during cycling. On the other hand, two weeks of training were not sufficient to achieve increases in fat oxidation and/or use of IMCL during exercise. All markers used to test insulin sensitivity point towards improved insulin sensitivity, albeit not significant. We conclude that the increase in IMCL content is a very early response to training, preceding significant changes in insulin sensitivity. The results suggest that solely the presence of triglycerides does not necessarily have detrimental effects on insulin sensitivity. We confirm earlier reports, that IMCL contribute to the energy used during prolonged sub maximal exercise. 


\section{Introduction}

Changes in lifestyle over the last decades have resulted in a dramatic increase in the prevalence of obesity and consequently type 2 diabetes worldwide (1). Type 2 diabetes is characterized by perturbations in glucose homeostasis due to decreased insulin sensitivity. Next to disturbances in glucose metabolism, fat metabolism in type 2 diabetes is deranged as well (2). An impairment in fat oxidation (3) and accumulation of intramuscular lipids (4) are found in type 2 diabetes. Moreover, strong positive correlations between insulin resistance and IMCL have been reported $(5,6)$. In this context, it is interesting to note that increased IMCL levels are reported in insulin resistant offspring of type 2 diaberic subjects, when compared to matched, insulin sensitive offspring (7), suggesting that a high $\mathrm{MMCL}$ content might be involved in the development of insulin resistance.

Strikingly, endurance trained athletes also show increased IMCL levels (8) while being very insulin sensitive. Training induced improvements in insulin sensitivity have been observed within a week after the onset of training in healthy sedentary individuals (9-12), whereas little is known about the time span needed to increase intramuscular lipid content with training. Therefore, the first aim of this study was to examine whether insulin sensitivity and IMCL content, (determined by ${ }^{1} \mathrm{H}-\mathrm{Magnetic}$ Resonance Spectroscopy ( $\left.{ }^{\mathrm{H}} \mathrm{H}-\mathrm{MRS}\right)$ ) are changed in response to a short-term training program.

It is well known that training increases fat oxidation during exercise. We recently showed, using stable isotopes, that the increase in fat oxidation after a three month training program was completely accounted for by an increase in oxidation of intramuscular triglycerides and/or very low density lipoproteins (VLDL) (13). This suggests that training induces a shift of the source of lipids used for oxidation towards increased use of intramuscular triglycerides and/or VLDL. However, with the stable isotope technique, it cannot be deduced whether the oxidation of specifically IMCL is increased. Nevertheless, other techniques indicate that, trained subjects rely more on IMCL oxidation during exercise compared to untrained $(8,14)$. Therefore, the second aim of the study was to examine with 'H-MRS whether a short-term training program also increases the use of IMCL during exercise. 'H-MRS facilitates quantification of IMCL content non-invasively and repeatedly in the same position in the muscle (15) and provides data from a relatively large tissue volume compared to conventional needle muscle biopsies.

\section{Research Design and Methods}

\section{Subjects}

Nine young, untrained and healthy male subjects (age $(y): 23.3 \pm 3.2$; W $\max$ $(\mathrm{W} / \mathrm{kg}): 3.8 \pm 0.6)$ participated in this study. Subjects were recruited by 
advertisement and were excluded from participation if they had performed aerobic exercise competitively for more than three months or were still exercising on a regular basis. "The study was approved by the institutional Medical Ethics Committee. Subjects gave their written informed consent after the nature of the procedure was explained.

\section{Experimental protocol}

A week preceding the experimental trial, an incremental test to determine Wmax was performed, which was repeated in the week after the experimental trial.

\begin{tabular}{|c|c|c|c|c|c|c|c|c|c|c|c|c|c|c|c|c|}
\hline lay 1 & 2 & 3 & 4 & 5 & 6 & 7 & 8 & 9 & 10 & 11 & 12 & 13 & 14 & 15 & 16 & 17 \\
\hline acst & rest & Lest & rest & 1nt & end & int & Iend & init & rest & int & end & int & end & rest & rest & test \\
\hline diet & diet & diet & & & & & & & & & & & & diet & diet & diet \\
\hline
\end{tabular}

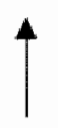

$W \max$

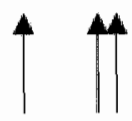

ITT MRS

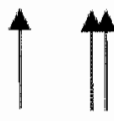

ITT' MRS fat ox

Figure 3.1: Scheme of experimental set up. White blocks indicate days without, grey blocks days with physical exercise. The physical exercise consisted of a three-hour cycling test (indicated by "test"), of endurance training (indicated by "end") or interval training (indicated by "inr"). The first three days before a test day, consisted of a standardization period with stanclardized diet. ITT = Insulin Tolerance test, $\mathrm{MRS}=$ quantification of $\mathrm{IMCL}$ content by ${ }^{\mathrm{H}} \mathrm{H}-\mathrm{MRS}$, fat $\alpha \mathrm{x}=$ measurement of fat oxidation during the cycling test by indirect calorimetry.

The set up of the trial was as follows (see Figure 3.1). Days 1-3 formed a standardization period, during which a standardized diet was provided and subjects refrained from exercise. In the afternoon of day 3 , a three-hour cycling test was performed, where subjects cycled at $40 \%$ of their predetermined Wmax while substrate oxidation was measured by indirect calorimetry and blood samples were taken every hour. Before, and about $15 \mathrm{~min}$ after the cycling test, IMCL content in the $m$. vastus lateralis was quantified by ${ }^{\mathrm{l}} \mathrm{H}$-MRS. Subjects then participated in a training program with alternating days with either 2 hours of endurance training or 45 minutes of interval training. Resting days were incorporated on day 4 and 10. Days 15 to 17 were again used as standardization period, with the same standardization diet as on day 1 to 3 and with subjects refraining from exercise. In the afternoon of day 17, subjects again cycled for 3 hours at $40 \% \mathrm{~W} \max$, with substrate oxidation being measured and blood samples being taken, and again IMCL content in the $m$. vastus lateralis was quantified by 'H-MRS before and after exercise. Insulin sensitivity was assessed by an insulin tolerance test (ITT) in the mornings of day 2 and 16, after an overnight fast. To ensure that training-induced alterations in insulin sensitivity were examined rather than the remnant effect of the final training session, the 
IT TI was planned in the morning of day 14 , so that 48 hours were in between the last training session and the ITT. The ITT begun with sampling of $10 \mathrm{ml}$ of blood to obtain fasting values of blood parameters.

\section{Diets}

'The macronutrient composition of the diets was such that $30 \%$ of the energy was consumed as fat, $55 \%$ as carbohydrate and $15 \%$ as protein.

Subjects were given a fixed amount of food (1.65\%BMR based on Harris and Benedict equations (16)) and were asked to eat all the food provided, and nothing else. The diet consisted of breakfast, lunch, ready to use dinner and snacks.

\section{Procedures}

Body composition

Whole body density was determined by underwater weighing in the morning in the fasted state. Body weight was measured with a digital balance with an accuracy of $0.01 \mathrm{~kg}$ (Sauter, type E1200). Lung volume was measured simultaneously with the helium dilution technique using a spirometer (Volugraph 2000, Mijnhardt). Percentage body fat was calculated using the equations of Siri (17).

\section{Insulin tolerance test (ITT)}

ITTs were performed as previously described (18) in the fasted state in the morning of the days 2 and 16 . Briefly, the fall in plasma glucose in response to the injection of $0.1 \mathrm{U} / \mathrm{kg}$ body weight human insulin (Actrapid, Novo Nordisk $\mathrm{A} / \mathrm{S}$, Denmark) was monitored every 2 minutes during 16 minutes. Insulin was injected via a carheter in the anticubital vein, while arterialized blood samples were obtained via a catheter inserted into a dorsal vein of the contra lateral hand, which was warmed in a heated air box at $60^{\circ} \mathrm{C}$. Since no changes were noted within 4 minutes after administration of insulin, the first 4 minutes were not considered in the analysis. Linear regression was used to fit a line through the plasma glucose values between 4 and 16 minutes. The time until half of the glucose had disappeared ( $(\mathrm{t} / 2)$ was calculated and taken as an indicator of insulin resistance. Therefore, insulin sensitive subjects will have a low, while insulin resistant subjects will have a high $t_{1 / 2}$.

\section{Three-hour cycling test}

The exercise test consisted of three hours of cycling on an electromagnetically braked ergometer at an intensity of $40 \%$ of the predetermined W/max. During the exercise test, substrate oxidation was measured every 15 minutes using indirect calorimetry (Oxycon- $\beta$, Mijnhardt, Mannheim, Germany) and blood samples were collected every 60 minutes. To facilitate the completion of the exercise test, subjects received twice $125 \mathrm{ml}$ of a maltodextrine drink (Extran Fresh Citrus; $131 \mathrm{~kJ} / 31 \mathrm{kcal}, 7,9 \mathrm{~g} \mathrm{CHO}, 0 \mathrm{~g}$ proteins and lipids per $100 \mathrm{ml}$ ) 
during the second half of the test (at $t=90 \mathrm{~min}$. and $t=135 \mathrm{~min}$.). Subjects were allowed to drink water ad libitum during the whole test. Fat and carbohydrate oxidation were calculated based on respiratory quotient (RQ) values according to Peronnet (19).

\section{Training program}

From day 5 to 14, subjects reported to the laboratory daily to follow supervised training sessions on cycle ergometers, except for the resting day on day 10. Training consisted of alternating days of interval- and endurance training and always started with 7.5 minutes of warming up at $40 \% \mathrm{~W} \max$ and ended with 7.5 minutes of cooling down at $40 \%$ Wmax. On days 5, 7, 9 and 11 , cycling interval training was performed, which consisted of 45 minutes of alternating three minutes intervals at 70\% Wmax and 35\% Wmax. At days 6, 8, 12 and 14, exercise consisted of 35 minutes at $55 \% \mathrm{~W} \max$, followed by 35 minutes at $50 \%$ W max, and 35 minutes at $45 \% W_{\max }$, for a total duration of 120 minutes.

\section{MRS measurement}

Image guided localized single voxel 'H-MRS was performed in the mavasus lateralis before and immediately after the three-hour cycling test on the test days at the beginning and at the end of the training period. The measurements were performed on a $1.5 \mathrm{~T}$ whole body scanner (Intera, Philips Medical Systems, Best, the Netherlands) with a flexible surface coil wrapped around the upper leg. To ensure that the fibers of the $m$. vastus lateralis ran essentially parallel to the external magnetic field, the leg was placed at an angle of about $30^{\circ}$ from the parallel position.

In every subject, voxels were carefully placed at the same position for all four measurements. Care was taken to avoid vascular structures and adipose tissue deposits within the voxel. To reproduce the same voxel position, the longitudinal distance of the voxel from the intercondylar eminence of the knee joint was determined in a coronal image of the upper leg. $T_{2}$ weighted fast spinecho (FSE) MR images consisting of 5 transversal slices were acquired at this position (slice thickness $5 \mathrm{~mm}$, TR/TE $2000 / 85 \mathrm{~ms}$, echo train length 12 , field-ofview $210 \mathrm{~mm}$ and matrix size $256 \times 256$ ). The patterns of the fat distribution were used to verify the longitudinal position and as landmarks to reproduce the voxel position in the transversal plane.

${ }^{1}$ H-MRS spectra from the regions of interest were acquired using a point-resolved spectroscopy (PRESS) sequence with the following acquisition parameters: TR/TE 3000/25 ms, 16 phase cycles, 128 averages, 1024 data points over $1000 \mathrm{~Hz}$ spectral width. The voxel volume was $(12 \times 11 \times 18) \mathrm{mm}^{3}$. The water signal was suppressed using Chemically Selective Saturation (CHESS). The unsuppressed water signal was subsequently measured in the same voxel under the same shimming conditions and was used as a reference signal. 


\section{Post-processing}

The spectra were fitted in the time domain using a nonlinear least-squares algorithm (AMARES (20)) in the jmrui software package (21). Eight peaks were fitted in total, namely two peaks for total creatine and trimethylammonium compounds (TMA), three peaks for extramyocellular lipids (EMCL) and three peaks for IMCL (see Figure 3.2). Prior knowledge (20) of the relative peak positions (22) and area ratios (private communication) as determined by Boesch et al. was used as a constraint. The line width of the $\mathrm{CH} z$ peak of IMCL was fixed relative to the line width of the unsuppressed water peak (measured in the same voxel) in order to increase the accuracy and reliability of the fitting procedure. The linewidths of total creatine and trimethylammonium compounds (TMA) were constrained to be equal. All other line widths were unconstrained. IMCL peaks and EMCL peaks were fitted with a gaussian curve, while total creatine, TMA and water peaks were fitted with a lorenztian curve. The signals were corrected for $\mathrm{T} 1$ and $\mathrm{T} 2$ relaxation using the $\mathrm{T} 1$ and $\mathrm{T} 2$ relaxation times as determined by Schick et al. (23). The corrected area of the $\mathrm{CH}_{2}$ peak of IMCL. was expressed relative to the area of the water peak.

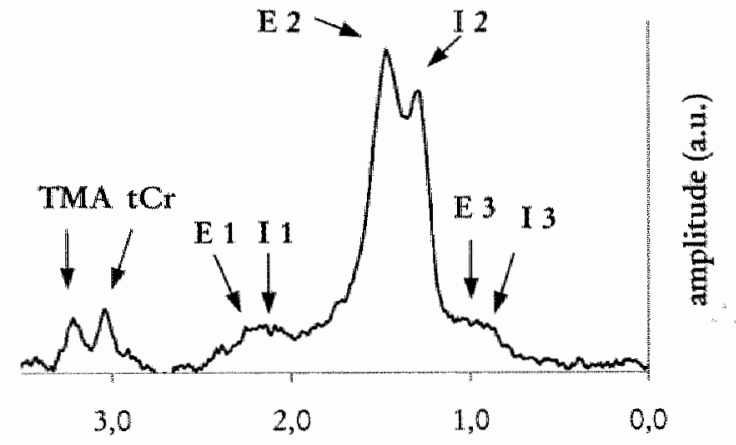

relative resonance frequency ( $\mathrm{ppm}$ )
Figure 3.2: Typical spectrum of the m.vastas dateralis.

"TMA = trimethylammonium compounds, $\mathrm{tCr}=$ total creatine, $\mathrm{E} I=$ broad peak of various, chemically different methylene protons of EMCL (22), E2 = methylene protons of EMCL, $\mathrm{E} 3$ = Methyl protons of EMCL, II = broad peak of various, chemically different methylene protons of IMCL (22), 12 methylene protons of IMCL, $13=$ Methyl protons of $\mathrm{IMCl}_{\text {i.t. }}$

The reproducibility of the quantification of IMCL in the $m$. vastus lateralis was determined in the setting of another study by measuring one subject several times with leaving the scanner table in between. From five corresponding pairs of measurements, we calculated an average coefficient of variation of $6.0 \% \pm 8.2 \%$ (mean \pm standard deviation) (unpublished results). If total creatine was used as reference instead of water, the coefficient of variation was larger, namely $11.5 \% \pm 11.9 \%$ (mean \pm standard deviation). 


\section{Analysis}

Blood analyses

For determination of FFA, glycerol and glucose, blood was collected in tubes containing $30 \mu \mathrm{l}$ of $0.2 \mathrm{M}$ EDTA. Plasma was immediately centrifuged at high speed, frozen in liquid nitrogen and stored at $-80^{\circ} \mathrm{C}$ for later analyses. Insulin concentrations were measured using Radio-immuno-assay (RIA) (linco research, St. Charles, USA). FFA were determined using the Wako Nefa $\mathrm{C}$ testkit (Wako chemicals, Neuss, Germany).

Plasma glucose was determined using the hexokinase method (LaRoche, Basel, Switzerland) and glycerol using the GPO-trinder (sigma).

\section{Statistics}

Characteristics of subjects and the coefficient of variation of the measurement are reported as mean \pm standard deviation, results are reported as mean \pm standard error of the mean (SEM). Statistical analyses were performed with SPSS for Windows 10.0.0 software (SPSS Inc., Chicago, Dlinois, USA). Differences before and after training were detected with paired student $t$-tests. The blood parameters during exercise were analyzed with a general linear model repeated measures analyses. If the repeated measures analyses detected significant differences, post hoc t-tests were performed. Stars in the figures indicate significant differences according to the $\mathrm{t}$-tests. Results were considered significant if $\mathrm{p}<0.05$.

\section{Results}

\section{Maximal Performance}

Maximal performance did not change significantly due to the training program $(272.8 \pm 14.0 \mathrm{~W}$ vs. $281.7 \pm 13.4 \mathrm{~W}$ before and after training respectively.)

\section{Substrate oxidation}

Fat oxidation gradually increased during the three-hour cycling test (see Figure 3.3A).

During the first $90 \mathrm{~min}$ (before the carbohydrate drink), fat oxidation before and after training did not differ significantly. After training, a decrease in fat oxidation was observed at $t=90 \mathrm{~min}$. This coincided with the administration of a carbohydrate drink. As a consequence, a significantly lower fat oxidation was observed after training compared to before training in the second 90 min of the test. 'The average fat oxidation over the entire 180 minutes of the test was not significantly different after training.

Reciprocal effects were observed for carbohydrate oxidation (see Figure 3.3B): During the first $90 \mathrm{~min}$ (before the carbohydrate drink), carbohydrate oxidation before and after training did not differ significantly. When the carbohydrate drink was administered, carbohydrate oxidation increased after training but not before training. As a consequence, a significantly higher carbohydrate oxidation 
was observed after training compared to before training in the second $90 \mathrm{~min}$ of the test. The average carbohydrate oxidation over the entire 180 minutes of the test was not significantly different after training.
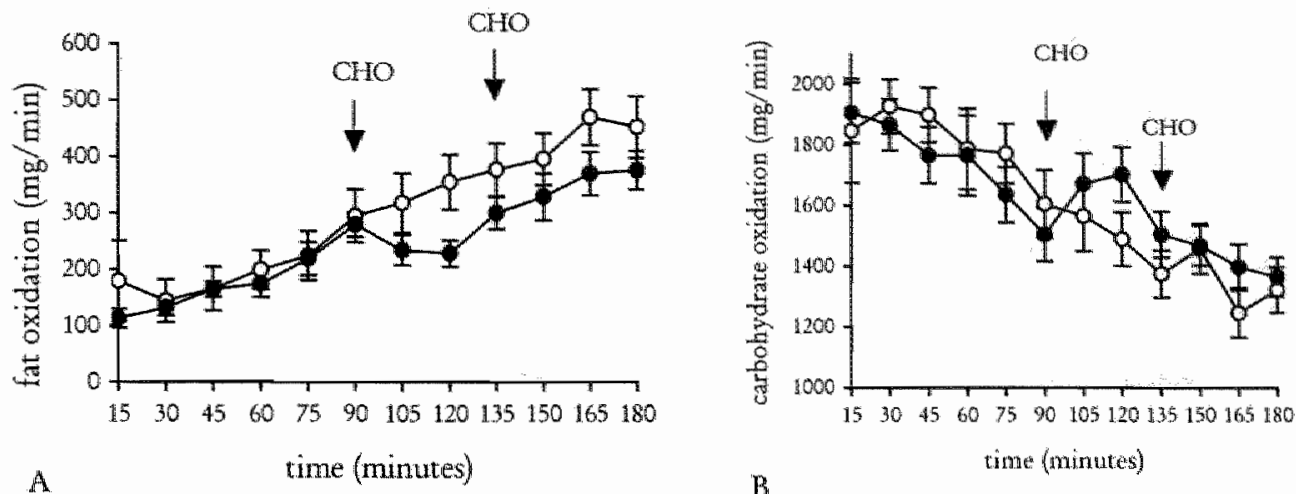

Figure 3.3: Fat oxidation (A) and carbohydrate oxidation (B) was measured every 15 minutes by indirect calorimetry during the three-hour cycling test. Open circles m before training, filled circles $=$ after training. The arrows indicate the gavage of a carbohydrate (GHO) drink.

\section{Blood parameters}

There were no significant differences before and after training in the fasting plasma values of insulin $(7.46 \pm 1.10$ vs. $7.44 \pm 1.12 \mu \mathrm{u} / \mathrm{ml}(\mathrm{nu} / \mathrm{l}))$, FFA (355.28 $\pm 48.34 \mu \mathrm{mol} / 1$ vs. $349.11 \pm 46.62 \mu \mathrm{mol} / 1)$ and glycerol $(67.99 \pm 6.03 \mu \mathrm{mol} / 1$ vs. $71.00 \pm 6.05 \mu \mathrm{mol} / \mathrm{l})$. However, there was a tendency of decreased fasting plasma glucose after training $(5.23 \pm 0.08 \mathrm{mmol}$ vs. $5.07 \pm 0.11 \mathrm{mmol}, \mathrm{p}=0.062)$.

During exercise, there was a significant effect of time for insulin with values decreasing with time $(\mathrm{p}<0.001)$, but no treatment (training), nor treatment ${ }^{*}$ time interaction effect (see Figure $3.4 \mathrm{~A}$ ). There was a significant effect of time $(p<0.001)$, treatment and of timettreatment interaction for FFA plasma values with values increasing with time (see Figure 3.4B). After training, values were lower than before training in the second half of the cycling test. For glycerol plasma concentrations, there was a time effect $(p<0.001)$, a treatment effect and a time ${ }^{*}$ treatment interaction effect. Glycerol concentrations increased gradually during the test. In the second half of the exercise test, concentrations were lower after training compared to before training (see Figure 3.4C). There was a significant effect of time for glucose plasma values with values decreasing with time, a tendency for a treatment effect with levels being higher after training $(p=0.07)$, and no treatment time interaction effect (see Figure 3.4D). 


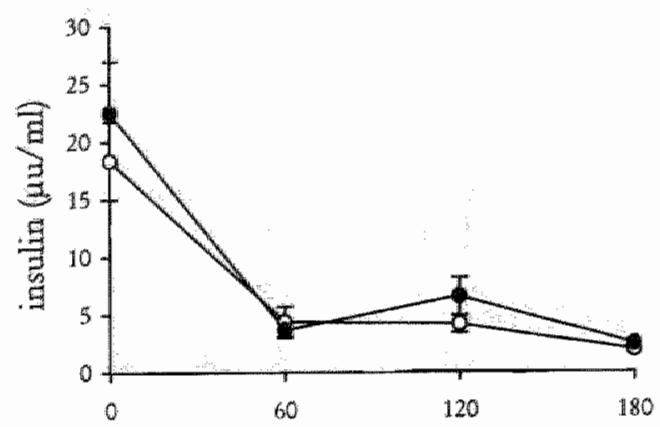

A

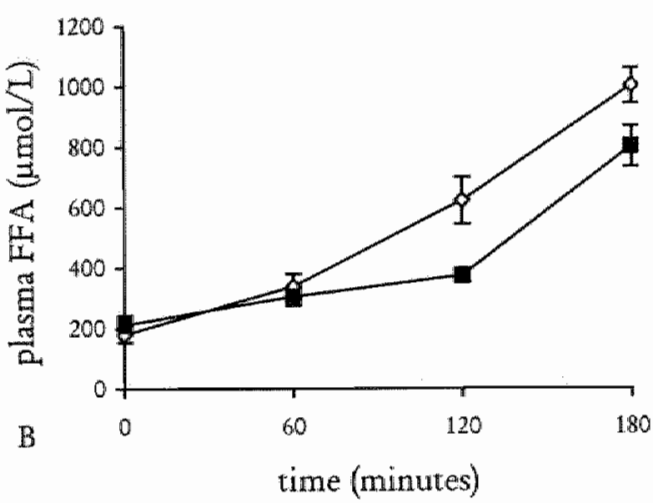

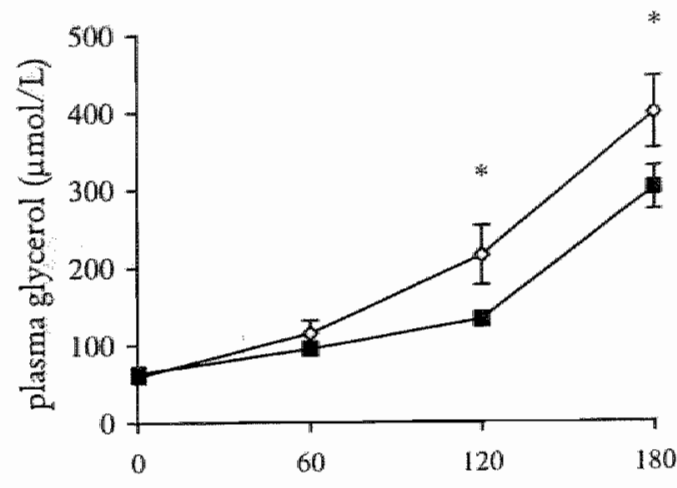

C

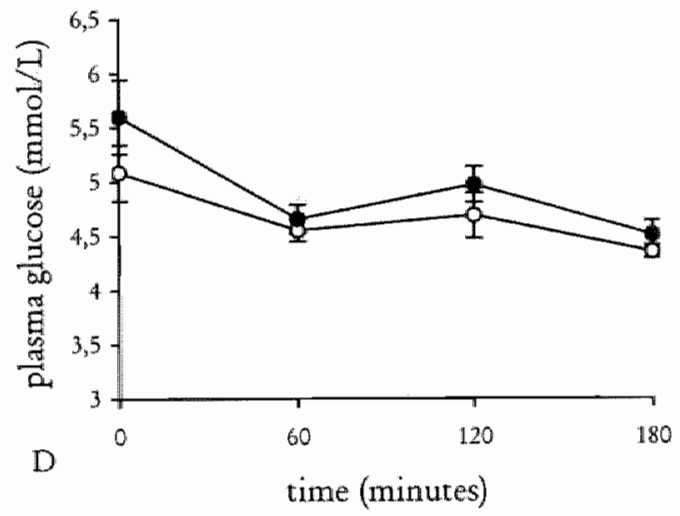

Figure 3.4: Blood plasma parameters during the three-hour cycling test. Open squares = before tratuing, filled squares = after training. Stars indicate significant differences between pre-and posttraining values.

A: Insulin plasina concentrations.

B: FFA plasma concentrations.

C: Glycerol plasma concentrations

B: Glucose plasma concentrations.

\section{Insulin Tolerance Test}

After training, there was a tendency for the plasma glucose to drop faster in response to insulin. The $\mathrm{t} / 2$ of glucose disappearance tended to be shorter after training compared to before training $(15.4 \pm 1.4 \mathrm{~min}$. vs. $14.1 \pm 1.1 \mathrm{~min}$, $\mathrm{p}=0.12)$.

\section{IMCL content}

Spectra from identical voxel positions at all four points in time were availlable from seven subjects. Before training, pre-exercise IMCL content was $0.35 \pm 0.02 \%$ of the water reference signal. Training increased the pre-exercise IMCL content 
significantly by $42 \pm 14 \%$ (see Figure 3.5). Before training the three-hour cycling test decreased the IMCL signal by $14 \pm 3 \%(\mathrm{p}<0.01)$. After training. the decrease in $\mathrm{MMCL}$ content during the three-hour cycling test was similar $(14 \% \pm 9 \%$ ) but this decrease did not reach significance (see Figure 3.5 ). If total creatine was used as reference instead of water, similar results were obtained: a significant increase in $\mathrm{MMCL}$ with training, a significant depletion during cycling before training, and a (non-significant) depletion during cycling after training. Insulin sensitivity did not correlate with IMCL content in this small group, neither before nor after training.

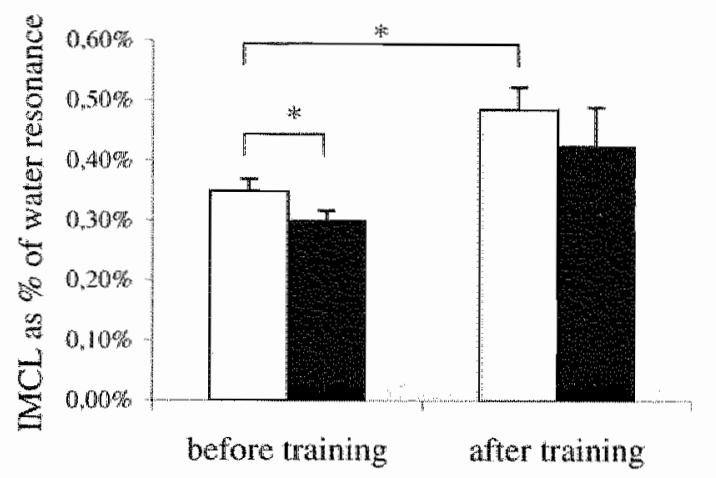

Figure 3.5: IMCL content, expressed as percentage of the water resonance. White bar $=$ before cycling test, black bar $=$ after cycling test. Stars indicate significant differences.

\section{Discussion}

The most important finding of the present study is that the IMCL content is increased significantly after a training period of as short as two weeks. During this period, no significant changes in fat oxidation or insulin sensitivity were detected. From this, we conclude that the increase in IMCL content is among the earliest responses to training. Furthermore, the results of the present study suggest that the solely presence of triglycerides in myocytes does not have detrimental effects on insulin sensitivity. Also, we confirm earlier reports, that IMCL contribute to the energy used during prolonged sub maximal exercise. It is generally accepted that training improves insulin sensitivity and it has previously been shown, that training can increase insulin sensitivity after a period of training as short as 7 days (9-12), although it cannot be excluded that some remnant effect of the last exercise bout was detected in these studies. In the present study, insulin sensitivity was not yet significantly increased. This lack of increase can be due to different indicators of insulin sensitivity used or to different training protocols employed (18). We chose to use the insulin tolerance test (IT'T) which measures the hypoglycemic action of injected insulin, because it is a short test, which has recently been shown to be sensitive enough to detect differences in the improvement in insulin sensitivity induced by different training programs (18). Although the increase in insulin sensitivity as quantified by the ITT was not significant $(p=0.12)$, we did find some indication of increased 
insulin action. There was a tendency for fasted glucose levels to be lower by $3 \%$ $(p=0.062)$, while insulin levels were unchanged. Furthermore, an oral carbohydrate load, administered in the second half of the exercise test to facilitate the completion of the test, lead to an increase in carbohydrate oxidation observed solely after training. In accordance with this, the carbohydrate load resulted in reduced lipolysis and fat oxidation after training in the second part of the test. These changes could indicate improved glucose absorption and disposal. It has been described, that exogenous carbohydrate oxidation is higher in trained subjects (24) and that a training intervention of 12 weeks can stimulate oxidation of exogenous glucose (25) and this could indicate an increased insulin sensitivity. Furthermore, short-term training has been reported to increase GLUT-4 content (26) and hexokinase activity $(27,28)$, indicating improved glucose disposal capacity. Alternatively, changes in perfusion of splanchnic system occur with training (29) and may induce increased absorption of glucose and contribute to the increased oxidation after an oral glucose load. Future studies should address the mechanism of increased glucose oxidation after an oral glucose load in trained versus untrained subjects in more detail.

The positive correlations of IMCL content with insulin resistance that were reported in different populations $(5,6)$ and the finding that the increase in IMCL content precedes the development of diabetes $(7,30)$ suggests that intramuscular lipids might be involved in the development of insulin resistance. However, the finding that IMCL content is also increased in highly trained, insulin sensitive athletes $(8,31,32)$ and that their IMCL contents are actually very similar to those reported in diabetic subjects is paradoxical and favors a more complex explanation (33). In the present study, we find an increase in IMCL, which is not coupled to a diminished insulin sensitivity; rather, we find indications of improved insulin sensitivity. Therefore, the results of the present study suggest that it is unlikely that solely the presence of triglycerides in myocytes is leading to a decrease in insulin sensitivity. Also, other authors have suggested an interference of lipid degradation derived intermediates such as long chain acylCoA and diacylglycerol with insulin signaling (34-37) to be more likely than the triglycerides themselves being responsible for disturbed insulin action.

We showed earlier that the increase in fat oxidation during exercise due to longterm training can be completely accounted for by increased oxidation of triglyceride-derived fatty acids (13). Therefore, and also based on earlier results from biochemical analyses of biopsies, it has been suggested that training might lead to an increased oxidation of intramuscular lipids during exercise (14). Others however, found no changes in intramuscular lipid oxidation with training (38). In the current study, we confirm earlier results, which showed that IMCL decrease during exercise $(15,39)$. However, the decrease in IMCL after 3 hours of exercise was similar before and after training, suggesting that the use of IMCL was not altered with training. However, it is important to note that also total fat oxidation over the 3 hours was not changed after training. Evenmore, we cannot 
exclude that the improved utilization of carbohydrate after training, which reduced fat oxidation in the second part of the exercise test, could have interfered with a decrease of IMCL content after training.

There has been some concern about using the water signal as a reference after exercise because water- and electrolyte shifts are possible. When using total creatine instead of water as internal standard in the current study, we found no statistical difference between the results using the two methods. In both cases we found a significant IMCL depletion before training, a non-significant depletion after training, and significant training-induced increase in baseline IMCL. We chose to use the water peak as internal reference, because the use of the small peak of total creatine introduced some additional variability so that the average coefficient of variation of repeated measurements increased from an average of $6 \%$ with water to $11.5 \%$ with total creatine. Since no trends in water signal or the water to total creatine signal ratio were found before versus after exercise, we feel that it is justified to use the water signal as internal standard in the present study.

It has been shown that training can lead to an increase in fat oxidation after seven days of endurance training (40). The finding that fat oxidation during the first 90 minutes (before any carbohydrate was administered) did not increase with the current protocol could be due to the nature of the training protocol, which consisted of endurance, as well as high intensity components. It is assumed that the current exercise protocol was too short to produce increases in fat oxidation in untrained subjects. Conclusively, in the present study we showed that in untrained subjects, IMCL content was increased with training before an adaptation in fat oxidation occurred and that the increase in IMCL content was not coupled to a decrease in insulin sensitivity, rather, we find indications of improved insulin sensitivity. These results suggest that solely the presence of IMCL does not hamper insulin sensitivity. Instead, the data are in line with models that suggest a more indirect relationship between IMCL content and insulin resistance, as those who emphasize on the accumulation of intermediates of fat oxidation (34-37). More studies are needed to investigate these mechanisms in detail.

\section{Acknowledgements}

We would like to thank Steven Constandse and Niels Boon for their help in performing this study. Dr. P. Schrauwen was supported by a grant from the Netherlands Organization for Scientific Research (NWO). 


\section{References}

1. Zimmer P, Alberi KG, Shaw J. Global and societal implications of the diabetes epidemic. Nature. $2001 ; 414: 7827$.

2. Colberg $\mathrm{SR}$, Simoneau JA, Thaete FL, Kelley DE. Skeletal muscle utilization of free fatry acids in women with wisceral obesity. J Clin lnvest. 1995; 95: 1846-53.

3. Blatk EE, van Aggel-Leifssen DP, Wagenmakers AJ, Saris WH, van Baak MA. Impaired axidation of plasma-deriwed fatty acids in type 2 diabetic subjects during moderate-intensity exercise. Diabetes. 2000;49,2102-7.

4. Levin K, Daa Schroeder H, Alford FP, Beck-Nielsen H. Morphometric documentation of abnormall intramyocellular fat storage and reduced glycogen in obese patients with Type II diabetes. Diabetologia. 2001; 44: 824-33.

5. Krssak M, Ealk Petersen $K$, Dresner A, DiPietro $\mathbb{L}$, Vogel SM, Rothman DL, Roden M, Shulman GI. Intramyocellular lipid concentrations are correlated with insulin sensitivity in humans: a 1H NMR spectroscopy study. Diabetologia. 1999; 42:113-6.

6. Pan DA, Lillioja S, Kriketos AD, Milner MR, Baur LA, Bogardus C, Jenkins AB, Storlien LH. Skeletal muscle triglyceride levels are inversely related to insulin action. Diabetes. 1997; 46:983-8.

7. Jacob S, Machann J, Rett $K$, Brechtel K, Volk A, Renn W, Maerker E, Matthaei S, Schick F, Claussen CD, Haring HU. Association of increased intramyocellular lipid content with insulin resistance in lean nondiabetic offspring of type 2 diabetic subjects. Diabetes. 1999; 48: 1113-9.

8. Decombaz J, Schmitt B, Ith M, Decarli B, Diem P, Kreis R, Hoppeler H, Boesch C. Postexercise fat intake repletes intramyocellular lipids but no faster in trained than in sedentary subjects. Am J Pbysiol Regul Integr Comp Physiol. 2001; 281: R760-9.

9. Houmard JA, Shaw CD, Hickey MS, Tanner CJ. Effect of short-term exercise training on insulin-stimulated PI 3-kinase activity in human skeletal muscle. Am J Pbysiol. 1999; 277 : E1055-60.

10. Cox JH, Cortright RN, Dohm GL, Houmard JA. Effect of aging on response to exercise training in humans: skeletal muscle GLUT'-4 and insulin sensitivity. I Appl Physiol. 1999; 86; $2019-25$.

11. Youngren JF, Keen S, Kulp JL, Tanner CJ, Houmard JA, Goldfine ID. Enhanced muscle insulin receptor autophosphorylation with short-term aerobic exercise training. Am $J$ Plbysial Endocinal Metab. 2001; 280: E528-33.

12. Tannex CJ, Koves TR, Cortright RL, Pories WI, Kim YB, Kahn BB, Dohm GL, Houmard JA. Effect of short-term exercise training on insulin-stimulated PI 3-kinase activity in middlle aged men. A w I Pbysiol Endocrinol Metab. 2002; 282: E147-53.

13. Schrauwen P, van Aggel-Leijssen DP, Hul G, Wagenmakers AJ, Vidal H, Saris WH, van Baak MA. The effect of a 3-month low-intensity endurance training program on fat oxidation and aceryl-CoA carboxylase-2 expression. Diabetes. 2002; 51: 2220-6.

14. Hurley BF, Nemeth PM, Martin WH, 3rd, Hagberg, JM, Dalsky GP, Holloszy JO. Muscle triglyceride utilization during exercise: effect of training. I Appl Physiol. 1986; 60: 562-7.

15. Boesch C, Decombaz J, Slotboon J, Kreis R. Observation of intramyocellular lipids by means of $1 \mathrm{H}$ magnetic resonance spectroscopy. Proc Nutr Soc. 1999; 58: 841-50.

16. Harris JA, Benedict FG. A bionetric study of basal metabolism in man. Washington: Carnegie lintitution of Wrashington. 1919 ;

17. Siri W. The gross composinion of the body. Adv Biol Med Pbysiol. 1956; 4: 239-280.

18. Borghouts $\mathbb{L} B$, Backx $\mathrm{K}_{\text {, Mensink }}$ ME, Keizer HA. Eflect of training intensity on insulin sensitivity as evaluated by insulin tolerance test. Eur I Appl Physiol Occup Physiol. 1999; 80: $461-6$.

19. Peronnet $F$, Massicotte D. Table of nonprotein respiratory quotient: an update. Can J Spont Sci. 1991; 16: 23-9. 
20. Vanhamme L, van den Boogaart A, Van Huffel S. Improved method for accurate and efficient quantification of MRS data with use of prior knowledge. / Magn Reson. 1997; 129: $35-43$.

21. Naressi A, Couturier C, Devos JM, Janssen M, Mangeat $C$, de Beer R, Graveron-Demilly D. Java-based graphical user interface for the MRUI quantication package. Maggwa. 2001; 12: 141-52.

22. Boesch $C$, Slorboom J, Hoppeler $H$, Kreis $R$. In vivo determination of intramyocellular lipids in human muscle by means of localized IH-MR-spectroscopy. Magm Reson Med. 1997; 37: $484-93$.

23. Schick F, Eismann B, Jung wI, Bongers $H$, Bunse M, Lutz O. Comparison of localized proton NMR signalls of skeleral muscle and far tissue in vivo: two lipid compartments in muscle tissue. Magn Reson Med. 1993; 29: 158-67.

24. Burelle $Y$, Peronnet $F$, Charpentier $S$, Lavoie $C$, Hillaire-Marcel $C$, Massicotre D. Oxidation of an oral [13C] glucose load at rest and prolonged exercise in trained and sedentary subjects. J Appl Phystol. 1999; 86:52-60.

25. Krzentowski G, Pirnay F, Luyckx AS, Lacroix M, Mosora F, Lefebwre PJ. Effect of physical training on utilization of a glucose load given orally during exercise. Am f Physiol. 1984; 246: E412-7.

26. Phillips SM, Han XX, Green HJ, Bonen A. Increments in skeletal muscle GLU"T-1 and GLUT-4 after endurance training in humans. Am J Physiol. 1996; 270: E456-62.

27. Phillips SM, Green HJ, Tarnopolsky MA, Heigenhauser GJ, Grant SM. Progressive effect of endurance training on metabolic adaptations in working skeletal muscle. Am / Pbysiol. 1996; 270: E265-72.

28. Coggan AR, Kohrt WM, Spina RJ, Bier DM, Holloszy JO. Endurance training decreases plasma glucose turnover and oxidation during moderate-intensity exercise in men. $\int \mathrm{Appl}$ Ploysiol. 1990; 68: 990-6.

29. Lash JM. 'Training-induced alterations in contractile function and excitation* contraction coupling in vascular smooth muscle. Med Sci Sports Exerc. 1998; 30: 60-6.

30. Malenfant $\mathbb{P}$, Tremblay A, Doucet E, Imbeault P, Simoneau IA, Joanisse DR. Elevated intramyocellular lipid concentration in obese subjects is not reduced after diet and exercise training. Am J Pbysiol Endocrinol Metab. 2001; 280: E632-9.

31. Morgan TE, Short FA, Cobb LA. Effect of Jong-term exercise on skeletal muscle lipid composition. Am J Pbysiol. 1969; 216: 82-6.

32. Hoppeler $H$, Howald $H$, Conley $K$, Lindstedt SL, Classen H, Vock P, Weibel ER. Endurance training in humans: aerobic capacity and structure of skeletal muscle. $J$ Appl Physiol, 1985; 59: 320.7.

33. Goodpaster BH, He J, Watkins S, Kelley DE. Skeletal muscle lipid content and irsulin resistance: evidence for a paradox in endurance-trained athletes. I Clin Endocrinol Metab. 2001; 86: 5755-61.

34. Laybutt DR, Schmitz-Peiffer C, Saha AK, Ruderman NB, Biden TJ, Kraegen EW. Muscle lipid accumulation and protein kinase $C$ activation in the insulin-resistant chronically gilucose-infused rat. Ann I Pbysiol. 1999; 277: E1070-6.

35. Ellis BA, Poynten A, Lowry AJ, Furler SM, Chisholm DJ, Kraegen EW, Cooney GJ. Longchain acy]-CoA esters as indicators of lipid metabolism and insulin sensitivity in rat and human muscle. Am J Physiol Endocrinol Metab. 2000; 279: E554 60.

36. Dobbins RL, Szczepaniak LS, Bentley B, Esser V, Myhill J, McGarry JD. Prolonged inhibition of muscle carnitine palmitoyltransferase 1 promotes intramyocellular lipid accumulation and insulin resistance in rats. Diabetes. 2001; 50: 123-30.

37. Irani SI, Ruderman NB, Schmieder F, Boden G. Lipid-induced insulin resistance in human muscle is associated with changes in diacylglycerol, protein kinase $\mathrm{C}$, and IkappaB-alpha. Diabetes, 2002; $51: 2005-11$. 
38. Bergman $B C$, Bunterfield $\mathrm{GE}_{\text {, Wolfel }} \mathrm{EE}$, Casazza $\mathrm{GA}$, Lopaschuk GD, Brooks GA. Evaluation of exercise and training on muscle lipid metabolism, Am J Physiol. 1999: 276: E106-17.

39. Krssak M, Petersen KF, Bergeron $R$, Price $T$, Laurent $D$, Rothman DL, Roden M, Shulman GI. Intramuscular glycogen and intramyocellular lipid utilization during prolornged exercise and recovery in man: a $13 \mathrm{C}$ and $1 \mathrm{H}$ nuclear magnetic resonance spectroscopy study. J Clin Endocrinal Metab. 2000, $85,748-54$.

40. Putmarn CT, Jones NL, Hultman E, Hollidge-Horvat MG, Bonen A, MeConachie DR, Heigenhauser GJ. Effects of short-term submaximal training in humans on muscle metabolism in exercise. Am J Physiol. 1998; 275: E132-9. 


\section{CHAPTER}

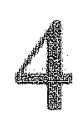

\section{THE ACCUMULATION OF INTRAMYOCELLULAR LIPIDS (IMCL) WITH SHORT-TERM TRAINING IS ACCOMPANIED BY A DOWN REGULATION OF ACC2 mRNA IN SKELETAL MUSCLE}

V.B. Schrauwen-Hinderling, M.K.C. Hesselink, E. Moonen-Kornips, G. Schaart, M.E. Kooi, W.H.M. Saris, P. Schrauwen

International Journal of Sports Medicine, 2006, in press 


\section{Abstract}

Recently, we showed that short-term training induced a rapid increase in IMCL whilst instlin sensitivity tended to improve. Here we investigate molecular adaptations accompanying this physiological training-induced accumulation of IMCL.

Nine untrained men (age: $23.3 \pm 3.2$ y, maximal power output: $3.8 \pm 0.6 \mathrm{~W} / \mathrm{kg}$ body weight) trained for two weeks. Before and after rraining, subjects cycled for three hours and biopsies were taken before and after exercise. mRNA concentrations of ACC2, HSL, LPL, Glut4 and HKII were quantified by RT-PCR and association of Glut4 with the membrane was quantified by immunohistochemical method.

Endurance training resulted in a decrease of $29.1 \%$ in ACC2 mRNA $(p=0.02)$. After training, ACC2 mRNA tended to decrease with acute exercise $(-24.4 \% \quad(p=0.06))$. HSL mRNA decreased with acute exercise after training ($37.3 \%(\mathrm{p}=0.002))$. LPL mRNA concentrations increased with acute exercise before training $(+42.4 \%(\mathrm{p}=0.05)$ and HKII $\mathrm{mRNA}$ increased with acute exercise before $(+72.5 \%$ $(\mathrm{p}=0,025)$ and after training $(+99.3 \% \quad(\mathrm{p}=0.05))$. After acute exercise, more Glut4 was associated with the membrane than before exercise, but it was not affected by training. We conclude that the training-induced increase in IMCL was accompanied by molecular adaptations in muscle to improve fat oxidative capacity, while markers of glucose metabolism were not yet changed. The present data are in line with the hypothesis that the fat oxidative capacity might be more important than the IMCL content in determining insulin sensitivity. 


\section{Introduction}

High intramyocellular lipid content has been associated with insulin resistance (1-4). However, paradoxically, endurance trained athletes are also characterized by high IMCL levels $(5,6)$ while being highly insulin-sensitive, suggesting that the relation is not causal. Based on cross-sectional data, comparing trained athletes with untrained subjects, a negative effect of intramuscular triglycerides themselves on insulin sensitivity can however not be ruled out, as it would be conceivable that other long term metabolic adaptations to training overcompensate negative effects of enlarged intramuscular triglyceride depots. Long term endurance training leads to many physiological adaptations such as increased capillary supply $(7)$, increased fat free mass and increased number of type I fibers (8) and increased fat oxidative capacity (9) which all have recognized positive effects on insulin sensitivity. Therefore, to study the (lack of) relationship between $\mathrm{MCL}$ and insulin sensitivity upon endurance training, it is required to examine the longitudinal effects of endurance training on IMCL content. To this end, we recently examined insulin sensitivity and IMCL content in response to a short-term training program (10). We found increased IMCL content after a short training period of two weeks that occurred in concert with a tendency to improved insulin sensitivity. As after two weeks of training, longterm adaptations are negligible, we concluded that IMCL content couldn't be directly responsible for insulin resistance.

As an alternative explanation for the relation between IMCL and insulin sensitivity, it has been suggested that not IMCL content per se, but a low fat oxidative capacity, which can result in the storage of LMCL, is responsible for the negative effects on insulin sensitivity $(4,11,12)$. Indeed, type 2 diabetes patients are characterized by low fat oxidative capacity (13), whereas endurance training results in increased IMCL levels along with increased fat oxidative capacity and improved insulin sensitivity.

In our short term training study, we observed that whole body fat oxidation measured by indirect calorimetry during a three-hour cycling test was not (yet) changed. It is conceivable that changes on whole body level are not yet detectable, even though adaptations on subcellular (muscular) level already occurred. We here examine the effect of acute exercise and two weeks of training on gene expression of marker genes with a recognized key role in the skeletal muscle metabolic pathways for fat oxidation.

In addition, markers of glucose metabolism were also investigated to examine whether two weeks of training already improved glucose metabolism. 


\section{Methods}

\section{Subjects}

Nine young, untrained and healthy male subjects (age (y) (mean \pm stdev.)): $23.3 \pm 3.2$; BMI $(\mathrm{kg} / \mathrm{m} 2)$ (mean \pm stdev.): $22.6 \pm 2.6$; maximal power output (W/max) (W/kg) (mean \pm stdev.): $3.8 \pm 0.6$; maximal oxygen uptake (VO2max) $(1 /$ min) (mean \pm stdev.): $3.54 \pm 0.55$ ) participated in this study. Subjects were recruited by advertisement and were excluded from participation if they had performed aerobic exercise competitively for more than three months or were still exercising on a regular basis. The institutional Medical Ethics Committee approved the study. Subjects gave their written informed consent after the nature of the procedure was explained.

\section{Experimental protocol}

A week preceding the experimental trial, an incremental test to determine Wmax was performed, which was repeated in the week after the experimental trial. The set up of the trial was as follows. Days 1-3 formed a standardization period, during which a standardized diet was provided and subjects refrained from exercise. In the afternoon of day 3, a three-hour cycling test was performed, where subjects cycled at $40 \%$ of their predetermined Wmax. Muscle biopsies were taken from the vastus lateralis muscle before and after exercise and immediately frozen in liquid nitrogen. Biopsy samples used for immunofluorescence assays were embedded in Tissue-Tek (Sakura Finetek, Zoeterwoude, The Netherlands) and frozen in liquid nitrogen-cooled isopentane. Subjects then participated in a training program with a mixture of endurance- and interval training. Resting days were incorporated on day 4 and 10. Days 15 to 17 were again used as standardization period, with the same standardization diet as on day 1 to 3 and with subjects refraining from exercise. In the afternoon of day 17, subjects again cycled for 3 hours at $40 \%$ W max. Again, biopsies were taken from the vastus lateralis muscle before and after exercise and immediately frozen.

\section{Diets}

The macronutrient composition of the diets during the three-day standardized period was such that $30 \%$ of the energy was consumed as fat, $55 \%$ as carbohydrate and $15 \%$ as protein.

Subjects were given a fixed amount of food (1.65*BMR based on Harris and Benedict equations (14)) and were asked to eat all the food provided, and nothing else. The diet consisted of breakfast, lunch, ready to use dinner and snacks.

\section{Procedures}

Three-bour cycling test

The exercise test consisted of three hours of cycling on an electromagnetically braked ergometer at an intensity of $40 \%$ of the predetermined W/max. To 
facilitate the completion of the exercise test, subjects received twice $125 \mathrm{ml}$ of a maltodextrine drink (Extran Fresh Citrus; $131 \mathrm{~kJ} / 31 \mathrm{kcal}, 7,9 \mathrm{~g} \mathrm{CHO}, 0 \mathrm{~g}$ proteins and lipids per $100 \mathrm{ml}$ ) during the second half of the test (at $\mathrm{t}=90 \mathrm{~min}$. and $t=135 \mathrm{~min}$.). Subjects were allowed to drink water ad libitum during the whole test.

\section{Training program}

From day 5 to 14, subjects reported to the laboratory daily to follow supervised training sessions on cycle ergometers, except for the resting day on day 10 . Training consisted of alternating days of interval- and endurance training and always started with 7.5 minutes of warming up at $40 \% \mathrm{~W} \max$ and ended with 7.5 minutes of cooling down at $40 \% \mathrm{Wmax}$. On days 5, 7,9 and 11 , cycling interval training was performed, which consisted of 45 minutes of alternating three minutes intervals at $70 \% \mathrm{~W} \max$ and $35 \% \mathrm{~W} \max$. At days 6, 8, 12 and 14 , exercise consisted of 35 minutes at $55 \%$ Wmax, followed by 35 minutes at $50 \%$ $\mathrm{W} \max$, and 35 minutes at $45 \% \mathrm{~W} \max$, for a total duration of 120 minutes.

\section{Muscle biopsy sampling and andlysis}

Muscle biopsies were taken from the mid-thigh region from $M$. vastus lateralis according to the technique of Bergström (15). The biopsy was used for isolation of total RNA using the acid phenol method of Chomozynski \& Sacchi (16), with acid Phenol extraction and Ethanol precipitation. The mRNA levels of lipoprotein lipase (LPL), hormone-sensitive lipase (HSL), hexokinase II (HKII), glucose transporter-4 (GLUT-4) and acetyl CoA carboxylase (ACC2) were quantified by RT-competitive PCR (17). For the assays, the reverse transcription reaction was performed from $0.2 \mu \mathrm{g}$ of skeletal muscle total RNA in the presence of a thermostable reverse transcriptase (Tth, promega) by use of one of the specific antisense primers. The competitive PCR assays were performed as previously described (18-20). To improve the quantification of the amplified products, fluorescent dye-labeled sense oligonucleotides were used. The PCR products were separated and analyzed on an ALFexpress DNA sequencer (Pharmacia) with the Fragment Manager Software. Total RNA preparations and RT-competitive PCR assays of all four skeletal muscle samples from the same individual (before and after exercise and before and after training) were performed simultaneously.

Subcellular localization of GLUT-4 was performed by indirect immunofluorescence assays using an affinity-purified polyclonal rabbit antibody (GLUT4-BW) (21). In short, multiple serial sections $(5 \mu \mathrm{m})$ from biopsies were collected and thaw mounted together on uncoated glass slides. After methanol/aceton fixation, the sections were incubated with the primary and appropriate secondary antibodies with multiple PBS washing steps in between. We determined sarcolemmal and sarcoplasmatic GLUT-4 content and the 
basement membrane protein laminin (2E8, Dev, Hybridoma Study Bank, lowa City, IA, USA) as used to identify the cellular border. The antibodies against GLUT-4 and laminin were used simultaneously in a double-staining. Stained sections were examined using a Nikon E800 fluorescence microscope. All samples from the same individual were treated identically with regard to dilution of the antibody, incubation time and camera setrings (exposure time and gain). Quantitative image analysis was performed by using LUCIA G/F image analysis software. Using the laminin staining, a binary overlay was created by interactive thresholding. The binary was used to measure the intensity of the RGB signals from individual muscle fibers. A second binary was created by stepwise eroding the first binary from the edges, so that this second binary could be used to measure the intensity from the cytosol of the individual muscle fibers. In this way we were able to compute the ratio of GLUTT-4 present in the sarcolemma over the GLUT-4 present in the sarcoplasma.

Due to insufficient quality of some coupes, coupes from only six subjects could be analyzed.

\section{Statistics}

Results are reported as mean \pm standard error of the mean (SEM). Statistical analyses were performed with SPSS for Windows 10.0.0 sofrware (SPSS Inc., Chicago, Illinois, USA). Differences before and after training and before and after exercise were detected with paired student t-tests. Results were considered significant if $\mathrm{p}<0.05$.

\section{Results}

\section{Earlier analysis}

The following data was reported earlier: Blood samples were taken before and after training in the fasted state and during exercise, substrate oxidation was measured during exercise, insulin sensitivity was measured before and after training, using an insulin tolerance test and IMCL content was determined using proton magnetic resonance spectroscopy (10).

Fat oxidarion gradually increased and carbohydrate oxidation decreased during the three-hour cycling test. There were no significant differences in the total fatand carbohydrate oxidation after training compared to before training (10).

Before training, the three-hour cycling test decreased the IMCL signal by $14 \pm 3 \%(\mathrm{p}<0.01)$. After training, the decrease in IMCL content during the three-hour cycling test was similar $(14 \% \pm 9 \%)$ but this decrease did not reach significance. 'Training increased the IMCL content significantly by $42 \pm 14 \%$ (IMCL content was $0.35 \pm 0.02 \%$ and $0.49 \pm 0.04 \%$ of the water reference signal, before and after training respectively) (10). 


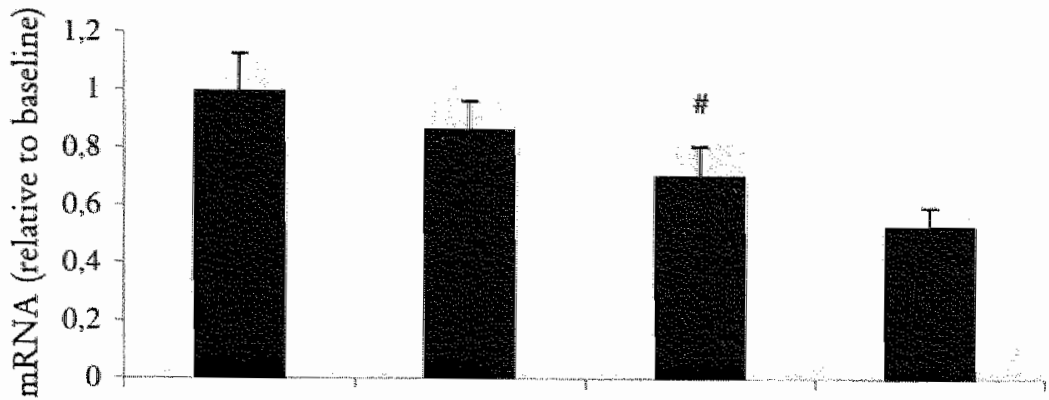

A before exercise, after exercise, before exercise, after exercise; pre-training pre-training post-training post-training

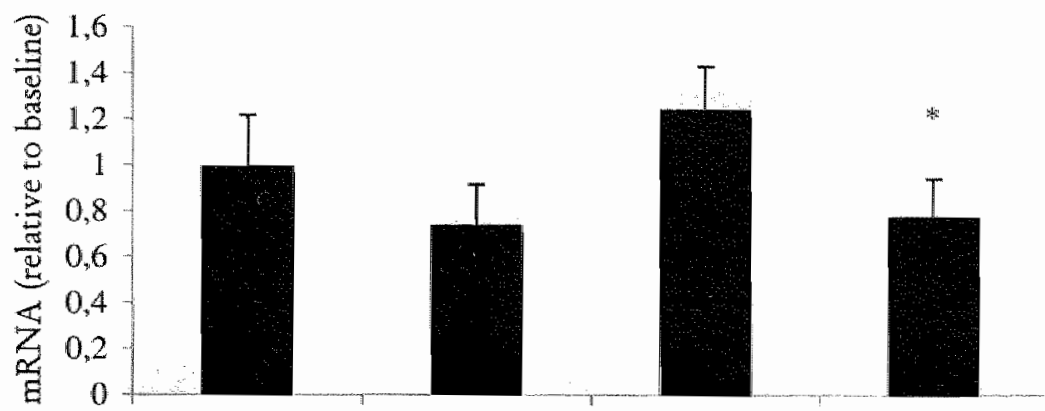

B before exercise, aiter exercise, before exercise, after exercise, pre-training pre-training post-training post-training

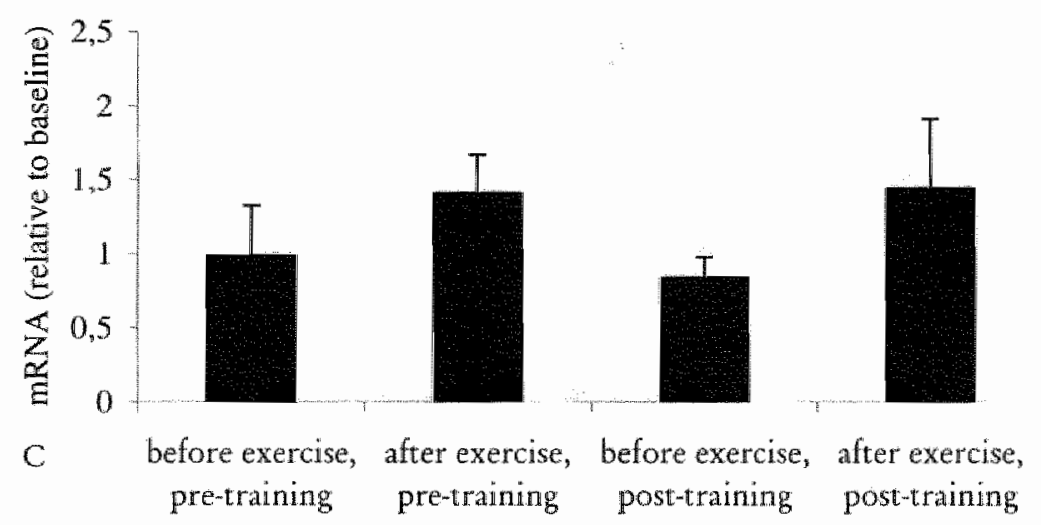

Figure 4.1: muscle mRNA concentrations of $\mathrm{ACC} 2$ (Figure A), HSL (Figure B) and LPL (Figure C) during training study. ${ }^{*}=$ Significantly different from before exercise, = Significantly different from before training. 


\section{Gene expression}

ACC2 mRNA tended to decrease during the three-hour cycling exercise after training $(24.4 \%,(\mathrm{p}=0.06))$ but not before training. Pre-exercise ACC2 mRNA concentrations were significantly decreased by $29.1 \%$ after training $(p=0.016)$ (Figure 4.1A).

HSL mRNA concentrations decreased with acute exercise after training (-37.3\%, $\mathrm{P}=0.002$ ) but not before training. Pre-exercise HSL mRNA concentrations were unchanged after training (Figure 4.1B).

LPL mRNA concentrations tended to increase with acute exercise before training $(+42.4 \%, p=0.05)$, but not after training and pre-exercise LPL mRNA concentrations did not change with training (Figure 4.1C).

HKII mRNA concentrations increased with the three-hour cycling exercise before training $(+72.5 \%, \mathrm{p}=0.03)$, and tended to increase after training $(+99.3 \%, \mathrm{p}=$ 0.05 ) (Figure 4.2A), but pre-exercise values did not differ before and after training. GLUT'-4 mRNA concentrations remained unchanged with acute exercise and with training (Figure 4.2B).

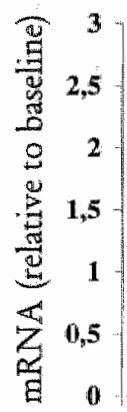

before exercise, after exercise, before exercise, after exercise,
A pre-training
post-training post-training

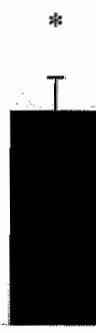

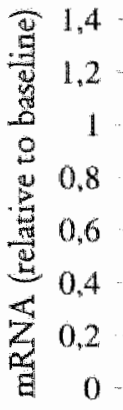

B
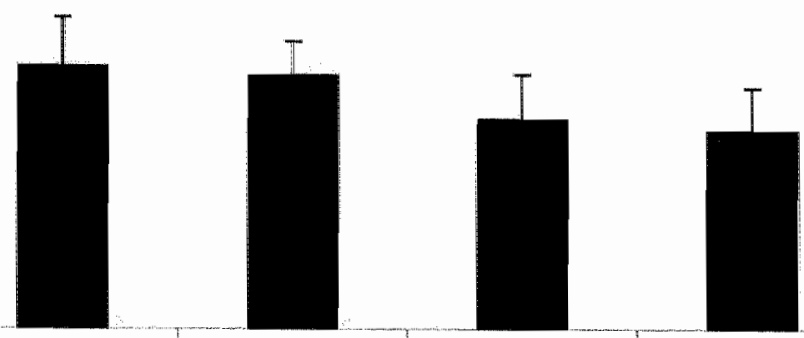

before exercise, after exercise, before exercise, after exercise, pre-training pre-training post-training post-training

Figure 4.2: muscle mRNA concentrations of HKII (Figure A) and GLUT-4 (Figure B) during training study. ${ }^{*}=$ Significantly different from before exercise. 


\section{GLUT-4 association with the membrane}

GLUT-4 association with the membrane increased by $17 \%$ in response to acute exercise after training $(\mathrm{p}=0.015)$ and tended to increase by $8 \%$ before training $(p=0.09)$. After training, not more GLUT-4 was associated with the membrane than before (Figure 4.3).

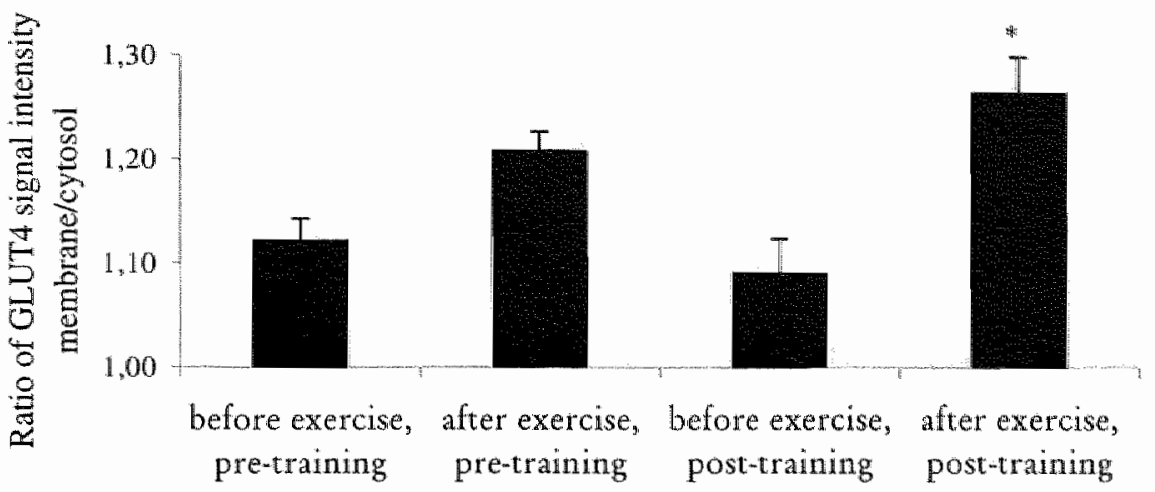

Figure 4.3: Association of GLUT 4 with the membrane during training study (ratio of signal intensity at membrane over signal intensity in cytosol). * Significantly different from before exercise.

\section{Discussion}

It has been suggested that IMCL content is a marker of insulin resistance (1-4), however there is accumulating evidence that not the IMCL but rather intermediates of fat oxidation, such as Acyl-CoA and diacylglycerol (DAG) interfere with insulin signaling $(22,23)$. If this holds true, the balance between oxidarive capacity and availability of FA is an important determinant in the development of insulin resistance. In line with this are recent results showing that overexpression of CPTI in myotubes increases $\beta$-oxidation and simultaneously increases insulin sensitivity without changing triglyceride content (12). We reported earlier that a two-week training program increased IMCL content with a tendency towards improved insulin sensitivity. However, no change in whole body fat oxidation was detected. To examine whether an adaptive response was detectable on muscular level, marker genes for fat oxidation were investigated in biopsy samples. To this purpose mRNA concentrations of ACC2, HSL and LPL were quantified.

ACC2 $\mathrm{mRNA}$ concentration tended to decrease in response to acute exercise bout and decreased in response to training in the present study. $\mathrm{ACC} 2$ has been suggested to control the rate of fatty acid oxidation in muscle (24), where it catalyses the carboxylation of acetyl-CoA to form malonyl-CoA which inhibits carnitine-palmitoyl-transferase I (CPTI). CPTI catalyses the conjugation of acyl-CoA to carnitine, a process which is mandatory for the transport of long chain fatty acids into mitochondria. This step has been shown to be rate-limiting 
for fatty acid oxidation and therefore, the activity of CPTI plays a regulatory role in fat oxidation. Therefore, $\mathrm{ACC} 2$ has been suggested to play a pivotal role in the inhibition of fat oxidation. This notion is substantiated by observations in ACC2 knock-out mice showing $30 \%$ higher fat oxidation rates compared to wild-type mice (25). In accordance, albeit at the mRNA level, we recently showed that three months of low intensity training decreased ACC2 mRNA levels by $36 \%$ accompanied with increased fat oxidation (26). Therefore, the tendency of $\mathrm{ACC} 2 \mathrm{mRNA}$ concentration to decrease with acute exercise indicates that a single endurance exercise session can already trigger the adaptive gene-regulatory response resulting in improved fat oxidative capacity which is a characteristic adaptation following consecutive bouts of endurance exercise. Although we did not (yet) find significant changes in whole body fat oxidation with the current training protocol of two weeks (10), the lowered ACC2 gene expression after training indicates that the initial steps towards improved fat oxidation are detectable at a cellular level within two-weeks of exercise training. The cumulative effect of acute exercise, performed daily during two weeks seems to produce a true training effect, still measurable more than 48 hours after the last exercise bout.

While the decrease in ACC2 mRNA suggests increased fat oxidation, it does not give hints towards the source of the fat used. LPL is necessary to take up and hydrolyze VLDL from plasma (27) and therefore, LPL gene expression can be used as a marker for VLDL lipid oxidation. LPL mRNA concentrations tended to increase after acute exercise before training in the current study, but the short term training program did not yet result in detectable changes in LPL gene expression. We previously showed that after three months of training, LPL mRNA content tended to be increased (26). This is in accordance with higher LPL mRNA concentration in trained subjects (28) and higher LPL activity in rodents after training $(29,30)$.

The oxidation of IMCL could be an alternative and directly available source of fat for oxidation. As in adipose tissue, triglyceride hydrolysis is catalyzed by HSL. While the regulation of hydrolysis of IMCL is an emerging field of research, the information about the regulation of HSL during exercise and the effect of exercise training is still fragmentary. HSL is thought to regulate the hydrolysis of IMCL in skeletal muscle $(31,32)$ and therefore, it might be used as a marker of IMCL use. This notion is underscored by reports showing HSL activation upon contractile activity $(31,32)$.

While Hurley et al. reported increased utilization of intramuscular triglycerides during exercise in the trained state (33), Bergman et al did not find this (34). In the present study no change in HSL mRNA concentration was observed after 2 weeks of endurance training, which is in line with our results from ${ }^{1} \mathrm{H}-\mathrm{MRS}$, showing that the decrease in IMCL during exercise was similar before and after the current two weeks' training program. In line with this are results from rat muscle, showing that HSL protein content did not change after training (35). In 
contrast to what was anticipated, HSL mRNA concentrations decreased in response to acute exercise after the training period. This is surprising as IMCL content clearly decreased during exercise. This might suggest that other lipases are involved in MCL hydrolysis. To our knowledge there is no other data on HSL gene expression in response to acute exercise.

Glucose disposal in response to insulin tended to be improved after a two-week training period and therefore we also investigated markers of glucose metabolism. To this end, the expression of two genes involved in regulatory steps of glucose metabolism, i.e. GLUT-4, the major glucose transporter in skeletal muscle and HKI, which catalyzes the phosphorylation of glucose to glucose-6-phosphate, a rate limiting step for glucose utilization, were examined.

HKII mRNA increased with acute exercise, which has been reported before (36). However, this marker of carbohydrate metabolism did not change by two weeks of training. GLUT-4 mRNA expression did not change with acute exercise, however more GLUT-4 protein was associated with the membrane after exercise after training. Before training, this effect was present as a tendency $(\mathrm{p}=0.09)$. Others have reported increased GLUT-4 protein content after training (37-40), however the training protocols were longer and/or at a higher intensity than the protocol of the present study, which might explain why we did not find an increase of GLU'T-4 mRNA in the current study. Richter and colleagues investigated the translocation of GLUT-4 to the sarcolemma in response to acute exercise wich different methodology, but also found an increased translocation after acute exercise (41). However, the authors reported that translocation was diminished after 3 weeks of high intensity training, a response that we did not detect with the current training protocol.

The increased IMCL content after 2 weeks of training, with insulin sensitivity tending to be increased, is paralleled by a decrease in ACC2 mRNA expression, which indicates increased fat oxidative capacity on muscle level. Therefore, the results of the current study are in line with the hypotheses that the balance between FA oxidative capacity and availability is important for insulin sensitivity of skeletal muscle. Interestingly, it was recently shown that high-fat feeding to wild type mice resulted in the development of a diabetic phenotype, whereas $A C C 2$ knock out mice were resistant against this high-fat induced obesity and diabetes (25). Our results are in concordance with an important role. for ACC2 in determining the effect of IMCL on insulin sensitivity. Future research is needed to improve our understanding of the role that $A C C 2$ is playing in the pathogenesis of diabetes.

In conclusion, the increase in IMCL content after a two-week training program which resulted in a tendency of improved insulin sensitivity was accompanied by molecular adaptations in muscle to improve fat oxidative capacity. 


\section{Acknowledgements}

We would like to thank Niels Boon and Steven Constandse for practical help with the study. We would also like to thank Dr. H. Vidal (INSERM U.449, R. Laennec Faculty of Medicine Claude Bernard University of Lyon) for kindly providing the competitors and Dr. H. Keizer (Dept. Movement Sciences, Maastricht University) for kindly providing the polyclonal GLUT4-BW antibody.

\section{Grants}

Dr. P. Schrauwen was supported by a grant from the Royal Netherlands Academy of Arts and Sciences (KNAW). 


\section{References}

1. Pan DA, Lillioja $S$, Kriketos AD, Milner MR, Baur LA, Bogardus $C$, Jenkins AB, Storliem LH. Skeletal muscle triglyceride levels are inwersely related to insulin action. Dialdetes. 1997; 46: 983-8.

2. Krssak M, Falk Petersen $\mathrm{K}$, Dresner A, DiPietro $\mathcal{L}$, Vogel SM, Rothman DL, Roden M, Shulman GI. Intramyocellular lipid concentrations are correlated with insulin sensitivicy in humans: a 1H NMR spectroscopy study. Diabetologia. 1999; 42: 113-6.

3. Jacob S, Machann J, Retr $\mathrm{K}$, Brechtel K, Volk $\mathrm{A}$, Renn W, Maerker E, Matthaei S, Schick $\mathrm{F}$, Claussen CD, Haring HU. Association of increased intramyocellular lipid content with insulin resistance in lean nondiabetic offspring of type 2 diabetic subjects. Diabetes. 1999; 48: 1113-9.

4. Goodpaster BH, He J, Warkins S, Kelley DE. Skeletal muscle lipid content and insulin resistance: evidence for a paradox in endurance-trained achletes. I Clin Endocrinol Metab. 2001; 86: 5755-61.

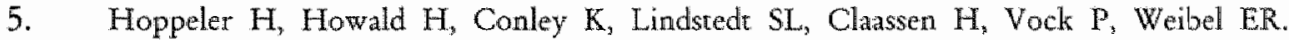
Endurance training in humans: aerobic capacity and structure of skeletal muscle. I Appl Physiol. 1985; 59:320-7.

6. Decombiz J, Schmitt B, Ith M, Decarli B, Diem P, Kreis R, Hoppeler H, Boesch C. Postexercise fat intake repletes intramyocellular lipids but no faster in trained than in sedentary subjects. Am J Plbysiol Regul Integr Comp Pbysiol. 2001; 281: R760-9.

7. Ingjer $F$. Effects of endurance trauning on muscle fibre ATP-ase activity, capillary supply and mitochondrial content in man. J Physiol. 1979; 294: 419-32.

8. Baumann $\mathrm{H}$, Jaggi $\mathrm{M}$, Soland $\mathrm{F}$, Howald $\mathrm{H}$, Schaub MC. Exercise training unduces transitions of myosin isoform subunits within histochemically typed human muscle fibres. Pflugers. Arch. 1987; 409: 349-60.

9. Martin WH, 3rd. Effects of acure and chronic exercise on tat metabolism. Exerc Spont Sci Rev. 1996; 24: 203-31.

10. Schrauwen-Hinderling VB, Schrauwen P, Hesselink MK, van Engelshowen JM, Nicolay K, Saris WH, Kessels AG, Kooi ME. The increase in intramyocellular lipid content is a very early response to training. J Clin Endocrinol Metab. 2003; 88: 1610-6.

11. Bruce CR, Anderson MJ, Carey AL, Newman DG, Bonen A, Kriketos AD, Cooney GJ, Hawley JA. Muscle oxidative capacity is a better predictor of insulin sensitivity than lipid status. J Clin Endocrinol Metab. 2003; 88: 5444-51.

12. Perdomo G, Commerford SR, Richard AM, Adams SH, Corkey BE, O'Doherty RM, Brown NF. Increased beta-oxidation in muscle cells enhances insulin-stimulated glucose metabolism and protects against fatty acid-induced insulin resistance despite intramyocellular lipid accumulation. J Biol Chem. 2004; 279:27177-86.

13. Blaak EE, van Aggel-Leijssen DP, Wagenmakers AJ, Saris WTH, van Baak MA Impaired oxidation of plasma-derived fatty acids in type 2 diabetic subjects during moderate-intensity exercise. Diabetes. 2000; 49: $2102-7$.

14. Harris JA, Benedict FG. A biometric study of basal metabolism in man. Washington: Camegie Institution of Washington. 1919;

15. Bergstrom J, Hermansen L, Hultman E, Saltin B. Diet, muscle glycogen and physical performance. Acta Pbysiol Scand. 1967; 71: 140-50.

16. Chomczynski $P$. Sacchi N. Single-step method of RNA isolation by acid guanidinium thiocyanate-phenol-chloroform extraction. Anal Biochem. 1987; 162: 156-9.

17. Auboeuf $\mathrm{D}$, Vidal $\mathrm{H}$. The use of the reverse transcription-competitive polymerase chain reaction to investigate the in viwo regulation of gene expression in small tissue samples. Anal Biachem. 1997; 245: 141-8.

18. Laville $M$, Auboeuf $D$, Khalfallah $X$, Vega $N$, Riou JP, Vidal H. Acute regulation by insulin of phosphatidylinositol-3-kinase, Rad, Glut 4, and lipoprotein lipase mRNA levels in human muscle. J Clin Invest. 1996; 98: 43-9. 
19. Millet $L$, Vidal $H_{3}$ Andredli $F$, Larrouy $\mathbb{D}$, Riou JP, Ricquier $D$, Laville $M$, Langin $D$. lncreased uncoupling protein-2 and -3 mRNA expression during fasting in obese and lean humadis. J Clin Invest. 1997; 100: 2665-70.

20. Andreelli $F$, Lawile M, Vega N, Riou JP, Vidal H. Regulation of gene expression during severe caloric restriction: lack of induction of $\mathrm{p} 85$ alpha phosphatidylinositol 3-kinase mRNA in skeletal muscle of patients with type II (non-insulin-dependent) diabetes mellitus. Diaberalogia. 2000; 43: 356-63.

21. Borghours LB, Scharart G, Hesselink MK, Keizer HA. GLUT-4 expression is not consistently higher in type-1 than in type-2 fibres of rat and human vastus lateralis muscles; an immunohistochemical study. Pftugers Arch. 2000; 441: 351-8.

22. Kelley DE, Mandarino LJ. Fuel selection in human skeletal muscle in insulin resistance: a reexamination. Diabetes. $2000 ; 49: 677.83$.

23. Dresner $A$, Laurent $D$, Marcucci $M$, Giffin ME, Dufour $S$, Cline GW, Slezak $L A$, Andersen DK, Hundal RS, Rothman DL, Petersen KF, Shulman GI. Effects of free fatty acids on glucose transport and IRS-1-associated phosphatidylinositol 3-kinase activity. J Clin Invest. $1999 ; 103: 253-9$.

24. Abu-Elheiga L, Matzuk MM, Abo-Hashema KA, Wakil SJ. Continuous fatty acid oxidation and reduced fat storage in mice lacking acetyl-CoA carboxylase 2. Science. 2001; 291: 2613-6.

25. Abu-Elheiga L, On W, Kordari P, Wakil SJ. Aceryl-CoA carboxylase 2 mutant mice are protected against obesity and diabetes induced by high-fat/high-carbohydrate diets. Proc Natl Acad Sci US SA. 2003; 100: 10207-12.

26. Schrawwen P, van Aggel-Leijssen DP, Hul G, Wagenmakers AJ, Vidal H, Saris WH, van Baak MA. The effect of a 3-month low-intensity endurance training program on fat oxidation and aceryl-CoA carboxylase-2 expression. Diabetes. 2002; 51: $2220-6$.

27. Levak-Frank S, Radner H, Walsh A, Stollberger R, Knipping G, Hoefler G, Sattler W, Weinstock PH, Breslow JL, Zechner R. Muscle-specific overexpression of lipoprotein lipase causes a severe myopathy characterized by proliferation of mitochondria and peroxisomes in transgenic mice. / Clin Invest. 1995; 96: 976-86.

28. Schmitt B, Fluck M, Decombaz J, Kreis R, Boesch C, Wittwer M, Graber F, Vogt M, Howald H, Hoppeler H. Transcriptional adaptations of lipid metabolism in tibialis anterior musde of endurance-trained athletes. Physiol Genomics. 2003; 15: 148-57.

29. Oscai $L B$, Caruso RA, Wergeles AC. Lupoprotein lipase thydrolyzes endogenous triacylglycerols in muscle of exercised rats. J Appl Physiol. 1982; 52: 1059-63.

30. Bagby GJ, Johnson JL, Bennett BW, Shepherd RE. Muscle lipoprotein lipase acrivity in

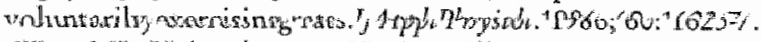

31. Watt MJ, Heigenhauser GJ, ONeill M, Spriet LL. Hormone-sensitive lipase activity and fatty acyl-CoA content in human skeletal muscle during prolonged exercise. J Appl Physiol. $2003 ; 95: 314-21$.

32. Langfort J, Donsmark M, Ploug T, Holm C, Galbo H. Hormone-sensitive lipase in skeletal muscle: regulatory mechanisms. Acta Pbysial Scand. 2003; 178:397-403.

33. Hurley BF, Nemeth PM, Martin WH, 3rd, Hagberg JM, Dalsky GP, Holloszy JO. Muscle triglyceride utilization during exercise: effect of training. J Appl Physiol. 1986; 60: 562-7.

34. Bergman BC, Burterfield GE, Wolfel EE, Casazza GA, Lopaschuk GD, Brooks GA. Evaluation of exercise and training on muscle lipid metabolism. Axn J Plyysiol. 1999; 276: E106-17.

35. Enevoldsen LH, Stallknecht B, Langfort J, Petersen LN, Holm C, Ploug T, Galbo H. The effect of exercise training on hormone-sensitive lipase in rat intra-abdominal adipose tissue and muscle. J Physiol. 2001; 536: 871-7.

36. Kraniou $\mathrm{Y}$, Cameron-Smith D, Misso M, Collier $G$, Hargreaves $M$. Effects of exercise on GLUT-4 and glycogenin gene expression in human skeletal muscle. J Appl Physiol. 2000; 88: $794-6$. 
37. Houmard JA, Shinebarger MH, Dolan PL, Leggetn-Frazier N, Bruner RK, McCammon MR, Israel RG, Dohm GL. Exercise training increases GLUT-4 proten concentration in previously sedentary miadle-aged men. Am/ Plyysol. 1993; 264: E896-901.

38. Gulve EA, Spina RJ. Effect of 7-10 days of cycle ergometer exercise on sketetal muscle GLUT-4 protein content. J Appl Physiol. 1995; 79: 1562-6.

39. Phillips SM, Han XX, Green HJ, Bonen A. Increments in skeleral nuscle GLUT-1 and GLUT-4 after endurance training in humans. Am J Physiol. 1996, 270: E456-62.

40. Kristiansen S, Gade J, Wojtaszewski JF, Kiens B, Richter EA. Glucose uptatke is increased in trained vs. untrained muscle during heavy exercise. J Appl Physiol. 2000; 89: 1151-8.

41. Richter EA, Jensen P, Kiens B, Kristiansen S. Sarcolemmal glucose transport and GLUT 4 translocation during exercise are diminished by endurance training. Am f Plyysiol. 1998; 274: E89-95. 


\section{CHAPTER}

\section{5}

\section{INTRAMYOCELLULAR LIPID CONTENTT AND MOLECULAR ADAPTATIONS IN RESPONSE TO A ONE- WEEK HIGH-FAT DIET}

V.B. Schrauwen-Hinderling, M.E. Kooi, M.K.C. Hesselink, E. Moonen-Kornips, G. Schaart, K.J. Mustard, D.G. Hardie, W.H.M. Saris, K.Nicolay, P. Schrauwen

Obesity Research 2005; 13: 2088-94 


\begin{abstract}
To investigate molecular adaptations which accompany the elevation of intramyocellular lipid (IMCL) content on a high-fat (HF) diet during one week.

Ten subjects consumed a normal-fat (NF) diet for one week, followed by a HF diet for another week. After both dietary periods, we determined the IMCL content by proton magnetic resonance spectroscopy (1H-MRS) in the vastus lateralis muscle and quantified changes in gene expression, protein content and activity in biopsy samples. We investigated genes involved in carbohydrate and fatty acid handling (LPL, ACC2, HSL, HKII, GLUT4) and measured protein levels of CD36 and phosphorylated and unphosphorylated ACC2, and the activity of AMPK.

IMCL content was increased by $54 \%$ after the HF period. LPL mRNA concentration was increased by $33 \%$, while ACC2 mRNA concentration tended to be increased after the HF diet. HKII, GLUT4 and HSL mRNA were unchanged after the $\mathrm{HF}$ diet. $\mathrm{ACC} 2$ and $\mathrm{CD} 36$ protein levels, phosphorylation status of $\mathrm{ACC} 2$ and $\mathrm{AMPK}$ activity did not change in response to the $\mathrm{HF}$ diet.

We found that IMCL content in skeletal muscle increased after one week of HF feeding, accompanied by molecular adaptations that favor fat storage in muscle rather than oxidation.
\end{abstract}




\section{Introduction}

High-fat diets, which are widely consumed in western societies, have been related to the development of chronic illnesses and obesity (1). Unlike carbohydrate and protein, fat does not stimulate its own oxidation and it is well known that the adaptation of fat oxidation is slow $(2,3)$, favoring fat storage when subjects switch from a low- to a high-fat diet. Although the major part of the excessive fat will be stored in white adipose tissue, triglyceride content in skeletal muscle has also been reported to increase after high fat feeding (4-8). With ${ }^{1} \mathrm{H}-\mathrm{MRS}$, separation between intramyocellular lipid (IMCL) content and contaminating adipose tissue (extramyocellular lipids, EMCL) can be made and IMCL can be quantified in a volume of a few cubic-centimeters. Using this method, so far only the very acute effect of high-fat diets (2-3 days) has been investigated $(5,6)$. Here we aimed to investigate IMCL content in $\mathrm{m}$. vastus lateralis by ${ }^{1} \mathrm{H}-\mathrm{MRS}$ after one week of a $\mathrm{HF}$ diet with a macronutrient composition similar to our previous work, in which we determined the effect of a high-fat diet on fatty acid oxidation (see below) (3).

An increase in IMCL content, as observed on a high-fat diet could be simply the consequence of a positive fat balance, due to the slow adaptation of fat oxidation to increased fat intake. However, it is interesting to note that endurance training also increases IMCL content (9) which is not due to a positive fat balance. With training, also the oxidation of non-plasma derived fatty acids (VLDL and/or IMCL) is increased $(10,11)$ suggesting that the increase in IMCL serves to increase IMCL oxidation. Indeed, some authors found intramuscular triglyceride content to be positively related to IMCL use during exercise $(6,7,12,13)$. Therefore, instead of being simply the result of a positive fat balance, an alternative explanation could be that an increased content of IMCL on a high-fat diet could lead to increased IMCL breakdown and therefore increased availability of intramuscular lipid substrate. In this context, we previously showed that whole-body fat oxidation was increased after one week of a high-fat diet, and that the increase in fat oxidation was completely accounted for by an increased oxidation of VLDL and/or IMCL (14).

Therefore, to examine whether the increase in IMCL content upon a high-fat diet is simply due to a positive fat balance, or serves to increase fat oxidation, we investigated molecular markers of lipid storage and oxidation in skeletal muscle. We recently investigated the same molecular markers after a short term endurance training period, which was shown to result in a $42 \%$ increase in IMCL content (15), and found a $29 \%$ decrease in ACC2 mRNA expression, indicating an improved fat oxidative capacity (16). In the present study, we quantified IMCL content by ${ }^{1}$ H-MRS after one week of normal fat diet and one week of high fat diet and we investigated mRNA and protein concentrations and protein activity in muscle biopsies at the end of both dietary periods. 


\section{Subjects and methods}

\section{Subjects}

Ten young and healthy male subjects (age (y) (mean \pm stdev): $25.0 \pm 6.2$ ) participated in this study. Subjects were recruited by advertisement and the study was approved by the institutional Medical Ethics Committee. Subjects gave their written informed consent after the nature of the procedure was explained.

\section{Experimental protocol}

Subjects were provided with the experimental diet for one week at a time (normal-fat diet and subsequently high-fat diet). In the morning of the seventh day, a biopsy was taken in the fasted state and in the afternoon of the same day, a ${ }^{1}$ H.MRS scan was performed to determine the IMCL content in the $m$. vastus lateralis. To exclude acute effects of exercise on IMCL content, subjects refrained from exercise the two days preceding the ${ }^{1} \mathrm{H}-\mathrm{MRS}$ measurements.

\section{Diets}

The macronutrient composition of the normal fat diet was such that $30 \%$ of the energy was consumed as fat, $55 \%$ as carbohydrate and $15 \%$ as protein. In the high-fat diet, $60 \%$ of the energy was consumed as fat, $25 \%$ as carbohydrate and $15 \%$ as protein.

According to the self-reported physical activity level, subjects were given 1.6 to 1.7 times their basic metabolic rate (BMR, based on Harris and Benedict equations (17)). Additionally, subjects got snacks with the same macronutrient composition as the whole diet, which they could eat if needed. The diet consisted of all normal ready-to-use food. Every subject received a personal schedule for every day, listing the provided food items for breakfast, lunch, dinner and snacks.

\section{Procedwres}

\section{MRS medstrement}

Image guided localized single voxel 'H-MRS was performed as described earlier (15) in the m.vastus lateralis after the normal-fat and the high-fat dietary period. MRS measurements were performed on only eight subjects and for one subject, the spectra were of insufficient quality to be analyzed reliably. Therefore, IMCL content is reported from seven subjects.

\section{Post-processing}

The spectra were fitted in the time domain using a nonlinear least-squares algorithm (AMARES (18)) in the jmrui software package (http://www.mrui.uab.es/mrui/) using prior knowledge as described earlier (15). Six peaks were fitted in total, namely three peaks for extramyocellular lipids (EMCL) and three peaks for IMCL. The signals were corrected for T1 and T2 
relaxation using the $\mathrm{T} 1$ and $\mathrm{T} 2$ relaxation times as determined by Schick et al. (20). The corrected area of the $\mathrm{CH}_{2}$ peak of $\mathrm{MMCL}$ was expressed relative to the area of the corrected water peak.

The reproducibility of the quantification of IMCL in the m. vastus lateralis was determined in the setting of another study and reported earlier (15).

\section{Body weeight}

Body weight was measured in the morning in the fasted state after both dietary periods on a digital scale (E1200; Sauter, Albstadtl-Elbingen, Germany) with an accuracy of $0.01 \mathrm{~kg}$.

\section{Analysis}

Blood analyses

For the determination of free fatty acids (FFA) and triacylglycerol plasma concentrations, blood was collected in tubes containing $30 \mu \mathrm{l}$ of $0.2 \mathrm{M}$ EDTA. Plasma was immediately centrifuged at high speed, frozen in liquid nitrogen and stored at $-80^{\circ} \mathrm{C}$ for later analyses. Triacylglycerol (GPO-trinder 337B, Sigma Diagnostics, St. Louis, MO, USA) and FFA (Wako NEFA×C kit, Wako Chemicals, Neuss, Germany) concentrations were analysed using the COBAS FARA semi-automatic analyser (Roche, Basel, Switzerland).

\section{Muscle biopsy sampling and analysis}

Muscle biopsies were taken from the mid-thigh region of $m$. vastus lateralis according to the technique of Bergström (21). The biopsy was used for isolation of total RNA using the acid phenol method of Chomozynski \& Sacchi (22), with concomitant acid phenol extraction and ethanol precipitation. The mRNA concentrations of lipoprotein lipase (LPL), hormone-sensitive lipase (HSL), hexokinase II (HKII), glucose transporter-4 (GLUT4) and acetyl CoA carboxylase (ACC2) were quantified by reverse transcription-competitive polymerase chain reaction (RT-competitive PCR) (23). For the assays, the reverse transcription reaction was performed from $0.2 \mu \mathrm{g}$ of skeletal muscle total RNA in the presence of a thermostable reverse transcriptase ( $T$ th, promega) by use of one of the specific antisense primers. The competitive PCR assays were pertormed as previously described (24-26). 'To improve the quantification of the amplified products, fluorescent dye-labeled sense oligonucleotides were used. 'The PCR products were separated and analyzed on an ALF express DNA sequencer (Pharmacia) with the Fragment Manager Software. Total RNA preparations and RT-competitive PCR assays of both skeletal muscle samples from the same individual (after normal-fat and high-fat diet) were performed simultaneously. The mRNA data is reported in arbitrary units and the average of the baseline value is set to 1 . CD36 protein concentrations were determined by Western blotting, using a monoclonal antibody (MO25) as previously described (27). Phosphorylated and unphosphorylated $\mathrm{ACC} 2$ protein concentrations were 
determined as previously described (28) and AMPK activity has been investigated as described earlier (28). ACC2 protein concentrations are reported as the ratio of $A C C 2$ to actin, while the phosphorylation status of $A C C 2$ is reported as ratio of phosphorylated to unphosphorylated ACC2 protein.

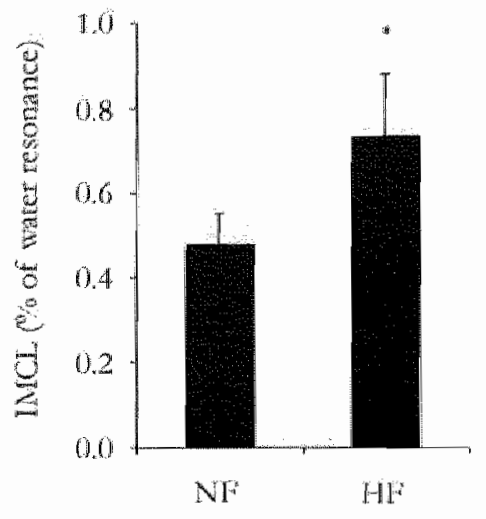

Figure 5.1: IMCL content after the normal-fat (NF) and the high-fat $(\mathrm{HF})$ dietary period $(\mathrm{n}=7$ ). The $\mathrm{MMCL}$. content was significantly higher after the HF diet $(p=$ $0.03)$.

\section{Siatistics}

Results are reported as mean \pm standard error of the mean (SEM). Statistical analyses were performed with SPSS for Windows 10.0.0 software (SPSS Inc., Chicago, Illinois, USA). Differences after the two dietary periods were detected with paired student $\mathrm{t}$-tests. Results were considered significant if $\mathrm{p}<0.05$.

\section{Results}

\section{Energy intake and body weight}

By design, energy intake during the two dietary periods was identical $(13.7 \pm 0.7 \mathrm{MJ} /$ day vs $13.7 \pm 0.7 \mathrm{MJ} /$ day on the NF- and the HF- diet respectively (n.s.)). The fat intake was $29.7 \pm 0.2 \%$ and $60.1 \pm 0.2 \%$ of total energy intake on the NF- and the HF diet, respectively.

Body weight was unaffected by the type of diet $(80.1 \pm 4.4 \mathrm{~kg}$ and $79.9 \pm 4.6 \mathrm{~kg}$ after the NF- and the HF diet, respectively (n.s.))

\section{$I M C L$}

IMCL content was significantly increased by $53.8 \%$ after the high-fat period, compared to the normal-fat period $(0.48 \% \pm 0.07 \%$ of the water resonance after the normal-fat diet vs. $0.73 \% \pm 0.15 \%$ after the high-fat diet, see Figure 5.1). If values were converted to values in mmol $/ \mathrm{kg}$ muscle wet weight as described by Boesch et al (29) $\mathrm{IMCL}$ content was $6.12 \pm 0.94 \mathrm{mmol} / \mathrm{kg}$ and $9.4 \pm 1.87 \mathrm{mmol} / \mathrm{kg}$ after the normal-fat and high-fat diet respectively. 


\section{$m R N A$}

Concentrations of HKII $(1.00 \pm 0.24$ a.u. vs $0.90 \pm 0.20$ arbitrary units (AU) after $\mathrm{NF}$ - and $\mathrm{HF}$-diet, respectively), Glut4 (1.00 $\pm 0.32 \mathrm{AU}$ vs $1.00 \pm 0.25 \mathrm{AU}$ after NF- and HF-diet, respectively) and HSL mRNA (1.00 $\pm 0.26 \mathrm{AU}$ vs $1.49 \pm 0.48 \mathrm{AU}$ after NF- and HF-diet, respectively) were not different after the two dietary periods. LPL mRNA concentration was increased significantly by $36 \%$ (Figure 5.2), and ACC2 mRNA tended to be increased by $33 \%$ after the highfat dietary period. $(1 \pm 0.22 \mathrm{AU}$ vs $1.33 \pm 0.24 \mathrm{AU}$ after $\mathrm{NF}$ - and HF-diet, respectively, $\mathrm{p}=0.08$ )

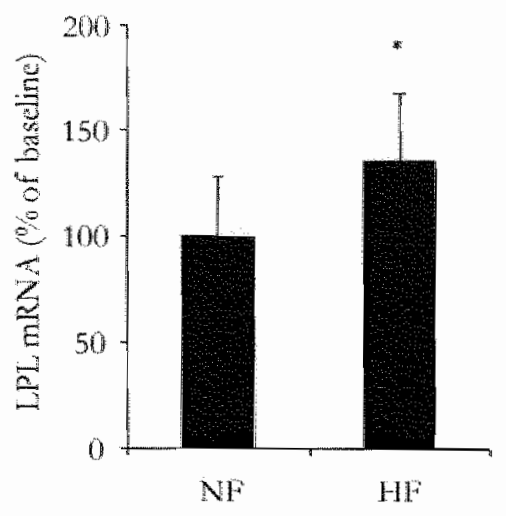

Figure 5.2: LPI mRNA concentrations increased significantly after the high-fat (HF) dietary period. compared ro the normal fat (NF) dietary period $(p=0.04)$.

\section{Protein concentrations and activities}

ACC2 protein concentration (ACC2/actin) was not different after the high-fat diet $(1.07 \pm 0.14$ AU vs $1.02 \pm 0.24$ AU after normal- and high-fat diet, respectively). The phosphorylation status (pACC2/ACC2) indicating the activation of the protein did not change either and was $2.97 \pm 0.47 \mathrm{AU}$ vs $3.33 \pm 0.50 \mathrm{AU}$ after the normal- and the high-fat diet, respectively (ratio of the signals obtained with the phosphospecific antibody and streptavidin). AMPK activity was not different after the two dietary periods $(0.0136 \pm 0.0022 \mathrm{U} / \mathrm{mg}$ and $0.0173 \pm 0.0054 \mathrm{U} / \mathrm{mg}$ after normal and high-fat diet, respectively). CD 36 protein. concentration was not different after the two dietary periods $(88 \pm 11 \mathrm{AU}$ after normal-fat diet vs. $87 \pm 12 \mathrm{AU}$ after high-fat diet).

\section{Plasma parameters}

Fasting FFA concentrations increased after the high-fat diet compared to the normal-fat diet, but there was no difference in triacylglycerol concentration after the two diets (see Table 5.1). 
Table 5.1: Plastra concentrations of FFA and triacylglycerols

\begin{tabular}{|l|c|c|}
\hline & normal-fat diet & high-fat diet \\
\hline FFA (pmol/L & $251 \pm 42$ & $334 \pm 54$ \\
\hline triacylglycerols (amol/L) & $961 \pm 136$ & $733 \pm 175$ \\
\hline
\end{tabular}

\section{Discussion}

In contrast to carbohydrates, the intake of fat does not acutely stimulate its own oxidation and consumption of a high-fat diet often leads to a positive fat balance. In addition to white adipose tissue, fat can also be stored in non-adipose tissues, such as heart; liver and muscle. Here we show that after one week of high-fat feeding, IMCL content of the vastus lateralis muscle was significantly increased. It can be suggested that increased IMCL content on a high-fat diet is simply the result of the positive fat balance that inevitably occurs when switching to a high-fat diet. Alternatively, it can be suggested that the increased IMCL content on the high-fat diet could lead to an increase in fat oxidation. Therefore, we examined in the present study the expression of genes involved in lipid handling in skeletal muscle and protein content and activity in response to a high-fat diet of one week.

First, when the increased IMCL content on a high-fat diet serves to allow increased IMCL oxidation, an up-regulation of hormone sensitive lipase (HSL) would be anticipated. HSL is necessary for the hydrolysis of intramuscular lipid to allow mitochondrial uptake and subsequent oxidation $(30,31)$. To the best of our knowledge, no data is available on the effect of high-fat feeding on HSL mRNA expression or activity in human skeletal muscle. Presently, we found that high-fat feeding did not affect skeletal muscle HSL mRNA expression.

Second, we examined the effect of high-fat feeding on ACC2 mRNA and protein expression, as well as ACC2 phosphorylation and AMPK activity. ACC2 has been reported to play a critical role in regulating fat oxidation in skeletal muscle. Its unphosphorylated form catalyzes the carboxylation of acetyl-CoA to form malonyl-CoA, an intermediate that inhibits the activity of carnitine-palmitoyltransferase-1 (CPT1). CPT1 catalyses the rate limiting step in the transfer of fatty acids into mitochondria, where they undergo oxidation. Therefore, a reduction in ACC2 or an increase in the phosphorylation of the protein would increase fat oxidation. Indeed, it was shown that ACC2 knock out mice are characterized by a strongly increased fat oxidation (32). Similarly, fat oxidation is stimulated when the acrivity of AMPK, which phosphorylates ACC2, increases. In humans, we have previously shown that a 3-month training program resulted in an increase in triacylglycerol (IMCL and/or VLDL) derived fat oxidation and a reduction in ACC2 mRNA expression (1.1). Therefore, when the increased IMCL content on the high-fat diet would serve to allow increased fat oxidation, we anticipated finding a reduction in ACC2 mRNA and protein concentration and/or increased 
phosphorylation of the protein after one week of high-far feeding. In the current study, however, we report a tendency $(p=0.08)$ to increased ACC2 mRNA concentrations and no change in protein concentration, rather than the anticipated decrease. Also AMPK activity and the phosphorylation of its downstream target, ACC2 were unaffected after the high-fat dietary period. This again suggests that it is unlikely that the increase in IMCL content on a high-fat diet serves to increase fat oxidation, but points towards a role for IMCL in storing excessive fat when consuming a high-fat diet. This might explain the negative effect of high-fat diet on insulin sensitivity (33), as IMCL content has been positively associated with the development of insulin resistance (34) and is increased in patients with type 2 diabetes mellitus $(35,36)$. However, we have recently shown that two weeks of endurance training resulted in a $42 \%$ increase in IMCL content, without any detrimental effect on insulin sensitivity (15). Interestingly, the increase in IMCL content was accompanied by a downregulation of ACC2 mRNA expression (16). This points towards an important role for $\mathrm{ACC} 2$ in determining the effect of IMCL on insulin sensitivity and suggests that high IMCL content does not affect insulin sensitivity as long as it is combined with improved fat oxidative capacity, as was also recently suggested by Goodpaster et al. (35). Interestingly, it was recently shown that high-fat feeding of wildtype mice resulted in the development of a diabetic phenotype, whereas ACC2 knock out mice were resistant against high-fat diet induced obesity and diabetes (32). Therefore, ACC2 seems to be an important target in the treatment of type 2 diabetes mellitus and obesity.

An alternative source for fat oxidation could be VLDL. Helge et al. showed that on a high-fat diet, VLDL oxidation was significantly increased during aerobic exercise (4). Triacylglycerols from VLDL particles, have to be hydrolyzed by LPL located on the endothelial cells lining the blood vessels in order to be taken up by the skeletal muscles. As the availability of triacylglycerols increases on a high-fat diet, a feasible response would be an increased expression of LPL. Indeed, we found the LPL mRNA concentration to be increased by $36 \%$ after the high-fat diet. The increase in LPL suggests that more fatty acids from VLDL. are taken up into myocytes.

Although FFA can enter the cells by passive diffusion (37), facilitated diffusion has been described and proteins with a high fatty acid binding affinity, such as CD36 have been characterized (38). It has been shown that increased fatty acid uptake may result in increased lipid accumulation in muscle (39). Therefore, we hypothesized that following the high-fat diet the increased fat availability would result in increased concentrations of CD36, a key fatty acid translocase. We did, however, not find changes in the protein concentration of CD36 after increased dietary fat. In contrast, in trained athletes, CD36 was increased after a high-fat diet (40). As training profoundly improves fat oxidative capacity and hence warrants increased trans-sarcolemmal transport of fatty acids, the discrepancy could be due to the differing training status of the subjects in the two studies. 
The reported increase in $\mathrm{MMC}$ content in the present study $(54 \%)$ is well in line with earlier results in a range of muscles and with different methodologies (36-57\% increase in MCL content after two to three days of a high-fat diet (5-7) and $86-130 \%$ increase after 4 to 5 weeks $(8,41)$ ).

To investigate whether one week of a high-fat diet already affected genes involved in glucose metabolism, we investigated markers of carbohydrate metabolism (HK II, GLUT4). However, these markers did not change in response to the high-fat diet.

Because the time-course of the adaptations to a high-fat diet of the genes under investigation is presently unknown, it cannot be excluded that transient changes in mRNA might have been missed in the present investigation. However, the protein data reported here are in line with the lack of effect on fat oxidative capacity after the one-week dietary intervention.

In conclusion, we investigated the adaptive response to a high-fat diet, as it is currently associated with an unhealthy life style. We found that IMCL content was increased after one week of high fat feeding which was not accompanied by molecular adaptations that improve far oxidative capacity.

\section{Acknowledgements}

PS was supported by a grant from the Royal Netherlands Academy of Arts and Sciences (KNAW). KJM and DGH were aided by the pharmaceutical companies supporting the Division of Signal Transduction Therapy Unit at the University of Dundee (AstraZeneca, Boehringer-Ingelheim, GlaxoSmithKline, Merck \& Co. Inc, Merck KgaA and Pfizer).

We would like to thank Niels Boon for practical help with the study and Dr. J. Glatz and Dr. N.N. Tandon for kindly providing the MO25 antibody. We would also like to thank Dr. H. Vidal (INSERM U.449, R. Laennec. Faculty of Medicine Claude Bernard University of Lyon) for kindly providing the competitors.

The MRUI software package was kindly provided by the participants of the EU Network programs: Human Capital and Mobility, CHRX-CT94-0432 and Training and Mobility of Researchers, ERB-FMRX-CT970160. 


\section{References}

1. Hill JO, Peters JC. Environmental contributions to the obesity epidemic. Science. 199; 280: $1371-4$.

2. Hill JO, Peters $ل_{C}$, Reed GW, Schlundt DG, Sharp T, Greene HL. Nutrient balance in humans: effects of diet composition. Am / Clin Nutr. 1991; 54: 10-7.

3. Schrauwen P, van Marken Lichtenbelt WD, Saris WH, Westerterp KR. Changes in far oxidation in response to a high-fat diet. Am J Clim Nutr. 1997; 66: 276-82.

4. Helge JW, W/atc PW, Richrer EA, Rennie MJ, Kiens B. Fat utilization during exercise: adapration to a fat-rich dier increases utilization of plasma fatty acids and very low density lipoprotein-triacylglycerol in humans. I Physiol. 2001; 537: 1009-20.

5. Bachmann OP, Dahl DB, Brechtel $\mathrm{K}$, Machann J, Haap M, Maier $T$, Loviscach $M$, Stumwoll M, Clanssen CD, Schick F, Haring HU, Jacob $S$. Effects of intravenous and dietary lipid challenge on intramyocellular lipid content and the relation with insulin sensitivity in humans. Diabetes. 2001; 50: 2579-84.

6. Johnson NA, Stannard SR, Mehalski K, Trenell MI, Sachinwalla T, Thompson CH, Thompson MW. Intramyocellular triacylglycerol in prolonged cycling with high-and lowcarbohydrate availability. J Appl Pbysiol. 2003; 94: $1365-1372$.

7. Zderic TW, Davidson CJ, Schenk S, Byerley LO, Coyle EF. High-Fat Diet Elevates Resting Intramuscular Triglyceride Concentration and Whole-Body Lipolysis During Exercise. Ann I Pbysiol Endocrinol Metab. 2004; 86: $\mathbb{E} 217-25$.

8. Vogt M, Puntschart A, Howald H, Mueller B, Mannhart C, Gfeller-Tuescher L, Mullis P, Hoppeler H. Effects of dietary fat on muscle substrates, metabolism, and performance in athletes. Med Sci Sports Exerc. 2003; 35: 952-60.

9. Hoppeler H. Exercise-induced ultrastructural changes in skeletal muscle. Int J Sponts Med. $1986 ; 7: 187.204$.

10. Phillips SM, Green HJ, Tarnopolsky MA, Heigenhauser GF, Hill RE, Grant SM. Effects of training duration on substrate turnover and oxidation during exercise. J Appl Pbysiol. 1996; 81: $2182-91$.

11. Schrauwen P, van Aggel-Leijssen DP, Hul G, Wagenmakers AJ, Vidal H, Saris WH, wan Baak MA. The effect of a 3-month low-intensity endurance training program on fat oxidation and acetyl-CoA carboxylase-2 expression. Diabetes. 2002; 51:2220-6.

12. Standll $\mathrm{E}$, Lotz N, Dexel T, Janka HU, Kolb HJ. Muscle triglycerides in diabetic subjects. Effect of insulin deficiency and exercise. Diabetologia. 1980; 18: 463-9.

13. Steffersen CH, Roepstorff C, Madsen M, Kiens B. Myocellular triacylglycerol brealkdown in females but not in males during exercise. Am f Pbysiol Endocrinol Metab. 2002; 282: E634. 42.

14. Schrauwen P, Wagenmakers AJ, wan Marken Lichtenbelt WD, Saris WH, Westerterp KR. Increase in fat oxidation on a high-fat diet is accompanied by an increase in triglyceride. derved farty acid oxidation. Diabetes. 2000; 49:640 6.

15. Schrauwen-Hinderling VB, Schrauwen P, Hesselink MK, van Engelshoven JM, Nicolay $\mathbb{K}$, Saris WH, Kessels $A G_{4}$ Kooi ME. The increase in intramyocellullar lipid content is a very early response to training. J Chin Endocrinol Metab. 2003; 88: 1610-6.

16. Schraw wen-Hinderling VB, Hesselink MK, Moonen-Kornips E, Schaart G, Kooi ME, Saris WH, Schrauwen $P$. Short term training is accompanied by a down regulation of ACC2 mRNA in skeletal muscle. Int J Sports Med, 2006; accepted.

17. Harris JA, Benedict FG. A biometric study of basal metabolism in man. Wablingrom: Carnegie Institution of Wasbington. 1919

18. Vanthamme $L$, van den Boogaart A, Van Huffel S. Improved method for accurate and efficient quantification of MRS data with use of prior knowledge. J Magn Resan. 1997; 129: $35-43$. 
19. Naressi $A$, Couturier $C$, Devos JM, Janssen M, Mangeat $C$, de Beer $R$, Graveron-Demilly D. Java-based graphical user interface for the MRUT quancitation package. Magma. 2001; 12 : $141-52$.

20. Schick F, Eismann B, Jung WI, Bongers H, Bunse M, Lutz O. Comparison of lacalized proton NMR signals of skeletal muscle and fat cissue in vivo: two lipid compartments in muscle tissue. Magn Reson Med. 1993; 29: 158-67.

21. Bergstrom J, Hermansen L, Hulman E, Saltin B. Diet, muscle glycogen and physical performance. Acta Plyysiol Scand. 1967; 71: 140-50.

22. Chomczynski P, Sacchi N. Single-step method of RNA isolation by acid guanidinim thiocyanate-phenol-chloroform extraction. And Biodem. 1987; 162: 156.9.

23. Auboeuf $\mathrm{D}$, Vidal $\mathrm{H}$. The use of the reverse transcription-competitive polymerase chain reaction to investigate the in vivo regulation of gene expression in small tissue samples. And Biactem. 1997; 245: 141-8.

24. Laville $M$, Auboeul D, Khalfallah $\mathrm{Y}$, Vega $\mathrm{N}$, Riou JP, Vidal $\mathrm{H}$. Acure regulation by insulin of phospthatidylinositol-3-kinase, Rad, Glut 4, and lipoprotein lipase mRNA levels in human muscle. J Clin Invest. 1996; 98: 43-9.

25. Millet $\mathrm{L}$, Vidal $\mathbb{H}_{\text {, Andreelli }} \mathrm{F}$, Larrouy $\mathrm{D}$, Riou $\mathbb{J}$, Ricquier $\mathrm{D}$, Laville $\mathrm{M}$, Langin $\mathrm{D}$. Increased uncoupling protein-2 and $-3 \mathrm{mRNA}$ expression during fasting in obese and lean humans. J Clin Invest. 1997; 100: 2665-70.

26. Andreelli $F$, Laville M, Vega N, Riou JP, Vidal H. Regulation of gene expression during severe caloric restriction: lack of induction of p.85 alpha phosphatidylinositol 3-kinase mRNA in skeletal muscle of patients with type II (non-insulin-dependent) diabetes mellitus. Diabetologia. 2000; 43:356 63 .

27. Keizer HA, Schaart $G$, Tandon NN, Glatz JF, Luiken JJ. Subcellular immunolocalisation of fatty acid translocase (FAT)/CD36 in human type-1 and type-2 skeletal muscle fibres. Histochem Cell Biol. 2004; 121: 101-7.

28. Hawley SA, Boudeau J, Reid JL, Mustard KJ, Udd L, Makela TP, Alessi DR, Hardie DG. Complexes between the LKB1 numor suppressor, STRAD alpha/beta and MO25 alpha/beta are upstream kinases in the AMP-activated protein kinase cascade. J Biol. 2003; 2; 28 .

29. Boesch C, Decombaz J, Slotboom J, Kreis R. Observation of intramyocellular lipids by means of $1 \mathrm{H}$ magnetic resonance spectroscopy. Proc Nutr Soc. 1999; 58: 841-50.

30. Langfort J, Ploug T, Ihlemann J, Saldo M, Holm C, Galbo H. Expression of hormonesensitive lipase and its regullation by adrenaline in skeletal muscle. Biochem I. 1999; 340 ( $\mathrm{Pt}$ $2): 45,65$.

31. Osca LB, Essig DA, Palmer WK. Lipase regulation of muscle triglyceride hydrolysis. / Appl Ploysiol. 1990; 69: 1571-7.

32. Abu-Elheiga L, Oh W, Kordari $P$, Wakil SJ. Aceryl-CoA carboxylase 2 mutant mice are protected against obesity and diabetes induced by high-fat/high-carbohydrate diets. Proc Nat Acad Sci U S A. 2003; 100: 10207-12.

33. Lovejoy JC. The influence of diecary fat on insulin resistance. Carr Diab Rep. 2002; 2: 43540.

34. Jacob S, Machann J, Rett K, Brechtel K, Volk A, Renn W, Maerker E, Mathaei S, Schick $\mathrm{F}$, Claussen CD, Haring HU. Association of increased intranyocellular lipid content with insulin resistance in lean nondiabetic offspring of type 2 diaberic subjects. Diabetes. 1999; 48: 1113-9.

35. Goodpaster BH, He J, Watkins S, Kelley DE. Skeletal muscle lipid content and insulin ressistance: evidence for a paradox in endurance-trained athletes. J Clin Endocrinol Metab. 2001: $86: 5755-61$.

36. Levin K, Daa Schroeder H, Alford FP, Beck-Nielsen H. Morphometric documentation of abnormal intramyocellulat fat storage and reduced glycogen in obese patients with Type II diabetes. Diatbetologia. 2001; 44: 824-33. 
37. Hamilton JA, Kamp F. How are free faty acids transponted in membranes? Is it by proteins or by free diffusion through the lipids? Diabetes. $1999,48,2255-69$.

38. Abumrad NA, el-Maghrabi MR, Amri EZ, Lopez E, Grimaldi PA. Cloning of a rat adipocyte membrane protein implicated in binding or transport of long-ehain fatty acids that is induced during preadipocyte differentiation. Honology with human CD36. $/$ Biol Chem. 1993; 268: 17665-8.

39. Hegarty BD, Cooney GJ, Kraegen EW, Furler SM. Increased efficiency of fatty acid uptake contributes to lipid accumularion in skeletal muscle of high fat-fed insulin-resistant rats. Diabetes. 2002; 51 : 1477-84.

40. Cameron-Smith D, Burke LM, Angus DJ, Tunstall RJ, Cox GR, Bonen A, Hawley JA, Hargreaves M. A short-term, high-fat diet up-regulates lipid metabolism and gene expression in human skeletal muscle. Am J Clin Nutr. 2003; 77: 313-8.

41. Helge JW, Wulff $B$, Kiens B. Impact of a fat-rich diet on endurance in man: role of the dietary period. Med Sci Sports Exerc. 1998; 30:456-61. 
CHAPTERS 


\section{CHAPTER}

INFLUENCE OF PROLONGED ENDURANCE CYCLING AND RECOVERY DIET ON INTRAMUSCULAR TRIGLYCERIDE CONTENT IN TRAINED MALES

L.J.C. van Loon, V.B. Schrauwen-Hinderling, R. Koopman, A.J.M. Wagenmakers, M.K.C. Hesselink, G. Schaart, M.E. Kooi, W.H.M. Saris Am J Physiol Endocrinol Metab. 2003 Oct;285(4):E804-11. 


\section{Abstract}

Intramyocellular lipids (MMCL) are assumed to form an important substrate source during prolonged endurance exercise. The aim was to asses the effects of endurance exercise and recovery diet on $\mathrm{MCL}$ content in vastus lateralis muscle. Nine cyclists were provided with a standardized diet for $3 \mathrm{~d}$ after which they performed a $3 \mathrm{~h}$ exercise trial at a $55 \% \mathrm{~W}$ max workload. Before, immediately after exercise and after 24 and $48 \mathrm{~h}$ of recovery, magnetic resonance spectroscopy (MRS) was performed to quantitate IMCL content. Muscle biopsies were taken after $48 \mathrm{~h}$ of recovery to determine IMCL content by using quantitative fluorescence microscopy. The entire procedure was performed twice; in one trial a normal diet containing $39 \mathrm{En} \%$ far was provided (NF), in the other a typical carbohydrate-rich athletes' diet (LF: 24 En\% fat).

During exercise, IMCL content decreased by $21.4 \pm 3.1 \%$. During recovery, IMCL content significantly increased in the NF trial only, reaching pre-exercise levels within $48 \mathrm{~h}$. In accordance with MRS, fluorescence microscopy showed significantly higher IMCL content in the NF compared to the LF trial, with differences restricted to the type I muscle fibres $(2.1 \pm 0.2$ versus $1.4 \pm 0.2$ \%area lipid staining, respectively). In conclusion, IMCL content in the vastus lateralis is significantly decreased during prolonged endurance exercise. When using a normal diet, IMCL contents are repleted within $48 \mathrm{~h}$ of post-exercise recovery. In contrast, IMCL repletion is substantially impaired when using a typical, carbohydrate-rich athletes" diet. In addition, our data obtained by quantitative fluorescence microscopy imply that MRS is a valid quantification method for IMCL content, providing a suitable means to enable repeated quantification of IMCL concentration in dietary intervention studies. 


\section{Introduction}

Fat and carbohydrate are the principal substrates that fuel aerobic ATP synthesis in human skeletal muscle. During moderate intensity exercise (40-60 VOmax) fat oxidation contributes about half of total energy expenditure, with plasma free fatty acids (FFA) being the main fat source (1-5). Recently, we quantitated plasma FFA oxidation in trained cyclists during moderate intensity exercise, which represented $51 \pm 4 \%$ of total energy derived from fat oxidation (5). Other fat sources contributing to total fat oxidation are plasma lipoprotein derived triglycerides (mainly very low density lipoproteins or VLDL) and the intramyocellular lipids (IMCL) stores. With the contribution of lipoproteinderived triglyceride oxidation assumed to be of minor quantitative importance $(6,7)$, IMCL stores are likely to form a major substrate source during exercise. The latter has been disputed as studies applying direct triglyceride measurements from muscle biopsies collected before and after exercise have reported contradictory results (see (8) for a recent review on this topic). The apparent controversy is likely the result from the marked between biopsy variability in IMCL content when using the muscle triglyceride extraction method $(8,9)$.

With the introduction of magnetic resonance spectroscopy (MRS) a novel noninvasive means to quantitate muscle lipid content in wivo (10) has become available, which is ideally suited for repeated measurements in time and, as such, to follow muscle triglyceride repletion. Several groups have applied this technique to quantitate IMCL content in various populations. This has recently lead to the proposed relation between increased IMCL content, obesity and decreased insulin sensitivity (11-14). The latter has strongly renewed interest in the role of both exercise as well as diet in the regulation of IMCL storage and utilisation. Sofar, only a few studies (15-22) have assessed IMCL contents before and after prolonged exercise by using MRS. All of these studies (15-22) have reported a substantial decrease in IMCL content ( - 20-40\%) following prolonged endurance exercise. Most of these studies have determined IMCL content by performing MRS in lower leg muscle (tibialis anterior and/or soleus), which is in contrast to the vast majority of studies on IMCL utilisation which have used the biochemical triglyceride extraction method on muscle biopsies taken from the vastus lateralis muscle. For a proper comparison of the used methods and the effects of exercise on different muscle groups, more MRS studies assessing IMCL. content in the wastus lateralis following various exercise and/or dietary intervention protocols are needed to confirm earlier reports on IMCL utilisation. With most studies focussing on IMCL depletion during exercise, far less data is available on post-exercise IMCL replenishment in humans $(18,19,23)$. The latter is in clear contrast to the numerous studies on muscle glycogen use and the efficacy of dietary interventions to improve (post-exercise) glycogen resynthesis $(24,25)$, which have lead to the recommendations for endurance athletes to use a 
high-carbohydrate diet, with a concomitant low fat intake $(26,27)$. Recent MRS data on post-exercise

IMCL repletion show that (extremely) low-fat diets substantially impair IMCL repletion when compared to the use of normal and/or high-fat diets $(18,19,23)$. In those studies, fat intake was set at 10-15\% of total energy intake (En\%) in the low-fat trials, which is considerably less than the reported fat intake in elite endurance athletes during periods of extreme physical exertion $(23 \mathrm{En} \%$ in the Tour de France (28)). The latter, of course, remains well below average fat intake when using a normal Western diet $(\sim 35-40 \mathrm{En} \%$; (29)). Therefore, we questioned whether such a typical carbohydrate-rich athletes" diet also limits post-exercise IMCL repletion when compared to a normal diet.

In this study we aimed to determine IMCL content in the vastus lateralis before and after prolonged endurance cycling by using MRS. In addition, we investigated the time course of subsequent IMCL repletion following 2 days of post-exercise recovery while using a normal diet or a typical carbohydrate-rich athletes' diet. In addition to the repeated MRS measurements, muscle biopsies from the vastus lateralis were collected after $2 \mathrm{~d}$ of recovery to assess the effects of dietary fat intake on IMCL repletion using quantitative fluorescence microscopy on oil-red $O$ stained muscle crosssections. The latter method was implemented to validate the MRS results and to provide additional information on muscle fibre type specific IMCL content.

\section{Methods}

\section{Subjects}

Nine endurance trained cyclists participated in this study. Subjects' characteristics are shown in Table 6.1. All subjects were informed about the nature and putative risks of the experimental procedures before their informed consent was obtained. This study was approved by the local Medical Ethical Committee.

Table 6.1: Subjects" characteristics

\begin{tabular}{|c|c|}
\hline Age $(y)$ & $23.9 \pm 0.8$ \\
\hline Body weight $(\mathrm{kg})$ & $72.7 \pm 1.3$ \\
\hline Height $(\mathrm{m})$ & $1.82 \pm 0.02$ \\
\hline BMI $\left(\mathrm{kg} / \mathrm{m}^{2}\right)$ & $21.9 \pm 0.6$ \\
\hline$W \max (W)$ & $421 \pm 11$ \\
\hline$W_{\max }(\mathrm{W} / \mathrm{kg})$ & $5.8 \pm 0.1$ \\
\hline $\mathrm{VO} 2_{\max }(1 / \mathrm{min})$ & $5.0 \pm 0.2$ \\
\hline $\mathrm{VO} 2 \max \left(\mathrm{ml}^{1 / 2} \mathrm{~min}^{-1 *} \mathrm{~kg}^{\prime}\right)$ & $68.1 \pm 1.9$ \\
\hline Maximal heart rate $(\mathrm{bts} / \mathrm{min})$ & $197 \pm 1$ \\
\hline
\end{tabular}

Data are means \pm SEM $(n=9)$. 


\section{Pre-testing}

Maximum oxygen uptake $\left(\mathrm{VO}_{2}\right.$ max) and maximum workload (W $\mathrm{Wax}$ ) were measured on an electronically braked cycle ergometer (Lode, Groningen, the Netherlands) during an incremental exhaustive exercise test two weeks before the first experimental trial (30). Findings were used to determine the $55 \%$ Wax workload, incorporated in the exercise trials.

\section{Standardisation diet}

All subjects received a standardisation diet (30 En\% fat) during the 3 days preceding both exercise trials, which were performed in the afternoon of the third day. Subjects were provided with a standard package of food products, beverages and instant meals, and were allowed to use these ad libitum. All main meals (breakfast, lunch and diner) as well as between-meal snacks were instructed to be taken at predetermined time intervals during each day. Total energy intake and macronutrient composition of actual dietary intake were calculated from the provided package minus the amount of food that was left from each package (Table 6.2). Subjects were instructed to refrain from heavy physical labour and/or exercise during both standardisation periods.

Table 6.2: Dietary intake before exercise and during recovery

\begin{tabular}{|l|c|c|c|}
\hline Dietary intake & standardisation & low-fat & normal-fat \\
\hline & preexercise & recovery & recovery \\
\hline Energy intake (MJ/d) & $14 \pm 0.2$ & $14 \pm 0.5$ & $15 \pm 0.4$ \\
\hline Fat intake (En\%) & $30 \pm 0.3$ & $24 \pm 1.7$ & $39 \pm 0.3$ \\
\hline Carbohydrate intake (En\%) & $56 \pm 0.8$ & $62 \pm 2.5$ & $49 \pm 0.3$ \\
\hline Protein intake (En\%) & $13 \pm 0.2$ & $14 \pm 0.3$ & $14 \pm 0.1$ \\
\hline
\end{tabular}

Data are means \pm SEM. Energy intake expressed in MJ per day; fat, carbohydrate and protein intake expressed relative to total energy intake $(\mathrm{En} \%)$. * significant difference in the contribution of fat and carbohydrate to total energy intake between the LF and NF dier.

\section{Protocol}

During the third day of both standardisation diets, subjects came to the laboratory at $2.00 \mathrm{pm}$. First, an MRS scan was performed to determine preexercise IMCL content. Thereafter, a blood sample was obtained from an antecubital vein. After $5 \mathrm{~min}$ of warming-up at $100 \mathrm{~W}$, subjects started cycling at a $55 \%$ Wmax workload for a $3 \mathrm{~h}$ period. Gas exchange measurements were performed each half $h$ over 10 min periods (Oxycon $\beta$, Mijnhardt, Mannheim, Germany) to determine total fat and carbohydrate oxidation rates $(5,31)$. Subjects were allowed to drink water ad libitum during their first exercise trial and the same amount of water was provided during their second trial. In case of the inability to maintain the $55 \%$ Wmax workload during the latter stages of the exercise trials, workload was decreased to $45 \% \mathrm{~W}$ max. After cessation of exercise subjects were allowed a quick shower ( $\max 5 \mathrm{~min}$ ) after which a blood sample 
was collected and a second MRS scan was performed. Subsequently, the athletes were subjected to $2 \mathrm{~d}$ of either a carbohydrate-rich, Jow-fat diet (LF) or a normal fat containing diet (NF). Similar to the standardisation diets, subjects were provided with (LF or NF) packages of food products, beverages and instant meals, and allowed to use these ad libitum. The latter with exception of (evening) dinner, which was eaten under supervision at the laboratory after the second and third MRS scan. After finishing their LF or NF meal, subjects left the lab to return after 24 and $48 \mathrm{~h}$ for another MRS scan, blood sample and subsequent dinner. In addition, after the fourth MRS scan ( $48 \mathrm{~h}$ post-exercise) a muscle biopsy was collected from the vastus lateralis of the same leg that was measured in the multiple MRS scans.

\section{Intervention diets}

Each subject performed two exercise trials, after which different recovery diets were provided; a typical carbohydrate-rich athletes' diet (LF: low in fat) and a normal fat containing diet (NF). Food packages and evening dinners in both diets were designed to result in an estimated fat content between $20-25$ and $35-40 \%$ of total energy intake (En\%) in the LF and NF trial, respectively.

\section{Magnetic resonance spectroscopy}

Image guided, localized single voxel ${ }^{1} \mathrm{H}$-MRS was performed in the wastus. lateralis. All measurements were performed on a $1.5 \mathrm{~T}$ whole body scanner (Intera, Philips Medical Systems, Best, the Netherlands) with a flexible surface coil wrapped around the upper leg with the leg placed in the parallel position. In every subject, voxels were carefully placed at the same position for all 8 measurements. Care was taken to avoid vascular structures and/or adipose tissue within the voxel. To reproduce the same voxel position, longitudinal distance from the voxel to the intercondylar eminence of the knee joint was determined in a coronal image of the upper leg. $\mathrm{T}_{2}$ weighted turbo spin-echo (TSE) MR images, consisting of 5 transversal slices, were acquired at this position (slice thickness $5 \mathrm{~mm}$, TR/TE $2000 / 85 \mathrm{~ms}$, echo train length 12, field-of-view $210 \mathrm{~mm}$ and matrix size $256 \times 256$ ). The patterns of fat distribution were used to verify the longitudinal position and as landmarks to reproduce the voxel position in the transversal plane.

'H-MRS spectra from the regions of interest were acquired using a point-resolved spectroscopy (PRESS) sequence with the following acquisition parameters: TR/TE $3000 / 25 \mathrm{~ms}, 16$ phase cycles, 128 averages, 1024 data points over 1000 Hz spectral width. The voxel volume was $(12 \times 11 \times 18) \mathrm{mm}^{3}$. The water signal was suppressed using Chemically Selective Saturation (CHESS). The unsuppressed water signal was subsequently measured in the same voxel under the same shimming conditions and used as a reference. For post-processing, the spectra were fitted in the time domain using a nonlinear least-squares algotithm (AMARES; (32)) in the jmrui software package. Three peaks were fitted for 
intramyocellular (IMCL) and 3 peaks for extramyocellular lipids (EMCL). Prior knowledge $(16,33)$ of the relative peak positions $(16,33)$ and area ratios as determined by Boesch et al. (personal commmications) were used as a constraint. In order to increase accuracy and reliability of the fitting procedure, the line width of the $\mathrm{CH}_{2}$ peak of IMCL was fixed relative to the line width of the unsuppressed water peak (in the same voxel) and soft constraints were used to limit the linewidth and position of the EMCL (E2) relative to the IMCL (I2) peak. IMCL and EMCL peaks were fitted with a gaussian curve, while water peaks were fitted with a lorenztian curve. The signals were corrected for T1 and 'T2 relaxation using the T1 and T2 relaxation times as determined by Schick et al. $(15,16,34,35)$. The corrected area of the $\mathrm{CH} 2$ peak of IMCL was expressed relative to the area of the water peak. Similar findings were obtained when expressed relative to the creatine peak. Figure 6.1 shows a typical MRS spectrum acquired in the present study, showing EMCL signals (E2) to be relatively small in the vastus lateralis of these trained cyclists. The reproducibility of the IMCL quantification in the vastus lateralis was determined by measuring one subject twice on several occasions. The subject left the scanning table between measurements after which the coil was again repositioned. The comparison of the IMCL quantification in corresponding voxels $(n=5)$ resulted in a coefficient of variance of $5.0 \pm 3.3 \%$, which is in accordance with ealier reports on the obtained variance when measuring IMCL content by using $\operatorname{MRS}(15,16,34,35)$.

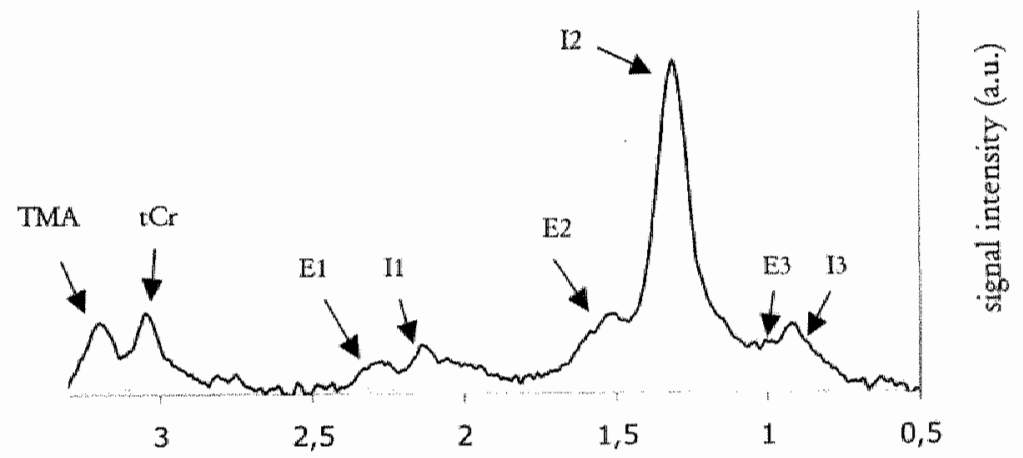

relative resonance frequency (ppm)

Figure 6.1: Typical spectrum acquired using image guided, localized single voxel 'H-MRS in the vastus lateralis. TMA = trimethyl ammonium compounds, $\mathrm{tCr}=$ total creatine, $\mathrm{El}=$ broad peak of various, chemically different methylene protons of EMCL (54), E2 = methylene protons of EMCL, E3 = methyl protons of EMCL, I1 = broad peak of various, chemically different methylene protons of IMCL (54), I2 = methylene protons of $\mathrm{MCL}, 13$ = methyl protons of IMCL. 


\section{Blood and muscle tissue analysis}

Blood was collected in EDTA containing tubes and centrifuged at $1000 \mathrm{~g}$ and $4^{\circ} \mathrm{C}$ for 5 min. Aliquots of plasma were frozen immediately in liquid nitrogen and stored at $-40^{\circ} \mathrm{C}$. Plasma free fatty acid (FFA) (Wako NEFA-C kit, Wako Chemicals, Neuss, Germany), free glycerol (148270, Roche, Diagnostics, Indianapolis, IN, USA) and triglyceride (GPO-trinder 337B, Sigma Diagnostics, St. Louis, MO, USA) concentrations were analyzed using the COBAS FARA semi-automatic analyzer (Roche, Basel, Switzerland).

Muscle samples were dissected carefully, freed from any visible non-muscle material, rapidly frozen in liquid nitrogen-cooled isopentane and embedded in Tissue-Tek (Sakura Finetek, Zoeterwoude, The Netherlands). Multiple serial sections $(5 \mu \mathrm{m})$ from biopsies collected in both trials were thaw mounted together on uncoated, precleaned glass slides. To permit quantification of intramyocellular lipid stained by oil red $O$ together with immunolabelled cellular constituents we used the protocol as described by Koopman et al. (36). Briefly, cryosections were fixed in $3.7 \%$ formaldehyde for $1 \mathrm{~h}$. Slides were rinsed with deionised water, treated with $0.5 \%$ Triton X-100 in PBS, and washed with PBS. Thereafter, sections were incubated with antibodies against human laminin (polyclonal rabbit antibody, Sigma Diagnostics, Steinheim, Germany) and human myosin heavy chain (A4.840), developed by Dr. Blau (37), enabling us to visualise individual cell-membranes and to determine muscle fibre type (I or $\mathrm{II}_{\gamma}$, respectively. Incubation was followed by washes in PBS, after which the appropriate conjugated antibodies GARIgG Alexa350 and GAMIgMAlexa488 (Molecular Probes, Leiden, The Netherlands) were applied. After several washes with $\mathrm{PBS}$, glass slides were immersed in the oil red $\mathrm{O}$ working solution. Oil red $O$ stock solution was prepared by adding $500 \mathrm{mg}$ oil red $\mathrm{O}$ (Fluka Chemie, Buchs, Switzerland) to $100 \mathrm{ml} 60 \%$ triethylphosphate. Prior to staining, a $36 \%$ triethylphosphate working solution, containing $12 \mathrm{ml}$ oil red $\mathrm{O}$ stock solution and $8 \mathrm{ml}$ deionised water, was prepared and filtered to remove crystallised oil red $O$. After $30 \mathrm{~min}$ of oil red $\mathrm{O}$ immersion, slides were rinsed with deionised water followed by a $10 \mathrm{~min}$ wash with tap water. Stained sections were embedded in Mowiol and covered with a coverslip. After $24 \mathrm{~h}$, slides were examined using a Nikon E800 fluorescence microscope (Uvikon, Bunnik, The Netherlands) coupled to a Basler A113 C progressive scan colour CCD camera, with a Bayer colour filter. Epifluorescence signal was recorded using a Texas red excitation filter (540-580 nm) for oil red O, a DAPI UV excitation filter $(340-380 \mathrm{~nm})$ for laminin, and a FITC excitation filter $(465-495 \mathrm{~nm})$ for muscle fibre type. Multiple digitally captured images (40x objective), at least 5 fields-of-view per muscle crosssection, were processed and analysed using Lucia 6.01 software (Nikon, Düsseldorf, Germany). The oil red $O$ epifluorescence signal was quantified for each cell, within 5 fields-of-view for each muscle section. An intensity treshold representing minimal absorbance values corresponding to lipid droplets was set manually and used for all images. Total area measured and the 
area as well as the number of objects emitting oil red $\mathrm{O}$ epifluorescence signal were recorded. Fibre type specific IMCL content was expressed as the percentage of the measured area that was stained with oil red $O$ in each muscle cell. Average lipid droplet size was calculated by dividing total area lipid stained by the total number of droplets. Lipid droplet density was calculated by dividing total number of droplets by total (intramyocellular) area measured.

\section{Statistics}

All results are expressed as means \pm SEM. Statistical significance of differences between trials was assessed by paired t-tests. A repeated measures ANOVA was applied to assess statistical differences over time within trials. A Sheffé post-hoc test was applied to locate any differences over time. Simple regression analysis was performed between IMCL content as determined by MRS and IMCL content as determined by quantitative fluorescence microscopy. Statistical significance was set at $P<0.05$.

\section{Results}

\section{Exercise trials}

In the exercise trials subjects cycled for $3 \mathrm{~h}$ at an average workload of $232 \pm 6 \mathrm{~W}$ $(55 \% \mathrm{~W}$ max). Due to fatigue, power output was decreased to $45 \% \mathrm{~W} \max$ in 2 subjects during the last $30 \mathrm{~min}$ of the $3 \mathrm{~h}$ exercise period. The same procedure was repeated in the second trial. Substrate use and total energy expenditure were similar in both exercise trials and are reported in Table 6.3. MRS quantification of IMCL content before and after the exercise trials are illustrated in Figure 6.2. IMCL content was significantly decreased by $22.6 \pm 5.3$ and $20.4 \pm 3.7 \%$ in both the exercise trials preliminary to the $L F$ and NF trial, respectively $(P<0.05)$. No differences were observed between trials.

Table 6.3: Substrate use during the exercise trials

\begin{tabular}{|l|c|c|}
\hline Preliminary to the & low-fat diet & normal-fat diet \\
\hline Energy expendinure (MJ) & $(n=9)$ & $(n=9)$ \\
\hline Fat oxidation (g) & $11.7 \pm 0.21$ & $11.7 \pm 0.28$ \\
\hline Carbohydrate oxidation (g) & $100 \pm 7$ & $88 \pm 3$ \\
\hline Fat oxidation (En\%) & $469 \pm 20$ & $502 \pm 20$ \\
\hline Carbohydrate oxidation (En\%) & $35 \pm 2$ & $31 \pm 1$ \\
\hline
\end{tabular}

Data are means \pm SEM. Energy expenditure expressed in MJ per $3 \mathrm{~h}$ period, fat and carbohydrate oxidation as $\mathrm{g}$ per $3 \mathrm{~h}$ period and as the relative contribution to total energy expenditure (En\%). No significant differences between trials. 


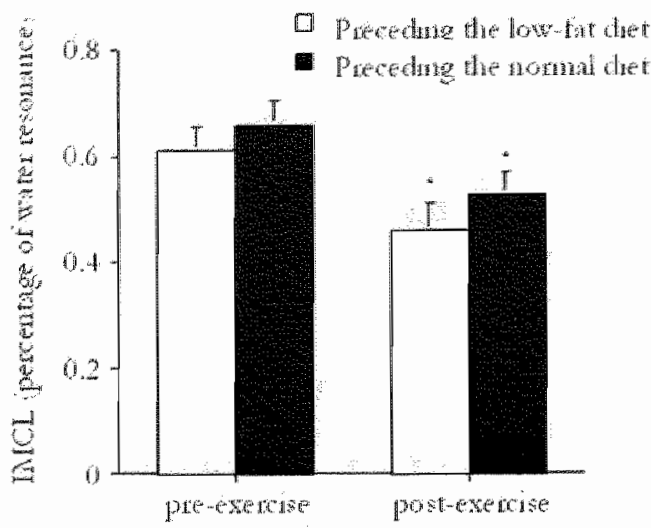

Figure 6.2: Intramyocellular lipids content (relative to water resonance) before and after exercise as quantitated by magnetic resonance spectroscopy. Data expressed as means $\pm S E M$; *: significantly decreased compared to pre-exercise values $(\mathrm{P}<0.05)$.

\section{Diet composition}

Dietary intake during the $3 \mathrm{~d}$ standardization period (before the exercise trials), and sub-sequent dietary intake in the $2 \mathrm{~d} \mathrm{LF}$ and NF diet are reported in Table 6.2. Dietary intake during both standardization periods was similar. In the recovery period, total energy and protein intake were not different between trials. However, fat and carbohydrate intake significantly differed; 24 versus 39 En\% fat and 62 versus $49 \mathrm{En} \%$ carbohydrate in the LF and NF trial, respectively $(\mathrm{P}<0.05)$.

Table 6.4: Plasma concentrations

\begin{tabular}{|c|c|c|c|c|}
\hline & 0 & $3 \mathrm{~h}$ & $24 \mathrm{~h}$ & $48 h$ \\
\hline \multicolumn{5}{|l|}{ free fatty acids } \\
\hline low-fat diet & $104 \pm 11$ & $1425 \pm 59^{x-4^{4}}$ & $197 \pm 44$ & $177 \pm 42$ \\
\hline normal-fat diet & $90 \pm 12$ & $1400 \pm 61^{* A}$ & $235 \pm 38$ & $317 \pm 107$ \\
\hline \multicolumn{5}{|l|}{ free glycerol } \\
\hline low fat diet & $58 \pm 9$ & $442 \pm 43^{\text {sti }}$ & $67 \pm 7$ & $66 \pm 8$ \\
\hline normal-fat diet & $45 \pm 5$ & $469 \pm 63$ & $70 \pm 6$ & $65 \pm 10$ \\
\hline \multicolumn{5}{|c|}{ plasma triglycerides } \\
\hline Low-fat diet & $1384 \pm 112$ & $644 \pm 52^{26^{2}}$ & $740 \pm 129^{\circ}$ & $1421 \pm 149$ \\
\hline normal-lat diet & $1522 \pm 189$ & $652 \pm 49^{2}$ & $750 \pm 101^{*}$ & $1222 \pm 211$ \\
\hline
\end{tabular}

Data are means \pm SEM. Plasma free fatty acid, glycerol and triglyceride concentrations before exercise $(0)$, within $5 \mathrm{~min}$ after exercise $(3 \mathrm{~h})$ and 24 and $48 \mathrm{~h}$ post-exercise. Plasma free farty acid, glycerol and triglyceride concentrations are expressed in $\mu \mathrm{mol} / \mathrm{L}$, * : significantly different from baseline value ( 0$)$, "significantly different from values at $24 \mathrm{~h}$ post-exercise, " significantly different from values at $48 \mathrm{~h}$ post-exercise. No significant differences between trials.

Plasma analysis

Plasma FFA, free glycerol and triglyceride concentrations are provided in Table 6.4. Plasma FFA and glycerol concentrations were significantly increased following exercise. After 24 and $48 \mathrm{~h}$ of recovery, concentrations were similar to preexercise values. Plasma triglyceride concentrations were substantially reduced following exercise and remained below baseline levels after $24 \mathrm{~h}$ of post-exercise 
recovery. At $48 \mathrm{~h}$ post-exercise, plasma triglyceride concentrations had increased significantly and were simillar to pre-exercise levels. No significant differences were observed between trials.

\section{IMCL repletion}

In the post-exercise recovery period, IMCL content was significantly increased in the NF trial only $(\mathrm{P}<0.05)$, with post-hoc analysis showing a significantly higher IMCL content after $48 \mathrm{~h}$ compared to the values reported immediately and $24 \mathrm{~h}$ after exercise. In the LF trial, no significant changes in IMCL content were observed (Figure 6.3). Comparing preexercise IMCL content with values recorded after $48 \mathrm{~h}$ of recovery showed similar contents in the NF trial and a significantly lower IMCL content after 48 h of recovery in the LF trial.

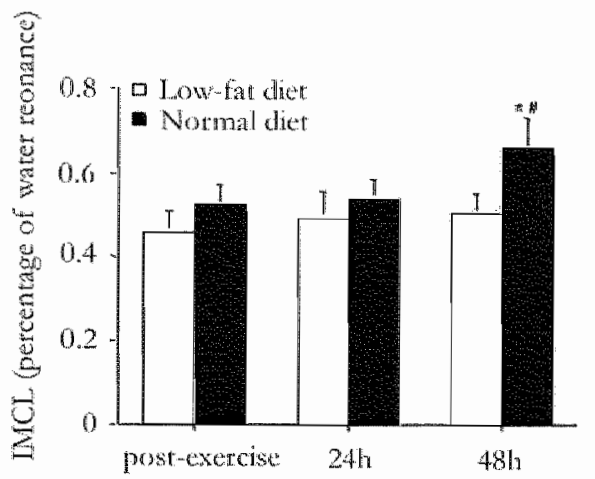

Figure 6.3: Intranyocellular lipids content (relative to water resonance) immediarely after exercise, after 24 and after 48 hours of recovery on a low fat (LF) or normal tat containing (NF) diet, as quantitated by magnetic resonance spectroscopy. Data expressed as means \pm SEM; ; significantly higher compared to baseline (post-exercise) value; \#: significantly higher compared to the value observed after 24 h of recovery.

In accordance to the MRS data, muscle tissue analysis for IMCL quantification using quantitative fluorescent microscopy on oil red $O$ stained muscle crosssections showed significantly higher intramyocellular lipid content in the type I fibres after $48 \mathrm{~h}$ of recovery in the NF compared to the LF trial (Table 6.5; $\mathrm{P}<0.05$ ). The higher lipid content was accounted for by a significantly greater lipid droplet size as well as an increased lipid droplet density. Intramyocellular lipid content in the type II fibres was not different between trials. Lipid content in the type II fibres was significantly lower compared to the type I fibres. The latter was accounted for by a lower lipid droplet density $(\mathrm{P}<0.05)$ but not lipid droplet size (NS).

Comparing the data on IMCL content after $48 \mathrm{~h}$ of post-exercise recovery on both the LF and NF diet following MRS quantification and the quantitative fluorescent oil red $\mathrm{O}$ method revealed a significant correlation between the two methods, reaching statistical significance in the type I fibres $(R=0.6 ; P=0.01)$ but not in the type II fibres $(R=0.5 ; P=0.06)$. 
Table 6.5: Oil red O staningy muscle triglyceride content 48 b post-exercise

\begin{tabular}{|l|c|c|}
\hline & low-fat diet & normal-fat diet \\
\hline Type I fibres & $(n=9)$ & $(n=9)$ \\
\hline MCL content & $1.39 \pm 0.21$ & $2.09 \pm 0.24^{*}$ \\
\hline Dropler size & $0.87 \pm 0.06$ & $1.00 \pm 0.04$ \\
\hline Droplet density & $0.016 \pm 0.002$ & $0.020 \pm 0.002$ \\
\hline Type II fibres & $0.51 \pm 0.11 \#$ & \\
\hline MCL content & $0.84 \pm 0.10$ & $0.66 \pm 0.12$ \\
\hline Droplet size & $0.010 \pm 0.002$ & $0.94 \pm 0.07$ \\
\hline Droplet density & & $0.009 \pm 0.003$ \\
\hline
\end{tabular}

Datal are neans \pm SEM. MMCL content expressed as percentage of measured area (\%), droplet size as measured area divided by the number of lipid droplets ( $\left.\mathrm{m}^{2} / \mathrm{droplet}\right)$ and droplet densicy expressed as the number of lipid droplets divided by totall surface area (droplets/ $\left./ \mu \mathrm{m}^{2}\right)$. " : significantly higher in the normal-fat trial compared to the lowfat trial; : significantly lower compared to the type I muscle fibres

\section{Discussion}

In the present study we observed a progressive increase in whole-body fat oxidation rates during exercise, resulting in a total of $94 \pm 4 \mathrm{~g}$ fat oxidised within the $3 \mathrm{~h}$ cycling trial (Table 6.3). Concomitantly, IMCL content in the vastus lateralis measured by MRS was substantially reduced by $21 \pm 3 \%$ after exercise (Figure 6.2). The reported decrease is in line with other studies reporting similar decreases (ranging $\sim 20-40 \%$ ) in IMCL content following MRS quantification in the tibialis anterior and soleus muscle before and after prolonged running or cycling exercise (15-21). We converted the IMCL data (Figure 6.2) to absolute muscle concentrations using formulas and assumptions published by Boesch et al. (15). As such, IMCL contents before and after exercise in the vastus lateralis muslce averaged $7.9 \pm 0.6$ (pre) and $5.9 \pm 0.7$ (post) and $8.5 \pm 0.6$ (pre) and $6.8 \pm 0.6$ (post) $\mathrm{mmol} / \mathrm{kg}$ wet muscle, preliminary to the LF and NF diet respectively. These absolute IMCL concentrations observed in the vastus lateralis are well above IMCL contents reported for tibialis anterior muscle (18). "This confirms the earlier conclusions by Boesch et al (15) that there are substantial differences in IMCL content between different muscle groups.

Our data clearly show that IMCL stores in the vastus lateralis form an important substrate source during prolonged (cycling) exercise. This confirms conclusions from earlier stable isotope studies reporting that $-50 \%$ of total fat oxidation is accounted for by plasma derived FFA oxidation, thereby suggesting that other substrate sources like IMCL play a substantial role in energy provision during exercise (3-6). However, as noted in the introduction, the importance of IMCL stores as a substrate source has been disputed as some $(9,38-44)$, but certainly not all studies (45-52) using the biochemical triglyceride extraction method on muscle samples collected before and after exercise have been able to show a significant 
decline in IMCL content following prolonged endurance exercise. This apparent controversy, as elegantly described in a recent review by Watt et al. (8), can be explained by the marked between biopsy wariability $(-24 \%)$ that has been reported when using this technique (52). Whether the high between biopsy variability is due to the contamination of the obtained muscle samples with extramyocellular triglycerides $(9,52)$ and/or simply due to high variability between IMCL content in various muscle sections (51) is not clear (8). In accordance with the apparent problems when using the biochemical extraction method, Howald et al. (53) reported a good correlation between IMCL content in the tibialis anterior as determined by MRS and electron microscopy (EM), but the results from the biochemical muscle triglyceride extraction method did not correlate well with the results from the other two methods.

In the post-exercise phase, we observed a significant increase in IMCL content over the $2 \mathrm{~d}$ recovery period only when using the NF diet. After $24 \mathrm{~h}$ of postexercise recovery, IMCL content was still low and did not differ from IMCL contents observed immediately after exercise (Figure 6.2). In line, plasma triglyceride concentrations remained substantially lower compared to preexercise values (Table 6.4). After $48 \mathrm{~h}$ of post-exercise recovery, IMCL content as well as plasma triglyceride levels had increased significantly on the NF diet. When comparing IMCL contents after $48 \mathrm{~h}$ of recovery on the NF diet to the corresponding pre-exercise values, no significant differences were observed. Therefore, we conclude that when using a normal diet after prolonged endurance cycling exercise, IMCL stores in the vastus lateralis can be fully repleted within 48h. These findings are somewhat different from Larson-Meyer et al. (19) who observed full restoration of the IMCL content in the soleus muscle of 7 female endurance runners within $-22 \mathrm{~h}$ of recovery from a $2 \mathrm{~h}$ treadmill run when using a similar normal fat containing diet ( $35 \mathrm{En} \%$ ). This apparent difference could be explained by a more extensive depletion of the IMCL stores following the $3 \mathrm{~h}$ exercise trials in the present study. In addition, gender differences in IMCL use and/or storage $(47,51)$ and/or differences in fatty acid uptake and IMCL storage between muscle groups could also have contributed to the apparent difference in the observed timing of IMCL repletion.

In line with the other studies on post-exercise IMCL repletion $(18,19)$, we also show that IMCL repletion is substantially impaired when a low-fat diet is used. In the present study, IMCL contents did not increase during $48 \mathrm{~h}$ of post-exercise recovery when using a typical low-fat athletes' diet ( $24 \mathrm{En} \%$ fat), with IMCL contents after $48 \mathrm{~h}$ still significantly lower compared to pre-exercise values $(\mathrm{P}<0.05)$. In accordance, others have reported that ingestion of a low-fat diet does not allow IMCL contents to return to pre-exercise levels within 30 (18) or 22 and 70 hours (19) of post-exercise recovery. Though in those studies more extreme low-fat diets (10-15 En\% fat) were applied, the present study shows that even a typical carbohydrate-rich athletes' diet containing $-24 \mathrm{En} \%$ fat (28) is insufficient to restore IMCL stores within $48 \mathrm{~h}$. As such, it could be speculated 
that such a dietary strategy potentially limits performance during periods of repeated bouts of prolonged endurance exercise. However, optimizing performance capacity by maximizing endogenous substrate repletion in the postexercise phase also includes the need to optimize post-exercise muscle glycogen synthesis. Clearly, when decreasing fat intake to favour carbohydrate ingestion as a precursor for glycogen storage, IMCL restoration will become impaired. In reverse, when favouring fat intake to maximize IMCL repletion, carbohydrate ingestion and subsequent muscle glycogen storage could proof to be suboptimal. Obviously, diets with an opposite fat-to-carbohydrate ratio seem to be prefered for IMCL or glycogen repletion, which makes the choice of post-exercise dietary strategy controversial. As recently suggested by Décombaz et al. (18), a highcarbohydrate diet provided immediately post-exercise, followed by a normal-tohigh fat diet could proof to result in optimal IMCL contents without compromising muscle glycogen storage. Clearly, future research is needed to determine the optimal dietary strategy to increase both IMCL and glycogen repletion to provide an ideal mixture of endogenous substrate availability which woull prevent endogenous substrate depletion during exercise.

MRS provides two different signals for muscle lipid content, with MRS experts assuming one to represent intramyocellular (IMCL) and the other extramyocellular (EMCL) lipid (54). However, the localisation of the lipid sources based on a shift in the MRS resonance frequency is not entirely unambiguous. Oil red $\mathrm{O}$ staining of muscle cross-sections and subsequent quantification of the staining intensity by fluoresence microscopy has recently been optimized in our laboratory (36), and enables direct and selective quantification of intramyocellular lipid content. Therefore, we applied this method to validate our findings obtained by MRS quantification. Due to the invasiveness of the percutaneous muscle biopsies, muscle sample collection was restricted to $48 \mathrm{~h}$ after exercise in both trials. Both MRS and quantitative fluorescence microscopy showed a substantially higher IMCL content following the use of a NF compared to a LF diet after $48 \mathrm{~h}$ of recovery. In accordance, a significant correlation was observed between the data obtained using both methods. This significant correlation could be restricted to the selected subject population and/or muscle group in the present study, in which the observed EMCL signal was relatively low (Figure 6.1). Our data suggest that MRS represents a valid method to quantify IMCL content. With MRS being unable to provide any information on fibre type specific intramyocellular lipid content, we also used fluorescence microscopy to show that the higher IMCL content following the NF compared to the LF diet is mainly due to an increased IMCL content in the type I but not type II muscle fibres (Table 6.5). The latter is in accordance with the predominant use of type I muscle fibres during submaximal endurance exercise. Interestingly, quantitative fluorescence microscopy also showed that IMCL repletion following exercise is explained by an increase in 
both size and density of the intramyocellular lipid droplets in the type I muscle fibres.

In summary, the present study shows that IMCL form an important substrate source during prolonged endurance cycling exercise in trained athletes. During post-exercise recovery $\mathrm{MMCL}$ repletion is impaired by ingestion of a carbohydrate-rich athletes' diet, which is typically low in fat. As such, MMCL stores are not repleted within $48 \mathrm{~h}$, which is in contrast to the situation when a normal fat containing diet is used. These results imply that carbohydrate-rich diets, as recommended to endurance athletes, are insufficient in providing ample substrate for IMCL repletion and could proof to result in sub-optimal performance capacity following periods in which prolonged endurance exercise is performed repeatedly. In addition, we show that MRS is a valid quantification method for IMCL content and being non-invasive provides a suitable means to enable repeated sampling of IMCL content in studies investigating the effects of nutritional intervention on changes in IMCL content over time.

\section{Acknowledgement}

We gratefully acknowledge the analytical assistance of Jos Stegen and Joan Senden and the enthusiastic support of the subjects who volunteered to participate in these trials. Dr. van Loon was supported with an individual fellowship from the Netherlands Organization for Scientific Research (NWO). The monoclonal antibody A 4.840 developed by Dr. Blau was obtained from the Developmental Studies Hybridoma Bank developed under the auspices of the NICHD and maintained by the university of Iowa, Deptartment of Biological Science, Iowa City, IA 52242, USA. 


\section{References}

1. Coyle EF, Jeukendrup AE, Wagenmakers AJ, Saris WH. Fanty acid oxidation is directly regulated by carbohydrate metabolism during exercise. Am. J. Physiol. 1997; 273:E268-75.

2. Holloszy JO, Booth FW. Biochemical adaptations to endurance exercise in muscle. Annu. Rev. Physiol. 1976; 38:273-91.

3. Martin WHd, Dalsky GP, Hurley BF, et al. Effect of endurance training on plasma free farty acid turnover and oxidation during exercise. Am. J. Physiol. 1993; 265:E708-14.

4. Romijn JA, Coyle EF, Sidossis IS, et al. Regulation of endogenous fat and carbohydrate metabolism in relation to exercise intensity and duration. Am. J. Physiol. 1993; 265:E38091.

5. Van Loon LJC, Greenhaff PL, Constantin-Teodosiu D, Saris WHM, Wagenmakers AJM. The effects of increasing exercise intensity on muscle fuel utilisation in humans. J. Physiol. 2001; 536:295-304.

6. Havel RJ, Pernow B, Jones NL. Uptake and release of free fatry acids and other metabolites in the legs of exercising men. J. Appl. Physiol. 1967; 23:90-9.

7. Oscai LB, Essig DA, Palmer WK. Lipase regulation of muscle triglyceride hydrolysis. J. Appl. Physiol. 1990; 69:1571-7.

8. Watt MJ, Heigenhauser GJ, Spriet LL. Intramuscular triacylglycerol utilization in human skeletal muscle during exercise: is there a controversy? J. Appl. Physiol. 2002; 93:1185-95.

9. Watt MJ, Heigenhauser GI, Dyck DJ, Spriet LL. Intramuscular triacylglycerol, glycogen and acetyl group metabolism during $4 \mathrm{~h}$ of moderate exercise in man. J. Physiol. 2002; 541:969-78.

10. Boesch $\mathrm{C}$, Kreis $\mathrm{R}$. Observation of intramyocellular lipids by $1 \mathrm{H}$-magnetic resonance spectroscopy. Ann. N. Y. Acad. Sici. 2000; 904:25-31.

11. Perseghin G, Scifo P, De Cobelli $F$, et al. Intramyocellular triglyceride content is a determinant of in vivo insulin resistance in humans: a ${ }^{1} \mathrm{H}^{14} \mathrm{C}$ nuclear mag-netic resonance spectroscopy assessment in offspring of type 2 diabetic parents. Diabetes 1999; 48:1600-6.

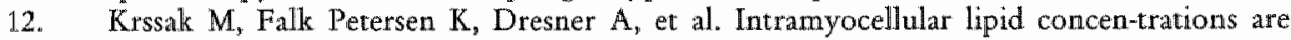
correlated with insulin sensitivity in humans: a 'H NMR spec-troscopy study. Diabetologia $1999 ; 42: 113-6$.

13. Forouhi NG, Jenkinson G, Thomas EL, et al. Relation of triglyceride stores in skeletal muscle cells to central obesity and insulin sensitivity in European and South Asian men. Diabetologia $1999 ; 42: 932.5$.

14. Jacob $\mathrm{S}$, Macliann J, Rett $\mathrm{K}$, et al. Association of increased intramyocellular lipid content with insulin resistance in lean nondiabetic offspring of type 2 dia-betic subjects. Diabetes $1999 ; 48: 1113-9$.

15. Boesch $\mathrm{C}$, Decombaz J, Slotboom J, Kreis R. Observation of intramyocellular lipids by means of 'FI magnetic resonance spectroscopy. Proc. Nutr. Soc. 1999; 58:841-50.

16. Boesch $C$, Slotboom J, Hoppeler H, Kreis R. In vivo determination of intra-myocellullar lipids in human muscle by means of localized "H-MR-spectroscopy. Magn. Reson. Med. $1997 ; 37: 484 \times 493$.

17. Brechtel $\mathrm{K}$, Niess AM, Machann J, et al. Utilisation of intramyocellular lipids (IMCLs) during exercise as assessed by proton magnetic resonance spec-troscopy (H-MRS). Horm. Metab. Res. 2001; 33:63-6.

18. Decombaz J, Schmitt B, Ith $M$, et al. Postexercise fat intake repletes intra-myocellular lipids but no faster in trained than in sedentary subjects. Am. J. Physiol. 2001; 281:R760-9.

19. Larson Meyer DE, Newcomer BR, Hunter GR. Influence of endurance running and recovery diet on intramyocellular lipid content in women: a 'H NMR study. Am. J. Plyysiol. 2002; 282:E95-E106.

20. Rico Sanz J, Moosavi M, Thomas EL, et al. In wivo evaluation of the effects of continuous exercise on skeletal muscle triglycerides in trained humans. Lipids 2000; 35:1313-8. 
21. Krssak M, Petersen KF, Bergeron $R$, et al. Intramuscular glycogen and intra-myocellular lipid utilization during prolonged exercise and recovery in man: a ${ }^{13} \mathrm{C}$ and $\mathrm{H}$ nuclear magnetic resonance spectroscopy study. J. Clin. Endocrinol. Metab. 2000; 85.748-54.

22. Schrauwen-Hinderling VB, Schrauwen $P$, Hesselink MK, van Engelshoven JM, Nicolay $\mathrm{K}$, Saris WH, Kessels AG, Kooi ME. The increase in intramyocellular lipid content is a very early response to training. J Clin Endocrinol Metab. 2003; 88:1610-6.

23. Decombaz J, Fleith M, Hoppeler $H$, Kreis $R$, Boesch C. Effect of diet on the replenishment of intramyocellular lipids after exercise. Eur. J. Nutr. 2000; 39:244-7.

24. van Loon LJC, Saris WHM, Kruijshoop M, Wagenmakers AJM. Maximizing post-exercise muscle glycogen synthesis: carbohydrate supplementation and the application of amino acid/protein hydrolyzate mixtures. Am. J. Clin. Nutr. 2000; 72: 106-111.

25. Iry JL. Muscle glycogen synthesis before and after exercise. Sports Med. 1991; 11:6 19.

26. Joint Position Statement: nutricion and athletic performance. American College of Sports Medicine, American Dietetic Association, and Dietitians of Canada. Med. Sci. Sports Exere. $2000 ; 32: 2130.45$.

27. Position of the American Dietetic Association, Dietitians of Canada, and the American College of Sports Medicine: Nutrition and athletic performance. J. Am. Diet. Assoc. 2000; 100:1543-56.

28. Saris WH, van Erp Baart MA, Brouns F, Westerterp KR, ten Hoor F. Study on food intake and energy expenditure during extreme sustained exercise: the Tour de France. Int. J. Sports Med. 1989; 2396:0172-4622.

29. de Castro JM. What are the major correlates of macronutrient selection in Western populations? Proc. Nutr. Soc. 1999; 58:755-63.

30. Kuipers H, Verstappen FT, Keizer HA, Geurten P, van Kranenburg G. Variability of aerobic performance in the laboratory and its physiologic corre-lates. Int. J. Sports. Med. $1985 ; 6: 197-201$.

31. Peronnet F, Massicotte D. Table of nonprotein respiratory quotient: an update. Can. J. Sport Sci. 1991; 16:23-9.

32. Van den Boogaart AH, van Huffel P, Graveron-Demilly S, Van Ormondr D, De Beer R. Proc. ESMRMB - Prague 1996; 318.

33. Vanhamme L, Van den Boogaart A, van Huffel P. Improved method for accu-rate and efficient quantification of MRS data with use of prior knowledge. J. Magn. Reson. 1997; 129:35-43.

34. Schick $F$, Eismann $B$, Jung WI, Bongers $H$, Bunse $M$, Lutz $O$. Comparison of localized proton NMR signals of skeletal muscle and fat tissue in vivo: two lipid comparments in muscle uissue. Magn. Reson. Med. 1993; 29:158-167.

35. Szczepaniak. LS, Babcock EE, Schick F, et al. Measurement of intracellular triglyceride stores by $\mathrm{H}$ spectroscopy: validation in vivo. Am. J. Playsiol. 1999, 276:E977-89.

36. Koopman $R$, Schaart $G$, Hesselink MK. Optimisation of oil red $O$ staining per-mits combination with immunofluorescence and automated quantification of lipids. Histochem. Cell. Biol. 2001; 116:63-8.

37. Cho M, Webster SG, Blau HM. Evidence for myoblastextrinsic regulation of slow myosin heavy chain expression during muscle fiber formation in embry-onic development. J. Cell Biol. 1993; 121:795-810.

38. Bergstrom J, Hultman $\mathbb{E}$, Saltin B. Muscle glycogen consumption during cross-country skiing (the Vasa ski race). Int. Z. Angew. Physiol, 1973; 31:71-5.

39. Carlson LA, Ekelund LG, Froberg SO. Concentration of triglycerides, phos-pholipids and glycogen in skeletal muscle and of free fatty acids and beta-hydroxybutyric acid in blood in man in response to exercise. Eur. J. Clin. Invest. 1971; 1:248-54.

40. Cleroux J, Van Nguyen P, Taylor AW, Leenen FH. Effects of beta 1- vs. beta 1+beta 2blockade on exercise endurance and muscle metabolism in humans. I. Appl. Physiol. 1989; $66: 548-54$. 
41. Essen B, Hagenfeldt L, Kaifser L. Utilization of blood-borne and intramuscular substrates during contimuous and intermituent exercise in mant. 1977; 265:489-506.

42. Hurley BF, Nemen PM, Martin WHd, Hagberg JM, Dalsky GP, Holloszy JO. Muscle righyceride willization during exercise: effect of training. J. Appl. Physiol. 1986; 60:562-7.

43. Phillips SM, Green HJ, Tamopolsky MA, Heigenhauser GJ, Grant SM. Progressive effect of endurance training on metabolic adaptations in working skeletal muscle. Am. J. Physiol. 1996; 270:E265-72.

44. Froberg $\$ O$, Mossfeldt F. Effect of prolonged strenuous exercise on the concen-tration of triglycerides, phospholipids and glycogen in muscle of man. Acta Playsiol. Scand. 1971; $82: 167-71$.

45. Kiens B, Richter EA. Uthization of skeletal muscle triacylglycerol during post-exercise recovery in thumans. Am. J. Pliysiol. 1998; 38:E332-337.

46. Kiens B, Essen-Gustavsson B, Christensen NJ, Saltin B. Skeletal muscle substrate utilization during submaximal exercise in man: effect of endurance training. J. Physiol. 1993; 469:45978.

47. Roepstorff $\mathrm{C}$, Steffensen $\mathrm{CH}_{3}$ Madsen $\mathrm{M}_{x}$ et al. Gender differences in substrate utilization during submaximal exercise in endurance-trained subjects. Am. J. Physiol. 2002, 282:E43547.

48. Starling RD, Trappe TA, Parcell AC, Kerr CG, Fink WJ, Costill DL. Effects of diet on muscle triglyceride and endurance performance. J. Appl. Physiol. 1997; 82:1185-9.

49. Bergman BC, Butterfield GE, Wolfel EE, Casazza GA, Lopaschuk GD, Brooks GA. Evaluation of exercise and rraining on muscle lipid metabolism. Am. J. Physiol. 1999; 276:E106-17.

50. Guo Z, Burguera B, Jensen MD. Kinetics of intramuscular triglyceride fatty acids in exercising humans. J. Appl. Physiol. 2000; 89:2057-64.

51. Steffensen $\mathrm{CH}$, Roepstorff C, Madsen M, Kiens B. Myocellular triacylglycerol breakdown in females but not in males during exercise. Am. J. Physiol. 2002; 282:E634-42.

52. Wendling PS, Peters SJ, Heigenhauser GJ, Spriet LL. Variability of triacyl-glycerol content in human skeletal muscle biopsy samples. J. Appl. Physiol. 1996; 81:1150-5.

53. Howald $H$, Boesch $\mathrm{C}$, Kreis $\mathrm{R}$, et al. Content of intramyocellular lipids derived by electron microscopy, biochemical assays, and 'H-MR spectroscopy. J. Appl. Physiol. 2002; 92:2264-72.

54. Boesch C, Kreis R. MR-spectroscopy (MRS) of different nuclei applied to human muscle: additional information obtained by 'H-MRS. Int. J. Sports Med. 1997; 18:\$310-2. 


\section{CHAPTER}

\section{INTRAMYOCELLULAR LIPID CONTENT IS INCREASED AFTER EXERCISE IN NON-EXERCISING HUMAN SKELETAL MUSCLE}

V.B. Schrauwen-Hinderling, L.J.C. van Loon, R. Koopman, K. Nicolay, W.H.M. Saris, and M.E. Kooi

J Appl Physiol. 2003 Dec;95(6):2328-32. 


\section{Abstract}

Intramyocellular lipid (IMCL) content has been reported to decrease following prolonged submaximal exercise in active muscle and therefore seems to form an important local substrate source. Since exercise leads to a substantial increase in plasma free fatty acid (FFA) availability with a concomitant increase in FFA uptake by muscle tissue, we aimed to investigate potential differences in the net changes in $\mathrm{IMCL}$ content between contracting and non-contracting skeletal muscle following prolonged endurance exercise.

IMCL content was quantified by magnetic resonance spectroscopy in 8 trained cyclists before and after a $3 \mathrm{~h}$ cycling protocol $(55 \% \mathrm{Wmax})$ in the exercising vastus lateralis and the non-exercising biceps brachii muscle. Blood samples were taken before and after exercise to determine plasma FFA, glycerol and triglyceride concentrations and substrate oxidation was measured with indirect calorimetry.

Prolonged endurance exercise resulted in a $20.4 \pm 2.8 \%$ $(\mathrm{P}<0.001)$ decrease in IMCL content in the vastus lateralis muscle. In contrast, we observed a substantial $(37.9 \pm 9.7 \%$; $\mathrm{P}<0.01$ ) increase in IMCL content in the less active biceps brachii muscle. Plasma FFA and glycerol concentrations were substantially increased following exercise (from $85 \pm 6$ to $1450 \pm 55 \mu \mathrm{M}$ and $57 \pm 11$ to $474 \pm 54 \mu \mathrm{M}$, respectively; $P<0.001$ ), whereas plasma triglyceride concentrations were decreased (from $1498 \pm 39$ to $703 \pm 7 \mu \mathrm{M}: \mathrm{P}<0.001$ ).

We conclude that IMCL is an important substrate source during prolonged moderate intensity exercise, and is substantially decreased in the active vastus lateralis muscle. However, prolonged endurance exercise with its concomitant increase in plasma FFA concentration results in a net increase in IMCL content in less active muscle. 


\section{Introduction}

During submaximal exercise, fat and carbohydrate form the main substrates for the exercising muscle. Stable isotope studies have shown that about $50 \%$ of total fat oxidation is accounted for by plasma free fatty acid (FFA) oxidation, suggesting that other fat sources play a substantial role in energy provision (1-3). Other fat sources include intramuscular lipid stores $(4,5)$, and lipoprotein derived triglycerides (6). Recent studies using ${ }^{1} \mathrm{H}$ magnetic resonance spectroscopy have shown that intramyocellular lipid (IMCL) content is decreased following prolonged endurance exercise in active muscle (5, 7-9). This suggests that IMCL oxidation contributes significantly to total energy expenditure. From the net depletion of IMCL content measured before and after a marathon run, Boesch et al. estimated that between 11 and $26 \%$ of the energy provided by fat oxidation had originated from IMCL breakdown (10).

As stated above, oxidation of IMCL and lipoprotein derived triglycerides contributes substantially to fat oxidation during exercise, however, the largest contribution is thought to come from plasma FFA. During prolonged endurance exercise, adipose tissue lipolysis is substantially increased to enable ample provision of plasma FFA to the working muscle. However, the release of FA by lipolysis exceeds the oxidation capacity of the working muscle, as it has been shown that only $70 \%-90 \%$ of the rate of disappearance of FFA is oxidized to $\mathrm{CO}_{2}$ $(1,11)$. The remaining part of FA taken up might be reesterified in adipose tissue, liver and exercising or non-exercising skeletal muscle. The contribution of adipose tissue is considered to be very small (12) and hepatic reesterification was estimated to account for $24 \%$ of total reesterification (12). Skeletal muscle has been shown to take up and reesterify FFA during exercise (12). Muscle contraction strongly increases the percentage of plasma FFA that is routed towards oxidation, leading to a net decrease in muscle triglyceride during exercise. In non-contracting muscle, however, the abundance of FFA during exercise could lead to an increase in muscle triglycerides.

Under resting conditions, skeletal muscle is capable of clearing FFA from plasma and elevated plasma FFA concentrations lead to a net accumulation of IMCL. Infusions of triglyceride/heparin, (13), 72 hours of fasting (14), as well as three days of high fat diet all lead to elevated plasma FFA levels and an increased IMCL content. Therefore, it is generally thought that during resting conditions elevated plasma FFA concentrations stimulate reesterification of FA in skeletal muscle. However, during exercise, lipolysis is stimulated in adipose tissue as well as in skeletal muscle. Though prolonged moderate to high intensity exercise leads to a net decrease in IMCL content in contracting muscle, it could be speculated that, similar to the observations at rest, IMCL content is increased in noncontracting muscle.

In the present study, we measured IMCL content in both exercising leg muscle and non-exercising arm muscle before and after a 3 h cycling protocol. If 
axidation rate outweighs the rate of reesterification in contracting muscle, wre would expect IMCL content in the exercising leg muscle to decrease. Analogously, if reesterification rate exceeds EFA oxidation rate in noncontracting muscle, a net increase in $\mathbb{M} M C L$ content in the non-exercising arm muscle should be observed.

\section{Materials and Methods}

\section{Subjects}

Eight young (age (y): $24 \pm 3$ ) (mean \pm stdev), highly trained (W/max $/ \mathrm{kg}$ : $5.8 \pm 0.46$ ) (mean \pm stdev), male cyclists participated in this study. The study was approved by the institutional Medical Ethics Committee. Subjects gave their written informed consent after the nature of the procedure and possible risks were explained.

\section{Experimental protocal}

Prior to the test days, subjects received a standardization diet $(13 \% \pm 1 \%$ of energy as protein, $56 \% \pm 3 \%$ as carbohydrate and $30 \% \pm 1 \%$ as fat (mean \pm stdev)) for three days during which they refrained from exercise. On the test day, subjects reported to the laboratory in the early afternoon. A baseline 'H-MRS scan was performed to quantify IMCL content in the vastus lateralis and the biceps brachii muscle. Subsequently, a blood sample was collected $(7 \mathrm{ml})$. Then a $3 \mathrm{~h}$ cycling protocol was performed. After 5 minutes of warming-up at $100 \mathrm{~W}$, subjects cycled for three hours at $55 \%$ of their maximal energy output (Wmax) which averaged $231 \pm 19 \mathrm{~W}$ (mean \pm stdev), During the exercise trial, oxygen uptake $\left(\mathrm{VO}_{2}\right)$ and carbon dioxide production ( $\mathrm{VCO}_{2}$ ) were measured every 30 min continuously over $10 \mathrm{~min}$ intervals (Oxycon- $\beta$, Mijnhardt, Mannheim, Germany). From respiratory measurements, total fat and carbohydrate oxidation rates were calculated using the non-protein respiratory quotient as given below (15).

$$
\begin{aligned}
& \text { Fat oxidation rate }=1.695 \mathrm{VO}_{2}-1.701 \mathrm{VCO}_{2} \\
& \text { Carbohydrate oxidation rate }=4.585 \mathrm{VCO}_{2}-3.226 \mathrm{VO}_{2}
\end{aligned}
$$

with $\mathrm{VO}_{2}$ and $\mathrm{VCO}_{2}$ in $1 \mathrm{~min}^{-1}$ and oxidation rates in $\mathrm{gmin}^{-1}$.

Subjects were allowed to drink water ad libitum during cycling. After cessation of exercise, subjects were allowed a quick shower ( $\max 5$ minutes) after which a second blood sample was taken. Immediately after this, a second MRS measurement was performed to quantify IMCL content in the leg and subsequently in the arm muscle.

\section{Procedures}

\section{MRS measurement}

Image guided localized single voxel 'H-MRS was performed in the vastus lateralis and the biceps brachii muscle before and immediately after the $3 \mathrm{~h}$ cycling test. The measurements were performed on a $1.5 \mathrm{~T}$ whole body scanner (Intera, 
Philips Medical Systems, Best, the Netherlands) with a flexible surface coil wrapped around the upper leg, respectively arm, with the extremity placed in the parallel position with the $\mathrm{B}$ o magnetic field.

In every subject, voxels were carefully placed at the same position for repeated measurements. Care was taken to avoid vascular structures and adipose tissue deposits within the voxel. To reproduce the same voxel position, the longitudinal distance of the voxel from the intercondylar eminence of the knee joint respectively from the elbow was determined in a coronal image. $T_{2}$ weighted turbo spin-echo (TSE) MR images consisting of 5 transversal slices were acquired at this position (slice thickness $5 \mathrm{~mm}$, TR/TE $2000 / 85 \mathrm{~ms}$, echo train length 12 , field-of-view $210 \mathrm{~mm}$ and matrix size $256 \times 256$ ). The patterns of the fat distribution were used to verify the longitudinal position and as landmarks to reproduce the voxel position in the transversal plane.

${ }^{1} \mathrm{H}-\mathrm{MRS}$ spectra from the regions of interest were acquired using a point-resolved spectroscopy (PRESS) sequence with the following acquisition parameters: TR/TE 3000/25 ms, 16 phase cycles, 128 averages, 1024 data points over $1000 \mathrm{~Hz}$ spectral width. The voxel volume was $(12 \times 11 \times 18) \mathrm{mm}^{3}$. The water signal was suppressed using Chemically Selective Saturation (CHESS). The unsuppressed water signal was subsequently measured in the same voxel under the same shimming conditions and was used as a reference signal.

\section{Post-processing}

The spectra were fitted in the time domain using a nonlinear least-squares algorithm (AMARES (16)) in the jmrui software package (17) (http://www.mrui.uab.es/mrui/). Three peaks were fitted for IMCL (I1, I2 and I3 in Figure 7.1A and 7.1B) and three peaks for extramyocellular lipids (EMCL) (E1, E2 and E3 in Figure 7.1A and 7.1B). Prior knowledge of the relative peak positions (5) and area ratios (private communication) as determined by Boesch et al. was used as a constraint. In order to increase the accuracy and reliability of the fitting procedure in the vastus lateralis muscle, the line width of the $\mathrm{CH}_{2}$ pealk of IMCL (I2 in Figure 7.1A) was fixed relative to the line width of the unsuppressed water peak (measured in the same voxel) and soft constraints were used on the line width and the position of the EMCL peak. In the biceps brachii muscle, these additional constraints were unnecessary. IMCL and EMCL peaks were fitted with a gaussian curve, while water peaks were fitted with a lorenztian curve. The signals were corrected for $\mathrm{T} 1$ and $\mathrm{T} 2$ relaxation using the $\mathrm{T} 1$ and $\mathrm{T} 2$ relaxation times as determined by Schick et al. (18). The corrected area of the $\mathrm{CH}_{2}$ peak of IMCL was expressed relative to the area of the water peak. 


\section{Analysis}

\section{Blood analyses}

Samples of venous blood $(7 \mathrm{~mL})$ were obtained in EDTA-coated tubes and immediately centrifuged at high speed $\left(1000 \mathrm{~g}, 4^{\circ} \mathrm{C}\right)$ for $10 \mathrm{~min}$. Plasma was immediately frozen in liquid nitrogen and stored at $-80^{\circ} \mathrm{C}$ until analyses for FFA (Wako NEFA test kid, Wako chemicals, Neuss, Germany), free glycerol. (148270, Roche Diagnostics, Indianapolis, IN, USA) and triacylglycerol (GPO-trinder 337B, Sigma Diagnostics, St.Louis, MO, USA) on a COBAS FARA semi-automatic analyzer (Roche, Basel, Switzerland).

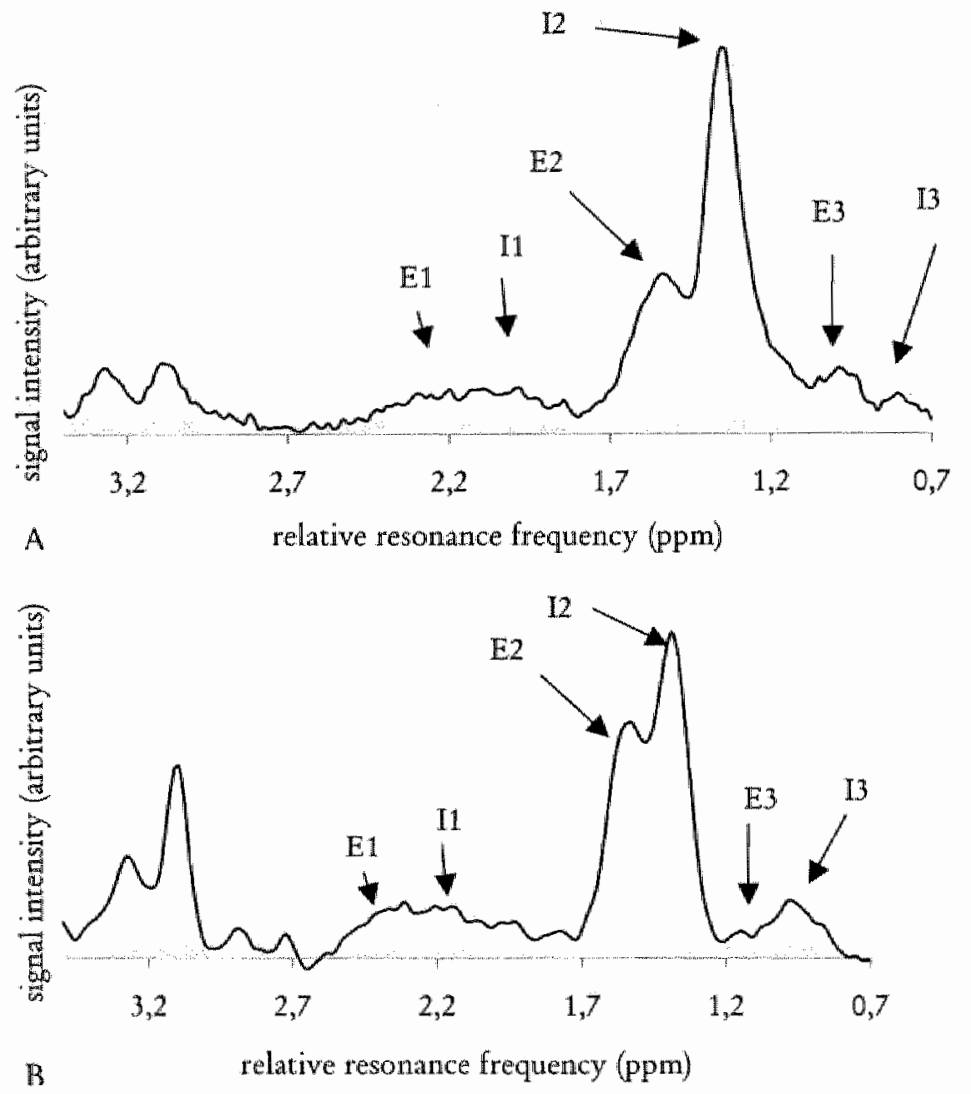

Fugure 7.1: Typical spectra of the vastus lateralis muscle $(A)$ and of the biceps brachii muscle (B). EMCL peaks are depicted as E1-E3, IMCL peaks are depicted as I1-13.

\section{Statistics}

Characteristics of subjects and diet composition are reported as mean \pm standard deviation (stdev), whille results are reported as mean \pm standard error of the mean (SEM). Statistical analyses were performed with SPSS for Windows 10.0.0 software (SPSS Inc., Chicago, Illinois, USA). Differences in values before and 
after exercise were detected with a paired t-test. Results were considered significant if $\mathrm{P}<0.05$.

\section{Results}

\section{Substrate oxidation}

Whole body fat oxidation increased continuously during the three-hour cycling protocol while carbohydrate oxidation decreased (see Figure 7.2). Subjects oxidized on average $91 \pm 4 \mathrm{~g}$ of fat and $494 \pm 17 \mathrm{~g}$ of carbohydrate during the exercise protocol. The total energy expenditure amounted to $11.7 \pm 0.2 \mathrm{MJ}$. The relative contribution of fat oxidation to the total energy expenditure was $32 \pm$ $1 \%$, while the relative contribution of carbohydrates was $68 \pm 1 \%$.

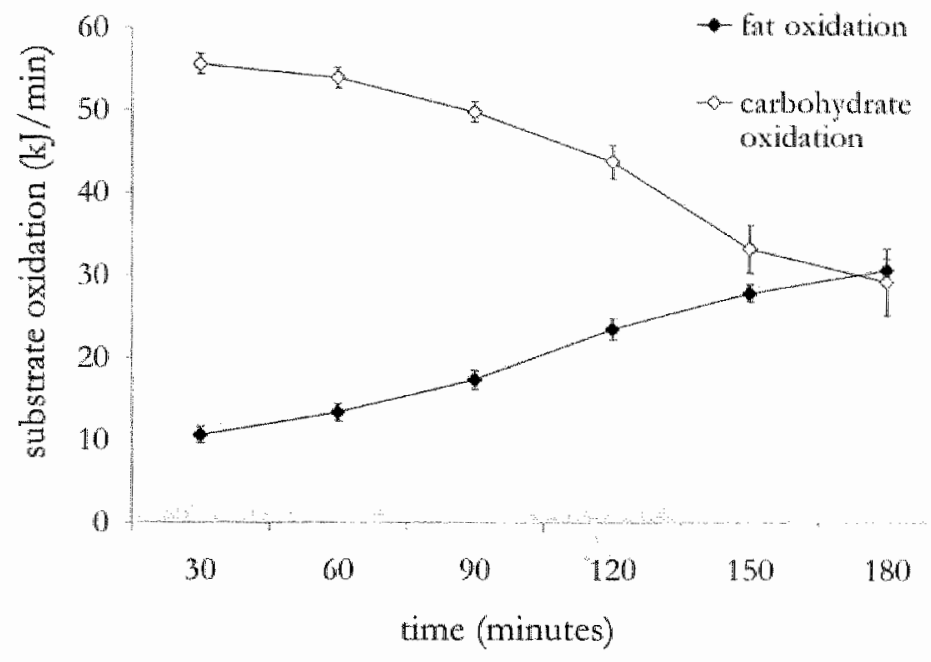

Figure 7.2: Average fat- and carbohydrate oxidation during the $3 \mathrm{~h}$ cycling protocol. Filled symbols and solid line: fat oxidation, open symbols and dashed line: carbohydrate oxidation.

\section{Blood parameters}

Plasma FFA concentrations increased during exercise $(85 \pm 6 \mu \mathrm{M}$ and $1450 \pm 55$ $\mu \mathrm{M}$ before vs. after exercise respectively, $\mathrm{p}<0.001$ ). Glycerol concentrations also increased $(57 \pm 11 \mu \mathrm{M}$ and $474 \pm 54 \mu \mathrm{M}$ before and after exercise respectively, $\mathrm{p}<0.001)$, while triacylglycerol concentrations decreased during exercise $(1498 \pm$ $139 \mu \mathrm{M}$ and $703 \pm 57 \mu \mathrm{M}$ before and after exercise respectively, $\mathrm{p}<0.001$ ).

\section{IMCL and EMCL content}

Baseline IMCL content was four times higher in the vastus lateralis muscle compared to the biceps brachii muscle $(p<0.001)$. IMCL content at baseline was $0.61 \% \pm 0.05 \%$ of the water resonance in the vastus lateralis muscle and decreased by $20.4 \% \pm 2.8 \%(\mathrm{p}<0.001$, see Figure $7.3 \mathrm{~A})$. The EMCL content did 
not change significantly $(0.39 \% \pm 0.06 \%$ before versus $0.36 \% \pm 0.06 \%$ after exercise, $\mathrm{p}=0.3$ ). In the non-exercising biceps brachii muscle, $\mathrm{IMCL}$ content at baseline was $0.14 \% \pm 0.02 \%$ of the water resonance and increased following exercise by $37.9 \% \pm 9.7 \%$ ( $<<0.01$, see Figure $7.3 \mathrm{~B})$. The EMCL content did not change significantly $(0.15 \% \pm 0.03 \%$ before versus $0.15 \% \pm 0.01 \%$ after exercise; $\mathrm{p}=1.0$ ).
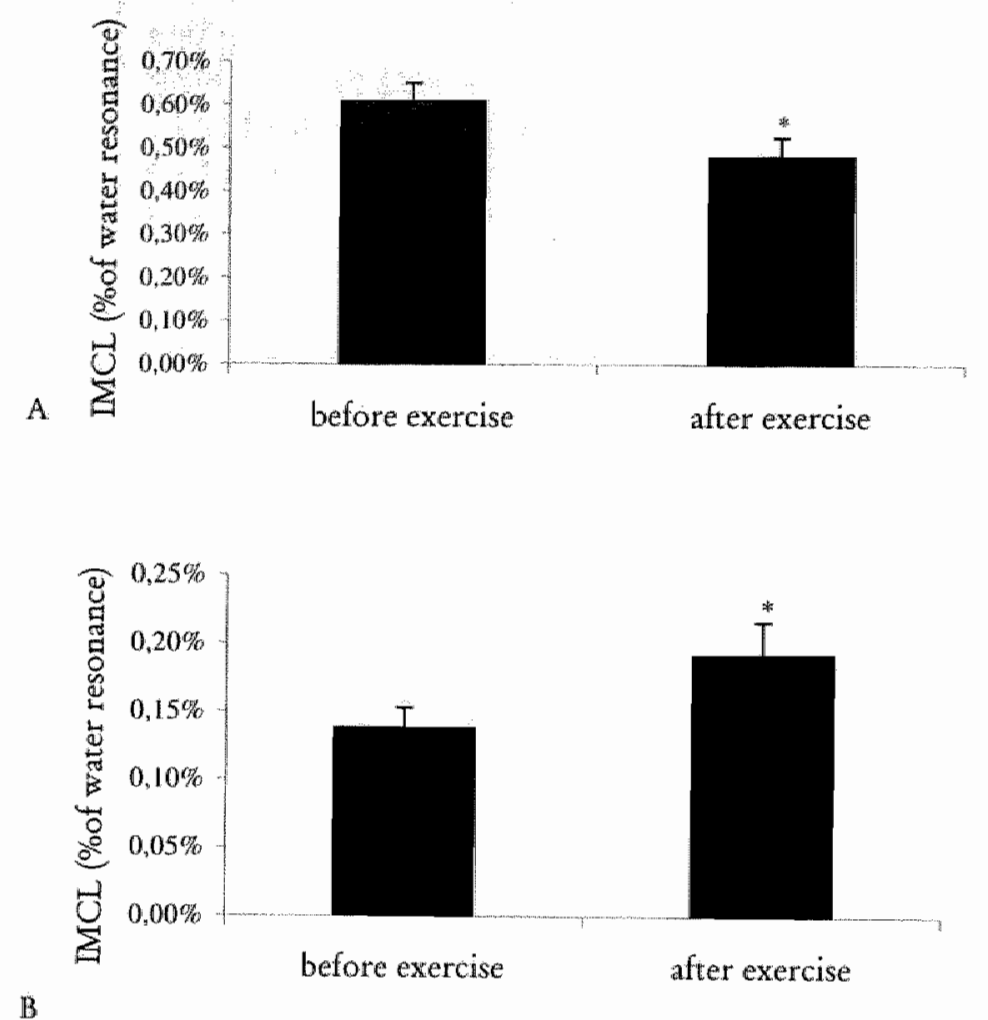

Figure 7.3: IMCL content in the wastus lateralis muscle (A) and in the biceps brachii muscle (B) before and after the 3 h cycling protocol $(\mathrm{n}=8)$. Content is expressed as percentage of the $\mathrm{CH} 2$ peak of $\mathbb{I M C L}$ relative to the water signal. * = significant differences between values. before and after exercise $(P<0.05)$

If values are converted to values in mmol $/ \mathrm{kg}$ muscle wet weight as described by Boesch et al., (10) IMCL content is $7.8 \pm 0.4 \mathrm{mmol} / \mathrm{kg}$ and $6.2 \pm 0.5 \mathrm{mmol} / \mathrm{kg}$ in the vastus lateralis muscle before and after exercise, respectively and $1.8 \pm 0.2 \mathrm{mmol} / \mathrm{kg}$ and $2.5 \pm 0.3 \mathrm{mmol} / \mathrm{kg}$ in the biceps brachii muscle before and after exercise, respectively. 


\section{Discussion}

The most important finding of the present study is that IMCL content in the less active muscle of the arm increased during prolonged submaximal cycling exercise while we confirm earlier reports of decreasing IMCL content in the working leg muscle $(5,7,8,19)$. We suggest that from the increased plasma FFA levels and subsequent increase in FFA uptake during exercise, a large portion of FA is routed towards oxidation in contracting muscle whereas in non-contracting muscle, plasma FFA uptake leads to a net accumulation of IMCL. This is in line with results from stable isotope studies from Sacchetti et al, who describes a net uptake and partial resynthesis of FFA by non-exercising leg muscle during onelegged exercise (20).

Others have reported that elevated FFA plasma concentrations increase uptake under resting conditions. Boden et al. reported that an increase in FFA (due to lipid/heparin infusions) during three hours resulted in an increased IMCL. content in the $m$. solews with the increase in IMCL content correlating with the FFA plasma concentrations (13). In addition, Stannard et al. observed that the increase in FFA concentration during 72 hours of fasting was accompanied by elevated IMCL content (14). Similarly, in the present study, FFA levels increased during exercise and the IMCL content in the biceps brachii muscle was elevated after exercise. These results suggest, that also in a physiological situation such as during exercise, relatively short term elevated FFA concentrations lead to accumulation of IMCL in non-exercising muscle thereby contributing to the clearance of FFA from plasma. As FFA are generally thought to be toxic at higher concentrations, it is important that plasma FFA concentrations are controlled. Inactive skeletal muscle seems to contribute to this control by acting as a buffer for FFA.

In contrast to the biochemical quantification of lipids in biopsy studies, the MRS technique enables us to differentiate lipid signals from two compartments, namely intramyocellular lipid droplets (IMCL) and adipose tisstie between muscle cells (EMCL) $(5,18)$. However, possible limitations of the technique should be considered. If the peaks are not clearly separated, the IMCL signal could be contaminated by the neighboring EMCL signal. In the current study, the EMCL and IMCL peaks are separated by $0.17 \mathrm{ppm}$ on average, which is typical for the vastus lateralis muscle (21), and which is sufficient for the quantification of the two peaks. Furthermore, the EMCL/TMCL ratio in the population of the highly trained athletes of the current study is relatively low, and therefore, contamination of the IMCL by the EMCL signal is expected to be relatively low as well.

Lactate, which accumulates in muscle at high intensity exercise, resonates in the same frequency range as the lipid signals and could in principle contaminate the lipid signals. Therefore, we estimated the possible contribution of residual lactate to the lipid signals. The estimation is based on a $r_{1 / 2}$ of lactate disappearance of 
10.6 minutes (22) the delay of 30 minutes between the end of the cycling exercise and the actual spectroscopic measurement and a lactate concentration of 11.6 to $15.6 \mathrm{mmol} / \mathrm{kg}$ dry weight immediately after exercise (1). From these calculations we conclude that the contribution of lactate to the lipid signals is less than $0.5 \%$ in the present study.

Care should be taken when using the water signal as concentration reference because water-and electrolyte shifts during exercise are possible. An alternative would be to use total creatine as a reference. When using total crearine instead of water as internal standard in the current study, similar results were obtained. We chose to use the water peak as internal reference, because the use of the small peak of total creatine introduced some additional variability so that the average coefficient of variation of repeated measurements increased from an average of $6 \%$ with water to $11.5 \%$ with total creatine as a reference (19). Since no trends in water signal were found before versus after exercise, we concluded that it is justified to use the water signal as internal standard in the present study.

We report considerably lower values of IMCL content in the biceps brachii muscle, compared with the IMCL content in the vastus lateralis muscle. This agrees with the finding by Boesch et al. that IMCL content is highly variable between muscle groups (10) and is in line with findings by Ward et al, who also report lower IMCL content in forearm muscle compared to leg muscle (23).

The EMCL content did not change significantly with exercise neither in the arm nor in the leg muscle. However, EMCL data should be interpreted with care as EMCL content generally shows a high spatial variation (5). Small changes in voxel position can have a high impact on the EMCL signal intensity. Furthermore, the ratio of EMCL/IMCL content in the leg of highly trained athletes of the current study is relatively low. Therefore, contamination of the EMCL signal by the IMCL signal is possible.

From the finding that IMCL content is increased during exercise in nonexercising muscle, the question arises whether FFA could also be reesterified in exercising muscle. This might not result in a net increase in IMCL, because of the continwous oxidation of IMCL during contraction. However, the simultaneous reesterification and even stronger hydrolysis of triglycerides could result in a turnover of IMCL with a net decrease in IMCL content in exercising muscle. The turnover is not quantifiable by 'H-MRS because only IMCL content, but not flux is measured with this method. Using stable isotopes, Sacchetti et al reported that FFA are reesterified in both, contracting and non-contracting muscle during one legged exercise (20). However, the rate of esterification was about four times higher in the non-contracting leg compared to the contracting leg. Although significant esterification took place also in the active leg, intramuscular lipid content was decreased by 30\% after exercise. Because reesterification has been shown to take place also in contracting muscle, the depletion data of the leg in the current study represent net changes and cannot be directly interpreted as fat oxidation. However, the data can be interpreted as a 
minimal estimate of MCL oxidation. In the study of Sacchetti et al, no net increase in muscle triglyceride was found in the non-contracting leg muscle (20). This discrepancy with the current study could be due to a different exercise protocol used and different muscles investigated.

In conclusion, we report the capacity of non-contracting muscle to take up and reesterify FFA during physiologically elevated plasma FFA. During exercise, when peripheral lipolysis is stimulated to increase plasma FFA availability and substrate oxidation, a net accumulation of IMCL occurs in non-exercising muscle.

\section{Acknowledgements}

We gratefully acknowledge the enthusiastic support of the subjects who volunteered to participate in these trials. Dr van Loon was supported with an individual fellowship from the Netherlands Organization for Scientific Research (NWO). 


\section{References}

1. wan Loon LJ, Grenhaff PL, Constantin-Teodosiu D, Saris WH, Wagenmakers AJ. The effects of increasing exercise intensity on muscle fuel utilisation in humans. J Pbysiol. 2001; $536: 295-304$.

2. Martin WH, 3rd, Dalsky GP, Hurley BF, Mathews DE, Bier DM, Hagberg JM, Rogers MA, King DS, Holloszy JO. Effect of endurance training on plasma free fatty acid turnover and oxidation during exercise. Am / Pbysiol. 1993; 265: E708-14.

3. Romijn JA, Coyle EF, Sidossis LS, Gastaldelli A, Horowitz JF, Endert E, Wolfe RR. Regulation of endogenous fat and carbohydrate metabolism in relation to exercise intensity and duration. Am f Pbysiol. 1993; 265: E380-91.

4. Hoppeler $\mathrm{H}$, Howald $\mathrm{H}$, Conley $\mathrm{K}$, Lindstedt SL, Claassen $\mathrm{H}$, Vock P, Weibel ER Endurance training in humans: aerobic capacity and structure of skeletal muscle. I Appl Pbysiol. 1985; 59: 32007 .

5. Boesch $\mathrm{C}$, Slotboom J, Hoppeler H, Kreis R. In vivo determination of intra-myocellular lipids in human muscle by means of localized 1H-MR-spectroscopy. Magn Reson Med. 1997; 37: 484-93.

6. Oscai LB, Essig DA, Palmer WK. Lipase regulation of muscle triglyceride hydrolysis. J Appt Pbysiol. 1990; 69: 1571-7.

7. Krsak M, Petersen KF, Bergeron R, Price 'T, Laurent D, Rothman DL, Roden M, Shulman GI. Intramuscular glycogen and intramyocellular lipid utilization during prolonged exercise and recovery in man: a $13 \mathrm{C}$ and $1 \mathrm{H}$ nuclear magnetic resonance spectroscopy study. $J \mathrm{Clim}$ Endocrinal Metab, 2000; 85: 748-54.

8. Rico-Sanz J, Moosavi M, Thomas EL, McCarthy J, Courts GA, Saeed N, Bell JD. In vivo evaluation of the effects of continuous exercise on skeletal muscle triglycerides in trained humans. Lipids. 2000; 35: 1313-8.

9. Schrauwen-Hinderling VB, van Loon LJ, Koopman $\mathbb{R}$, Nicolay $\mathbb{K}$, Saris WH, Kooi ME. Intramyocellular lipid content is increased after exercise in nonexercising human skeletal muscle. J Appl Pbysiol. 2003; $95: 2328-32$.

10. Boesch $\mathrm{C}$, Decombaz $\mathrm{J}$, Slotboom J, Kreis R. Observation of intramyocellular lipids by means of $1 \mathrm{H}$ magnetic resonance spectroscopy. Proc Nutr Soc. 1999; 58: 841-50.

11. van Hall $G$, Sacchetri $M$, Radegran $G$, Saltin B. Human skeletal muscle fatty acid and glycerol metabolism during rest, exercise and recovery. I Pbysiol. 2002; 543: 1047.7-58.

12. Van Hall G, Bulow J, Sacchetti M, Al Mulla N, Lyngso D, Simonsen L. Regional fat metabolism in human splanchnic and adipose tissues; the effect of exercise. / Physiol. 2002; 543: 1033446.

13. Bodlen G, Lebed B, Schatz M, Homko C, Lemieux S. Effects of acute changes of plasma free fatty acids on intramyocellular fat content and insulin resistance in healthy subjects. Diabetes. 2001; 50: 16127.

14. Stannard SR, Thompson MW, Fairbairn K, Huard B, Sachinwalla T, Thompson CH. Fasting for $72 \mathrm{~h}$ increases intramyocellular lipid content in nondiabetic, physically fit men. Am J Pbystol Endocrinol Metab. 2002; 283: E1185-E1191.

15. Peronnet F, Massicote D. Table of nonprotein respiratory quotient: an update. Can J Sport Sci. 1991; 16: 23-9.

16. Vanhamme $L$, van den Boogaart $A_{3}$ Van Huffel $S$. Improved method for accurate and efficient quantification of MRS data with use of prior knowledge. J Magn Resom. 1997; 129: 35-43.

17. Naressi $A$, Couturier $C$, Devos JM, Janssen $M$, Mangeat $C$, de Beer $\mathbb{R}$, Graveron-Demilly D. Java-based graphical user interface for the MRUI quantitation package. Magma. 2001; 1.2: $141-52$.

18. Schick F, Eismann B, Jung WI, Bongers $H$, Bunse $M$, Lutz $O$. Comparison of localized proton NMR signals of skeletal muscle and fat tissue in vivo: two lipid comparments in muscle tissue. Magn Reron Med. 1993; 29: 158-67. 
19. Schrauwen-Hinderling VB, Schraumen P, Hesselink MK, wan Engelshoven $\mathrm{MM}_{*}$ Nicolay $\mathrm{K}$, Saris $\mathrm{WH}_{3}$ Kessels $\mathrm{AG}$, Kooi ME. The increase in intramyocellular lipid content is a wery early response to training. J Clin Endocrinol Metal, 2003, 88, 1610-6.

20. Sacchetri $M$, Saltin $B$, Osada $T$, wan Hall $G$. Intramuscular farty acd nnetabolism in contracting and non-contracting human skeletal muscle. J Plyysiol. 2002; 540,38795.

21. Kooi ME, Schrauwen P, Mensink M, Wagenmakers AJM, Kemerink G], Goossens $G$, Hinderling $\mathrm{V}$, van Loon L, Blak EE. IH MRS of the intra-nyocellular lipid content in the m. vastus lateralis. Abstract book. ISMRM, 2001; Glasgow:

22. Pan JW, Hamm JR, Hetherington HP, Rothman DL, Shulman RG. Correlation of lactate and $\mathrm{pH}$ in human skeletal muscle after exercise by 1 H NMR. Magn Reson Med. 1991; 20.57 65.

23. Ward JA, Enright A, Thompson CH. In vivo assessment of intramyocellular lipid stores in the flexor digitorum superficiallis. Magma. 2001; 14:61-212, Abstract. 


\section{CHAPTER}

INTRAMYOCELLULAR LIPID CONTENT AND IN VIVO MITOCHONDRIAL FUNCTION OF PATIENTS WITH TYPE 2 DIABETES MELLITUS AND BMI MATCHED CONTROLS

V.B. Schrauwen-Hinderling, M. Mensink, M.K.C. Hesselink, J.A.L. Jeneson, W.H. Backes, C.J.A. van Echteld, J.M.A. van Engelshoven, P. Schrauwen, and M.E. Kooi

Submitted 


\section{Abstract}

A decreased oxidative capacity due to mitochondrial dysfunction may lead to accumulation of intramyocellular lipids (IMCL) and lipid metabolites in skeletal muscle. The accumulation of lipid metabolites has been suggested to contribute to the development of insulin resistance, which is a cardinal fearure in the pathogenesis of type 2 diabetes mellitus (T2DM).

The aim was to investigate whether mitochondrial function is decreased and $\mathrm{MMCL}$ content is increased in T2DM patients compared to control subjects.

Nine patients with T2DM and nine BMI matched normoglycemic controls were investigated (age (y): $62.3 \pm 4.6$ and $56.1 \pm 6.8$; BMI $\left(\mathrm{kg} / \mathrm{m}^{2}\right): 28.8 \pm 3.2$ and $29.3 \pm 2.7$; VOmax $\left(\mathrm{ml}^{*} \mathrm{~min}^{-1 *} \mathrm{~kg}^{-1}\right): 28.8 \pm 3.2$ and $29.3 \pm 2.7$ in T2DM and controls, respectively (mean \pm stdev)). Mitochondrial function was determined by 31-phosphorous magnetic resonance spectroscopy ( $\mathrm{P}$-MRS), by measuring $\mathrm{PCr}$ recovery half-time immediately after exercise. IMCL content was determined by proton magnetic resonance spectroscopic imaging ( $\left.{ }^{1} \mathrm{H}-\mathrm{MRSI}\right)$ and insulin sensitivity was assessed with a hyperinsulinaemic euglycemic clamp.

The half time of $\mathrm{PCr}$ recovery was $40 \%$ longer in T2DM patients $(27.2 \pm 3.9 \mathrm{~s}$ versus $19.6 \pm 1.0 \mathrm{~s}$, (mean $\pm \mathrm{SEM}$ ), $\mathrm{p}<0.05$ ), while IMCL content was similar as in controls $(1.0 \pm 0.21 \%$ vs. $1.25 \pm 0.22 \%$ of the water resonance (mean \pm SEM), $\mathrm{p}=\mathrm{n}$.s.). Insullin sensitivity was $19 \%$, but nonsignificantly, lower in T2DM patients $(21.0 \pm 2.7$ and $26.0 \pm$

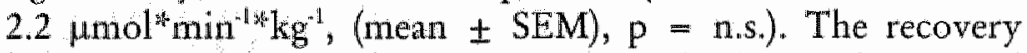
half time of $\mathrm{PCr}$ correlated positively with plasma glucose and $\mathrm{HbA1c}$ in diabetic patients and with $\mathrm{VO}_{2 \text { max }}$ in all subjects.

The finding that in vivo mitochondrial function is decreased in T2DM patients in combination with similar IMCL content as in controls, is in line with the suggestion that a high IMCL content is only linked with disease, if it is associated with a low mitochondrial function. The correlation of plasma glucose concentration as well as $\mathrm{HbA1c}$ with $\mathrm{PCr}$ recovery half-time reveals that the impairment of mitochondrial function is related to the degree of illness. Our results support the hypothesis that decreased mitochondrial function is a predisposition to develop type 2 diabetes mellitus. 


\section{Introduction}

As western lifestyle spread globally, type 2 diabetes mellitus (T2DM) has become an epidemic (1). Type 2 diabetes occurs when insulin production fails to compensate insulin resistance of peripheral tissues leading to hyperglycemia. Skeletal muscle is responsible for the major part of postprandial glucose uptake (2). Therefore, it is an important tissue with regard to glucose homeostasis and aberrations in skeletal muscle may contribute to the pathogenesis of type 2 diabetes mellitus. Indeed, an increased accumulation of triglycerides (intramyocellular lipids, IMCLs) $(3,4)$ and decreased levels of oxidative enzymes (4) in skeletal muscle have been reported in diabetic subjects. In addition, ultrastructural electron microscopy studies reveal that in skeletal muscle mitochondria of type 2 diabetic patients morphological aberrations are apparent (5). A decreased oxidative capacity due to mitochondrial dysfunction may lead to accumulation of triglycerides and its metabolites in skeletal muscle, which has been suggested to interfere with insulin signaling (6).

With Magnetic Resonance Spectroscopy (MRS) both, mitochondrial function and IMCL content can be measured non-invasively in the same muscle $(7,8)$. With this technique, a decreased mitochondrial function, and an increased IMCL content was found in healthy subjects at high risk of developing diabetes (insulin resistant offspring of T2DM patients). The finding that these aberrations were already present in healthy offspring of T2DM patients suggests that the decreased. mitochondrial function may be a primary risk factor for developing diabetes later in life. In these studies, mitochondrial function was measured by quantifying unidirectional rates of ATP synthesis in the resting muscle with the use of the saturation transfer method applied to the exchange between inorganic phosphate and ATP in the soleus muscle $(7,8)$. Here, we employ an alternative ${ }^{31} \mathrm{P}$-MRS method to investigate mitochondrial function immediately after exercise, under conditions of enhanced metabolic demand. Determination of both mitochondrial function and IMCL content was performed in the m. vastus lateralis. The present determination of mitochondrial function is based on the measurement of phosphocreatine (PCr) kinetics during recovery from exercise $(9,10)$. During the recovery period after exercise, the $\mathrm{PCr}$ resynthesis is driven almost purely oxidatively $(11,12)$ and therefore the half-time of $\mathrm{PCr}$ recovery is a parameter for oxidative capacity. A fast recovery reflects an excellent oxidative capacity while delayed recovery kinetics may indicate mitochondrial malfunctioning.

Additionally, IMCL content is quantified by proton magnetic resonance spectroscopic imaging ('H-MRSI). This approach, rather than single voxel ${ }^{1} \mathrm{H}-\mathrm{MRS}$, was chosen to overcome confounding of the IMCL signal by the signal of adipose tissue present between muscle bundles (extramyocellular lipid, EMCL). In the past, we used single voxel ${ }^{1} \mathrm{H}$-MRS to quantify IMCL in the vastus lateralis muscle and voxel positions were chosen to avoid adipose tissue 
deposits (13). However, in overweight subjects, the extensive marbling of the muscle by adipose tissue makes it difficult to position the relatively large voxel in a region that does not contain adipose tissue. With $\mathrm{H}$-MRSI, which has been used in the muscles of the lower leg in previous studies (14-16), signal from a matrix of e.g. $20 \times 20$ voxels can be acquired (17). With this technique, the voxels are considerably smaller and voxels with little EMCL contamination can be chosen retrospectively. An additional advantage of the ${ }^{1} \mathrm{H}$-MRST technique is that information regarding IMCL distribution over the muscle can be obtained. Fibre type distribution has been reported to be inhomogeneous throughout the vastus lateralis muscle with higher type 1 muscle fibre concentration in the deeper layers of the muscle (18). As IMCL content is higher in type 1 muscle fibres (19), we hypothesize that IMCL content in the deeper, more medial part of the vastus lateralis is higher than in the lateral part.

Although in vivo mitochondrial function has been investigated in combination with IMCL content in subjects at high risk for developing diabetes later in life, this has never been done in overt type 2 diabetes. Therefore, it is unknown whether in vivo mitochondrial function is indeed decreased in diabetic patients, neither it is known how it relates to IMCL content and insulin resistance. Thus, the main objective of the present study is to investigate whether a high IMCL content and a decreased in vivo mitochondrial function is more prominent in the vastus lateralis muscle of type 2 diabetes patients than in body weight-matched normoglycemic control subjects. Furthermore, the local measurement of mitochondrial function in skeletal muscle is compared to the classical wholebody measurement of oxidative capacity by breath gas analysis during cycling ergometry.

\section{Subjects and Metbods}

Nine male patients with T2DM (mean duration of diabetes $6.3 \pm 5.4$ years; all subjects were on oral anti-diabetic medication) and 9 male control subjects were investigated in the current study (see Table 8.1 for subjects' characteristics). The protocol was approved by the institutional Medical Ethics Committee, and every subject signed an informed consent after the procedures had been explained. Subjects were recruited by advertisements in local newspapers and on the university and hospital grounds.

\section{Experimental protocol}

Prior to the inclusion, all subjects underwent a medical examination including a medical history and a physical examination. Also an electrocardiogram (ECG) was registered, blood pressure was assessed and a fasting blood sample was taken to determine glucose and (in diabetic patients only) glycated haemoglobin ( $\mathrm{H}$ - $\mathrm{HA} 1 \mathrm{c})$ concentrations. Control subjects underwent a glucose tolerance test to ensure normal glucose tolerance. Two weeks prior to the experimental measurements, patients stopped with their anti-diabetic medication. 
Table 8.1: Characteristics of subjects given as mean \pm stdev.

\begin{tabular}{|c|c|c|c|}
\hline & Dilabetic patients & Control subjects & pwalue \\
\hline Age (years) & $62.3 \pm 4.6$ & $56.1 \pm 6.8$ & $p<0.05$ \\
\hline Fasting plasma glucose (mM) & $9.76 \pm 2.42$ & $5.73 \pm 0.37$ & $p<0.01$ \\
\hline $\mathrm{HbA1}(\%)$ & $7.3 \pm 1.0$ & & \\
\hline $\mathrm{BMI}\left(\mathrm{kg} / \mathrm{m}^{2}\right)$ & $28.8 \pm 3.2$ & $29.3 \pm 2.7$ & $n_{s} s_{1}$ \\
\hline VO2max/lkg $\left(\mathrm{ml}^{15} \mathrm{~min}^{-1 / 7} \mathrm{~kg}^{-1}\right)$ & $30.9 \pm 6.5$ & $34.6 \pm 4.8$ & n.s. \\
\hline
\end{tabular}

As part of the experiment, the following parameters were compared in type 2 diabetic patients and their BMI matched controls: maximal oxygen uptake, insulin sensitivity, $\mathbb{M C L}$ content and the half-time of $\mathrm{PC}$ recovery after exercise in the vastus lateralis muscle as well as muscular pH during exercise.

\section{Glucose tolerance test}

A standard oral glucose tolerance test (OGTT) according to WHO criteria was performed in control subjects. In short, after taking a fasting blood sample subjects received 75 gram of glucose dissolved in $250 \mathrm{ml}$ of water. Two hours after glucose ingestion another blood sample was drawn. Fasting plasma glucose below

$7.0 \mathrm{mmol} / \mathrm{L}$ and 2-hour glucose below $7.8 \mathrm{mmol} / \mathrm{L}$ was considered normal glucose tolerance.

\section{Maximal oxygen uptake (whole body oxidative capacity)}

A routine incremental cycling test was used to determine the maximal aerobic capacity as described earlier (20). After a warming-up period of five minutes, the intensity was increased every three minutes until exhaustion. Oxygen consumption was measured continuously throughout the test using indirect calorimetry (Oxycon Beta, Mijnhardt, The Netherlands) in order to determine maximal oxygen uptake (VOmax). VOmax was determined in all but three diabetic subjects.

\section{Insulin sensitivity}

Insulin sensitivity was measured with a 3-hour hyperinsulinaemic euglycemic clamp according to DeFronzo (21). The last three days before the clamp, subjects were asked to keep a constant eating pattern and to refrain from intense physical exercise. After an overnight fast, subjects were infused with insulin at a fixed rate $\left(40 \mathrm{mU} / \mathrm{m}^{2} / \mathrm{min}\right)$. Glucose was infused at a variable rate in order to maintain euglycemia $( \pm 5 \mathrm{mmol} / \mathrm{L}$ ). Insulin sensitivity was expressed as the glucose infusion rate during euglycemia (GIR; $\mu \mathrm{mol} / \mathrm{kg} / \mathrm{min})$. 
Determination of maximal capacity in MRS-compatible ergometer Maximal capacity of the knee-extension exercise was assessed with an incremental protocol in the MRS compatible exercise device. Subjects were asked to perform knee-extensions at $0.5 \mathrm{~Hz}$, increasing the weight to be lifted every 30 seconds by $500 \mathrm{~g}$. The weight at the beginning was $3 \mathrm{~kg}$ for patients and $5 \mathrm{~kg}$ for healthy subjects. The test was performed until exhaustion or until the frequency of $0.5 \mathrm{~Hz}$ could no longer be maintained.

\section{P-MRS}

The measurements were performed on a $1.5 \mathrm{~T}$ whole body scanner (Gyroscan, Philips Medical Systems, Best, the Netherlands). A $10 \mathrm{~cm}$ surface coil was used for localization and was fixed in the middle of the vastus lateralis muscle. MR images were acquired using the body coil to confirm the position of the coil and to determine the shimming volume. A spectrum with fully relaxed magnetization was acquired (TR $=20 \mathrm{sec}, 16$ measurements, spectral bandwidth $1500 \mathrm{~Hz}$, offset frequency $-100 \mathrm{~Hz}$, adiabatic pulse, 90 degree pulse angle, phase cycling 4), see Figure 8.1 for typical spectrum. Subsequently, a sertes of 180 partially saturated spectra was acquired (TR $=4$ seconds, 1 measurement, spectral bandwidth $1500 \mathrm{~Hz}$, offset frequency $-100 \mathrm{~Hz}$, adiabatic pulse adiabatic pulse, 90 degree pulse angle), see Figure 8.2 for typical spectrum. The 12 minutes acquisition time of the time-series was structured as follows: 2 minutes of rest, 5 minutes of knee-extension exercise and 5 minutes of recovery. The knee extension exercise was performed at $0.5 \mathrm{~Hz}$ to an auditory cue on a home-built MR compatible ergometer with a pulley system. The exercise was performed with a weight corresponding to $50 \%-60 \%$ of the predetermined maximal capacity. The maximal capacity was determined beforehand (on a different day) in an incremental maximal test with the same ergometer.

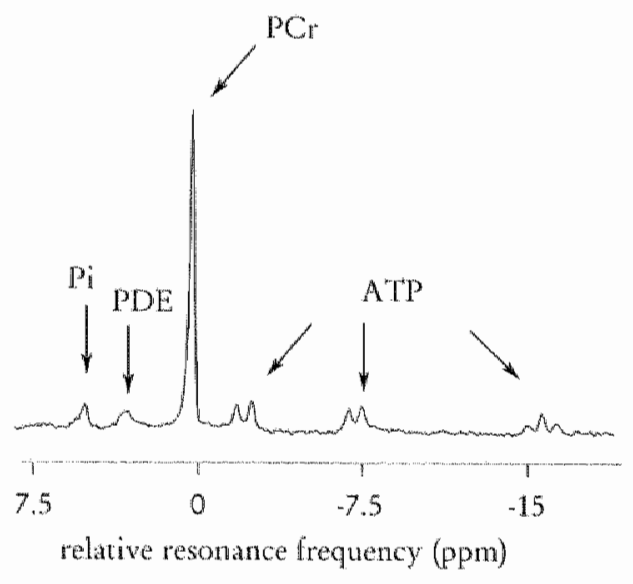

Figure 8.1: Typical, fully relaxed " spectrum of the vastus lateralis muscle at rest (post-processed with $5 \mathrm{~Hz}$ lorentzian line broadening). The arrows point out inorganic phosphate (Pi), phospho-diester (PDE), creatine phosphate (PCr), and adenosinetriphosphate (ATP). 


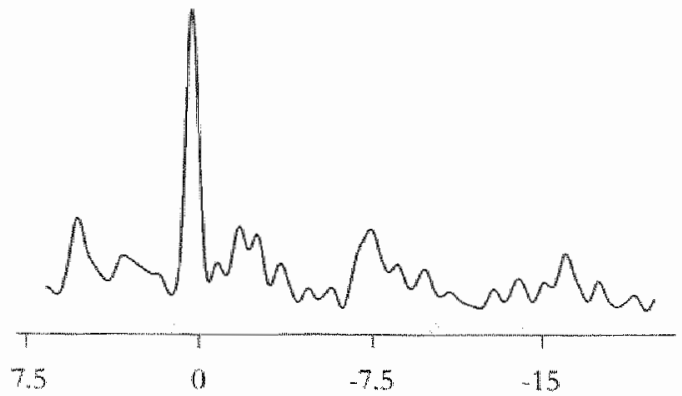

relative resonance troquency (ppm)
Figure 8.2: "Typical, partially saturated "p. MR spectrum of the vastus laterallis muscle during exercise with 4 seconds timeresolution (postprocessed with $30 \mathrm{~Hz}$ gaussian line broadening and $-15 \mathrm{~Hz}$ lorentzian line sharpening.

Post-processing ${ }^{31}$ P-MRS:

Peak fitting

All spectra were fitted in the time domain with the AMARES algorithm in the jMRUI software http:// www.mrui.uab.es) (22) using prior knowledge.

The fully relaxed spectra were manually phase-corrected, apodized $(5 \mathrm{~Hz}$ lorenzian line broadening) and the PCr peak was set to 0 ppm. Nine to ten peaks were fitted with lorentzian lines: The $\mathrm{Pi}$ and $\mathrm{PCr}$ peak and 7 peaks for the two doublets and the triplet of ATP and the phosphodiester (PDE) peak if present. The relative shift and amplitude ratios of the ATP multiplets were used as prior knowledge. The $\mathrm{Pi} / \mathrm{PCr}, \mathrm{PCr} / \mathrm{ATP}$, and $\mathrm{Pi} / \mathrm{ATP}$ ratios were calculated.

The partially saturated spectra of the time series were DC corrected, manually phased, apodized $(30 \mathrm{~Hz}$ Gaussian line broadening and $-15 \mathrm{~Hz}$ Lorentzian line sharpening) and 5 peaks were fitted with gaussian lines $(\mathrm{Pi}, \mathrm{PCr}$, and $3 \mathrm{ATP}$ peaks). Prior knowledge was applied to the relative amplitudes of the three ATP peaks, considering the different $\mathrm{T} 1$ relaxation times (23).

To determine the $\mathrm{pH}$ during the exercise period, five consecutive spectra of the time-series were added, resulting in better signal-noise ratio in order to be able to fit the small inorganic phosphate peak. After DC correction, manually phasing, and apodization ( $15 \mathrm{~Hz}$ Gaussian line broadening and $-7.5 \mathrm{~Hz}$ Lorentzian line sharpening), nine to ten peaks were fitted with lorentzian lines: The $\mathrm{Pi}, \mathrm{PCr}$ peaks and 7 peaks for the two doublets and the triplet of ATP and the phosphodiester (PDE) peak if present. Prior knowledge was applied to the relative amplitudes of the three ATP peaks, considering the different 'T1 relaxation times (23). The $\mathrm{pH}$ was calculated in $\mathrm{jMRUI}$ from the frequency shift between $\mathrm{PCr}$ and Pi peak ( $\left.\delta_{0}\right)$, according to:

$$
p H=6.75+{ }^{10} \log \left(\frac{3.27-\delta_{0}}{\delta_{0}-5.63}\right)
$$

Analysis of time-course of $\mathrm{PCr}$

Models assuming a mono-exponential time-course of $\mathrm{PCr}$ during recovery $(9,10)$ are generally employed to describe $\mathrm{PCr}$ kinetics during recovery after 
submaximal exercise when no substantial acidification occurs and the recovery half time ( $\mathrm{t} / 2)$ of the monomexponential time-course is often used as characteristic parameter, with a long $t / 2$ representing a decreased mitochondrial function.

The $\mathrm{PCr}$ amplitude was normalised to the baseline value (during the 2 minutes of rest) and plotted against the time. The time-course $(\operatorname{PCr}(t))$ during the last minute of exercise (steady state) and during the recovery period was fitted with the MATLAB software (The Mathworks. Inc.) using the LevenbergMarquardt algorithm to the formulas:

Before to: $\quad \operatorname{PCr}(t)=\operatorname{PCr}(t o)$

After to: $\quad P C r(t)=P C r(t 0)+D\left(1-e^{- \text {tht }}\right)$

With to $=$ end of exercise, $D=$ difference between steady state and $\mathrm{PCr}$ level after recovery, $\mathrm{PCr}(\mathrm{ta})=\mathrm{PCr}$ content in steady state, $\mathrm{k}=$ rate constant of $\mathrm{PCr}$ resynthesis. The following parameters were fitted by the program: to, $\mathrm{D}, \mathrm{PCr}(\mathrm{t} 0)$, k

The end point of exercise (to) was constrained to the interval between the time point at which subjects were instructed to stop and two seconds later. In those two seconds, subjects were able to react and return their leg to the resting position. From the fitted curve, the $t_{1 / 2}$ of the $\mathrm{PCr}$ recovery was determined according to $\mathrm{t}_{1 / 2}=\ln 2 / \mathrm{k}$ (see Figure 8.3 for typical example).

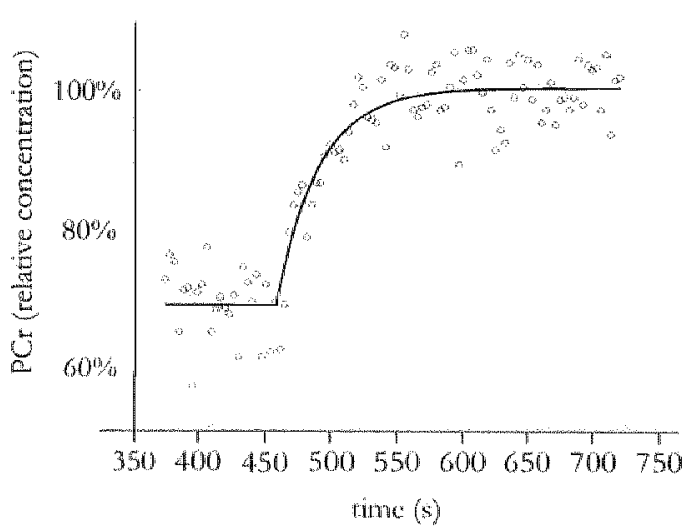

Figure 8.3: The figure shows a typical $\mathrm{PCr}$ recovery of an individual patient with the mono-exponential curve fitted to the data $(\mathrm{t} u / 2=24.9$ seconds).

\section{'H-MRSI:}

Image guided 'H-MR spectroscopic imaging was performed in the vastus lateralis muscle. The measurements were performed on a $1.5 \mathrm{~T}$ whole body scanner (Gyroscan, Philips Medical Systems, Best, the Netherlands) with a flexible surface coil wrapped around the upper leg. T2-weighted Fast Spin Echo (FSE) MR images consisting of 5 transversal slices were acquired at this position (slice thickness $5 \mathrm{~mm}, \mathrm{TR} / \mathrm{TE} 2000 / 85 \mathrm{~ms}$, echo train length 12, field-of-view (FOV) $210 \mathrm{~mm} \times 210 \mathrm{~mm}$ and matrix size $256 \times 256$ ). A PRESS box was placed to cover the whole vastus lateralis muscle and outer volume suppression was used to suppress the signal of subcutaneous adipose tissue and bone marrow. ${ }^{1} \mathrm{H}-\mathrm{MRSI}$ (matrix size: $20 \times 20$ ) was used with the following parameters: FOV $100 \mathrm{~mm} \mathrm{x}$ 
$100 \mathrm{~mm}$, slice thickness $18 \mathrm{~mm}$, no. of signal averages 2, TR/TE $1500 / 24 \mathrm{~ms}$, 1024 data points over $1000 \mathrm{~Hz}$ spectral width. The resulting nominal volume was $(5 \times 5 \times 18) \mathrm{mm}^{3}$. The water signal was suppressed using Chemically Selective Saturation (CHESS). The unsuppressed water signal was acquired in the same sequence with identical resolution and was used for Bo correction and as a reference signal. The scan time was 39 minutes (see Figure 8.4 for typical spectrum).

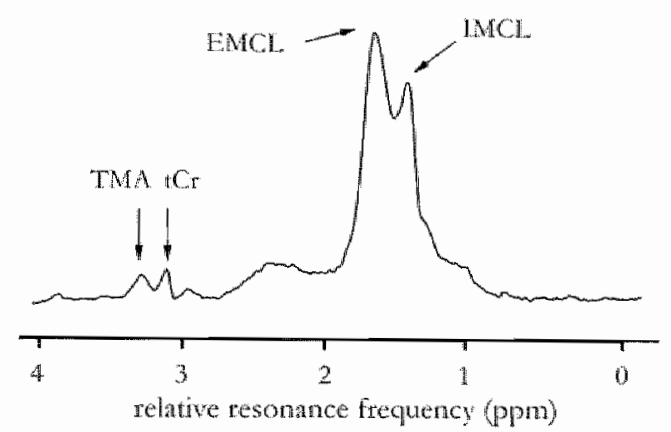

Figure 8.4: Typical 1 H-MR spectrum of the vastus lateralis (postprocessed with $1 \mathrm{~Hz}$ lorentzian line broadening). The arrows point out peaks of trimethylammonium componds (TMA), total creatine ( $\mathrm{tCr})$, the peak of the methylene protons of EMCL (EMCL) and the peals of the methylene protons of IMCL (MCL).

\section{Post-processing of ${ }^{\prime} H-M R S I$}

Two dimensional Fourier transformation was applied on the scanner to the water-suppressed- and the non-suppressed measurement, with applying spatial apodization (Hanning filter, 0.25 width) and a Digital Shift Accumulation (DSA) filter with an optimum frequency around $300 \mathrm{~Hz}$ to remove the residual water signal. Voxel positions inside the vastus lateralis muscle were identified on the T2 weighted images and the corresponding spectra were inspected in the SIview software (Institute of Biomedical Engineering (IBE), University and ETH Zuerich, Switzerland) and spectra with good to moderate separation of IMCL and EMCL were further processed. A home-written MATLAB script was used to extract the information of a single voxel from the file and to perform inverse Fourier transformation. The resulting signal of a single voxel in the time-domain was then read into jMRUI and fitted in the time domain using a nonlinear leastsquares algorithm (AMARES (24)) as previously described (13). Six peaks were fitted in total, namely three peaks for extramyocellular lipids (EMCL) and three peaks for IMCL. Prior knowledge (24) of the relative peak positions (25) and area ratios (private communication) as determined by Boesch et al. was used as a constraint. The line width of the $\mathrm{CH}_{2}$ peak of $\mathrm{IMCL}$ was fixed relative to the line width of the unsuppressed water peak (measured in the same voxel) in order to increase the accuracy and reliability of the fitting procedure. All other line widths were unconstrained. IMCL peaks and EMCL peaks were fitted with gaussian curves. The signals were corrected for $\mathrm{T} 1$ and $\mathrm{T} 2$ relaxation using the $\mathrm{T} 1$ and $\mathrm{T} 2$ relaxation times as determined by Schick et al. (26). The corrected 
area of the $\mathrm{CH}_{2}$ peak of IMCL was expressed relative to the corrected area of the water peak.

\section{Selection of spectra}

An experienced blinded spectroscopist, performed quality ratings on all the spectra using categories excellent, good, reasonable, moderate, and bad quality. The vastus lateralis was divided in three layers of the same volume: a medial, a middle and a laterall layer. Spectra from voxels in the middle layer of the vastus lateralis were used for comparison of the groups. The intrasubject coefficient of variation (CV) in the middle layer was $26.2 \pm 6.3 \%$ if all spectra in the categories reasonable, good and excellent were included and $14 \pm 3.5 \%$ if only the spectra with the ratings good and excellent were included. Therefore, only the categories good and excellent were included.

\section{Analysis}

\section{Blood analyses}

For determination of plasma glucose, blood was collected in tubes containing Sodium Fluoride (NaF). Plasma glucose was determined using the glucose oxidase method with the SYNCHRON LX System (Beckman Coulter Inc, Fullerton, CA, USA). Glycated haemoglobin was determined in a fasting plasma sample with high performance liquid chromatography (HPLC), using VARIANT II (BIO-RAD, Hercules, CA, USA) and reference values of $4.4-6.2 \%$.

\section{Statistics}

Characteristics of subjects are reported as mean \pm standard deviation, results are reported as mean \pm standard error of the mean (SEM). Statistical analyses were performed with SPSS for Windows 11.5 software (SPSS Inc., Chicago, Illinois, USA). Differences between groups were determined by unpaired student t-tests. T"wo-sided tests were used generally, except for $t_{1 / 2}$ and IMCL, because we tested the hypothesis that mitochondrial function was decreased, and IMCL content increased in type 2 diabetic patients. Intrasubject differences in IMCL content between the three muscle layers were determined by repeated measures ANOVA with Scheffe post-hoc test. To evaluate the relationship between variables, Pearson correlation coefficients were calculated when a linear relationship was expected ( $\mathrm{VO}_{2}$ max ws. $\mathrm{PCr}$ recovery half-time). Otherwise, Spearman correlation coefficients were calculated. Results were considered significant if $\mathrm{p}<0.05$.

\section{Results}

Subject characteristics

Subjects were carefully matched for BMI and were of similar age (see Table 8.1 for subjects characteristics). 


\section{Insulin sensitivity}

The mean glucose infusion rate (GIR) was $19 \%$ lower, but non-significantly in T2DM patients, compared to controls $\left(21.0 \pm 2.7\right.$ and $26.0 \pm 2.2 \mu \mathrm{mol}^{\mathrm{*t}} \mathrm{min}^{\mathrm{t}} \mathrm{kgg}^{\mathrm{th}}$, in T2DM patients and control subjects respectively, $\mathrm{p}=\mathrm{n} . \mathrm{s}$.).

\section{IMCL content}

On average, $37 \pm 2$ voxels fell inside the vastus lateralis muscle, from which $5 \pm 1$ voxels per subject were of good or excellent quality and therefore considered for analysis. Because most voxels were in the middle layer, this region was used for comparison of the two groups. The inter-voxel coefficient of variation (CV) inside the middle layer was considerably smaller $(14 \% \pm 3.5 \%)$ than over the whole muscle $(29 \% \pm 5 \%)$. The CV of neighbouring voxels was $10.5 \% \pm 1.2 \%$.

Only in 4 subjects (three controls and one patient), voxels of good to excellent quality were obtained in all three muscle layers. In these subjects, the IMCL content was significantly different between the three layers $(p=0.02)$, with a significant higher IMCL content in the medial layer compared to the lateral layer (see Figure 8.5).
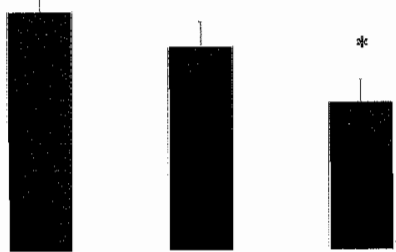

mediall layer middle layer lateral hayer
Figure 8.5: IMCL content of the three layers of the vastus lateralis muscle (medial, middle and lateral). IMCL content in the lateral layer is stignificantly lower than in the medial layer $(n=4)$.

The IMCL content in the middle layer was not different between the type 2 diabetic patients and control subjects $(1.00 \pm 0.21 \%$ of the water reference signal in T2DM patients vs. $1.25 \pm 0.22 \%$ in controls, $\mathrm{p}>0.05$ ). There was no correlation between IMCL content and insulin sensitivity (GIR) in neither group nor in the pooled data from diabetics and controls.

\section{In vivo mitochondrial function}

During the exercise protocol, the PCr concentration decreased and plateaued at a similar level in the two groups (at $73.1 \pm 2.5 \%$ and $71.7 \pm 2.9 \%$ of the baseline value for the diabetics and controls, respectively, $\mathrm{p}>0.05$ ). None of the subjects showed substantial acidification during the exercise protocol, with the $\mathrm{pH}$ decreasing to the same amount in both groups from $7.14 \pm 0.01$ to $7.10 \pm 0.01$ (delta $\mathrm{pH}=0.04, \mathrm{p}<0.05$ ). The end-exercise $\mathrm{pH}$ ranged from 7.05 to 7.14 .

The mean PCr recovery half-time was significantly longer in the T2DM group $(27.2 \pm 3.9 \mathrm{~s}$ versus $19.6 \pm 1.0 \mathrm{~s}$ in the diabetic group versus the control subjects, 
$\mathrm{p}=0.04$ see Figure 8.6$)$. The $\mathrm{PCr}$ recovery half-time correlated positively with HbAlc $(R=0.72, p=0.03)$ and fasting plasma glucose $(R=0.748, p=0.02$, see Figure 8.7) in T2DM patients but not in controls. There was a strong correlation between the half-time of $\mathrm{PCr}$ recovery and $\mathrm{VO}_{\max } / \mathrm{kg}(\mathrm{R}=0.71, \mathrm{p}=0.003$, see Figure 8.8).

No differences were observed between the groups in the $\mathrm{Pi} / \mathrm{PCr}(0.17 \pm 0.02$ and $0.15 \pm 0.01$ in T2DM vs. controls, $\mathrm{p}=0.29), \mathrm{PCr} / \mathrm{ATP}(3.93 \pm 0.47$ and $4.55 \pm 0.25$ in T2DM vs. controls, $\mathrm{p}=0.27)$ and $\mathrm{Pi} / \mathrm{ATP}$ ratios $(0.68 \pm 0.12$ and $0.66 \pm 0.04$ in T2DM vs. controls, $\mathrm{p}=0.87$ ) at rest before exercise.

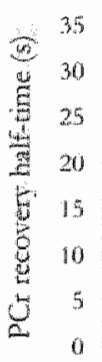

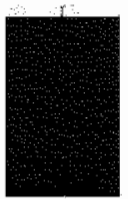

controls

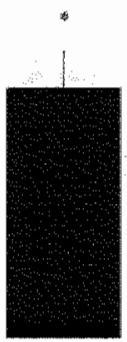

T2DiM
Figure 8.6: PCr recovery half-time was longer in "T2DM patients $(n=9)$ than in BMI-matched controls $(n=9)(p<0.05)$. * significamily different from the control group

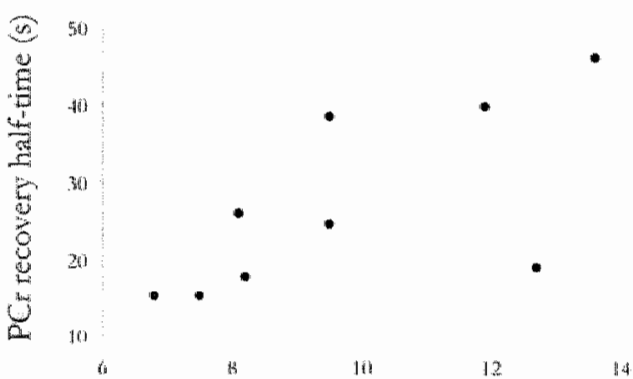

Fasting plasmaglucose (mmol)

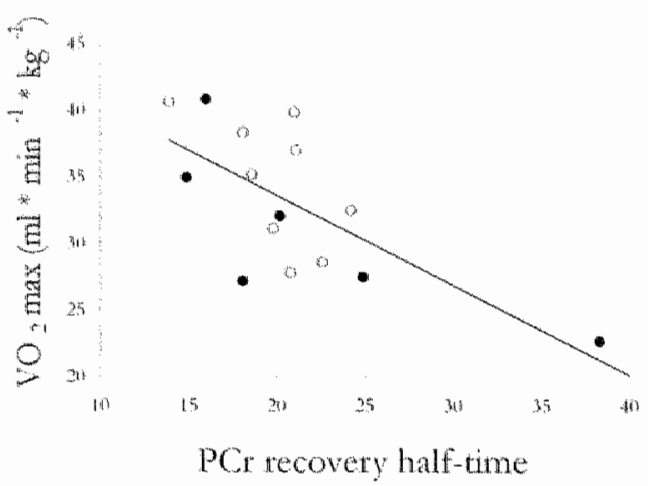

Figute 8.7: Plasma glucose concentration correlates with the half-time of PCr recovery in diabetes patients.

Figure 8.8: Correlation of skeletall muscle oxidative capacity as determined by "P. MRS in the vastus lateralis muscle and whole body maximal oxygen uptake as assessed by cycle ergometry. Filled circles represent diabetic patients, open circles represent control subjects. 


\section{Discussion}

A decreased mitochondrial function, and therefore a low oxidative capacity, has been implicated in the development of insulin resistance via the accumulation of IMCL and fat metabolites in skeletal muscle. Here, we determined skeletal muscle oxidative capacity by investigating $\mathrm{PCr}$ recovery kinetics and $\mathrm{IMCL}$ content in the vastus lateralis muscle in T2DM patients and BMI-matched controls. No difference in IMCL content was found, while the $\mathrm{PCr}$ recovery half-time was prolonged in diabetic patients, suggesting impaired mitochondrial function.

A decreased mitochondrial function has been reported in offspring of T2DM patients by Petersen et al. (7). In their studies, mitochondrial function was assessed by quantifying the unidirectional flux of inorganic phosphate to ATP by saturation transfer. The measurement was performed in the resting muscle, when only a fraction of the oxidative potential is used. Here, we used an alternative ${ }^{31}$ P-MRS method to investigate mitochondrial function under a condition in which oxidative metabolism is stimulated by moderate intensity exercise. In line with the data from Petersen et al., (7) we report a longer $\mathrm{PCr}$ recovery half time, suggesting a reduced mitochondrial function, in diabetic patients. These data fit well with the hypothesis that mitochondrial function is an important player in the development of type 2 diabetes mellitus. The correlation of plasma glucose concentrations as well as the long term marker for glycemic control HbAlc with PCr recovery half times suggests that the impairment in oxidative capacity is related to the degree of illness, underscoring the relevance of a decreased oxidative capacity in the pathogenesis of type 2 diabetes. In addition, the strong correlation of the half time of $\mathrm{PCr}$ recovery with $\mathrm{VO}_{2 \mathrm{max}} / \mathrm{kg}$ shows that the oxidative capacity measured locally in the vastus lateralis muscle is representative also for whole body oxidative capacity.

When investigating in vivo mitochondrial function, one cannot differentiate between a decreased function due to a decreased number of mitochondria, due to changes in mitochondrial phenotype or due to limited supply of oxygen. Similarly, it cannot be deduced from the present study, whether the decreased in vivo mitochondrial function is cause or consequence of the diabetic state.

An interesting aspect of the present study, is that despite marked differences in mitochondrial function, IMCL content was not different between our obese type 2 diabetic patients and their BMI matched controls. As the non-diabetic control group was BMI matched with the diabetic patients, the controls were also overweight. It is well known that obesity is associated with elevated IMCL content (27) and the lack of difference in IMCL content between these group is in line with previous work showing similar IMCL content in type 2 diabetes patients compared to obese subjects $(27,28)$.

The finding that IMCL content was similar in the two groups, while in vivo mitochondrial function was lower in diabetic patients suggests that a low 
mitochondrial function is a more important risk factor than a high IMCL content for developing diabetes. This observation fits well with the generally accepted hypothesis that not IMCL per se but fatty acid metabolites like diacylglycerol and fatty acyl-CoA are causally related to insulin resistance, and these metabolites may specifically be elevated when oxidative capacity is reduced. One other study determined PCr recovery half-time in diabetic patients and BMI matched controls (29) and also reported longer $\mathrm{PCr}$ recovery half times after exercise in diabetic subjects than in healthy controls (29) albeit in the gastrocnemius muscle and after maximal intensity exercise. Near infrared spectroscopy showed that the delay in $\mathrm{PCr}$ resynthesis in the gastrocnemius muscle in the lower leg after exhaustive exercise could mainly be attributed to the limited supply of oxygen probably due to impaired perfusion in diabetic subjects. Signs of ischemia in T2DM are mainly manifested in the lower leg (30). Here, we investigated the vastus lateralis muscle of the thigh, with a moderate intensity exercise protocol, and find $\mathrm{PCr}$ recovery to be slower in diabetics. The modest and identical decrease in $\mathrm{pH}$ in the two groups in the present study makes it unlikely that the observed differences in $\mathrm{PCr}$ recovery originate from aberrations or differences in post-exercise blood flow. Therefore, our results are more comparable to the findings by Petersen et al., who showed decreased mitochondrial function in the soleus muscle in pre-diabetic subjects, and suggest that the prolonged $\mathrm{PCr}$ recovery half-time indeed reflects a reduced mitochondrial function.

Another interesting finding of the present study is the substantial spatial variation in IMCL content over the whole vastus lateralis muscle. When the muscle was divided into three layers (medial to lateral), the variation within a single layer of the muscle was much less pronounced, suggesting regional differences in IMCL content. Indeed, the IMCL content in the lateral layer was lowest and augmented to the more medial part of the muscle, although the number of subjects in this comparison was low. An important implication of this observation is that to allow valid comparison of IMCL content between groups, the IMCL content should be determined at the same anatomical position in both groups. Also when multiple examinations of a subjects' IMCL content are performed, the voxel should be positioned at the same anatomical position repeatedly.

The origin of the spatial differences in IMCL content may lie in different fibre typology. It has been described in the vastus lateralis muscle that the proportion of type I fibres increases towards the femur (18) and it is well known that type I fibres contain more lipids than type II fibres (19). Therefore, our findings are well in line with a higher type 1 content in deeper layers of the vastus lateralis muscle.

A relatively large proportion of voxels did not show good separation of the IMCL and EMCL signal and needed to be excluded in the current study. In an obese population, the acquisition of high quality spectra is generally difficult, due 
to high intensity of EMCL signalls. The measurement in the vastus lateralis is further complicated by the fact that the best separation of the IMCL and EMCL peaks occurs when muscle fibres run parallel to the static magnetic field. Due to the pennation angle of the vastus lateralis, fibres in this muscle normally run at a slight angle with respect to the static magnetic field when subjects are in a supine position in the magnet bore. The advantage of spectroscopic imaging is that voxels with good separation of EMCL and IMCL can be selected retrospectively. In that way spectra of good or excellent quality were acquired in the vastus lateralis in all but three individuals in the current study with obese subjects and reasonable quality spectra were acquired in all but one subject.

In conclusion, we have shown that $\mathrm{PCr}$ recovery half-time is increased in diabetic patients when compared to BMI-matched control subjects, which leads to propose that mitochondrial function is impaired in type 2 diabetes mellitus. $\mathrm{PCr}$ half-time correlated positively with plasma glucose concentration in the diabetic population, revealing that the decrease in oxidative capacity is related to the degree of illness. The decrease in in vivo mitochondrial function was not accompanied by a difference in IMCL content between the two groups. Furthermore, we show that IMCL content shows large variation over the vastus lateralis muscle with higher IMCL content in the deeper layers.

\section{Acknowledgements:}

We thank Thomas Lange and Dr. Ulrike Dydlak (Institute of Biomedical Engineering (IBE), University and ETH Zuerich, Switzerland) for providing the SIVIEW software. Dr. P.Schrauwen is supported by a fellowship of the Royal Netherlands Academy of Arts and Sciences. Dr. M. Hesselink is supported by a VIDI Research Grant for innovative research from the Netherlands Organization for Scientific Research (Grant 016.066.359). 


\section{References}

1. Zimmer $\mathrm{P}$, Albeni $\mathrm{KG}_{\text {; }}$ Shaw J. Global and societal implications of the diabetes epidemic. Nature. $2001 ; 414: 782-7$.

2. Meyer C, Woerle HJ, Dostou JM, Welle SL, Gerich JE. Abnormal renal, hepatic, and muscle glucose metabolism following glucose ingestion in type 2 diabetes. Am / Physiol Endocrignol Metab. 2004, 287: E1049-56.

3. Goodpaster $\mathbb{B H}_{3}, \mathrm{He} \mathrm{J}$, Wakins $\mathrm{S}$, Kelley DE. Skeletal muscle lipid content and insulin resistance: evidence for a paradox in endurance-trained athletes. J Clin Endocrinol Metab. 2001:86:5755-61.

4. He J Watkins S, Kelley DE. Skeletal muscle lipid content and oxidative enzyme activity in relation to muscle fiber type in type 2 diabetes and obesity. Diabetes. 2001; 50:817-23.

5. Kelley DE, He J, Menshikova EV, Rutov VB. Dysfunction of mitochondria in human slleletal muscle in type 2 diabetes. Diabetes. $2002 ; 51: 2944-50$.

6. Shulman GI. Cellular mechanisms of insulin resistance. J Clin Invest. 2000; 106: 171-6.

7. Petersen KF, Dufour S, Befroy D, Garcia R, Shulman GI. Impaired mitochondrial activity in the insulin-resistant offspring of parients with type 2 diabetes. N Engl J Med. 2004; 350: 66471.

8. Petersen KF, Befroy $\mathrm{D}$, Dufour $\mathrm{S}$, Dziura J, Ariyan $\mathrm{C}$, Rothman DL, DiPietro L, Cline GW, Shulman GL. Mirochondrial dysfunction in the elderly: possible role in insulin resistance. Science. 2003; 300: 1140-2.

9. Meyer RA. A linear model of muscle respiration explains monoexponential phosphocreatine changes. Am J Pbysiol. 1988; 254: C548-53.

10. Kemp GJ, Radda GK. Quantitative interpretation of bioenergetic data from 31P and $1 \mathrm{H}$ magnetic resonance spectroscopic studies of skeletal muscle: an analytical review. Magn Reson Q. 1994; 10:43-63.

11. Sahlin $\mathrm{K}$, Harris RC, Hultman E. Resynthesis of creatine phosphate in human muscle after exercise in relation to intramuscular $\mathrm{pH}$ and availability of oxygen. Scand J Clin Lab Invest. 1979; $39: 551-8$.

12. Taylor DJ, Bore PJ, Styles P, Gadian DG, Radda GK. Bioenergetics of intact human muscle. A $31 \mathrm{P}$ nuclear magnetic resonance study. Mol Biol Med. 1983; 1: 77-94.

13. Schrauwen-Hinderling VB, Schrauwen $P$, Hesselinik MK, van Engelshoven JM, Nicolay $\mathrm{K}$, Saris WH, Kessels AG, Kooi ME. "The increase in intramyocellular lipid content is a very early response to training. J Clin Endocrinol Metab. 2003; 88: 1610-6.

14 Hown JH. Pan JW Hewdari S. Hetherington HP, Stein DT. Regional differences in intramyocellular lipids in humans observed by in vivo IH-MR spectroscopic imaging. I Appl Pbysiol. 2001; 90: 1267.74.

15. Weis J, Courivaud F, Hansen MS, Johansson L, Ribe LR, Ahlstrom H. Lipid content in the musculature of the lower leg; evaluation with high-resolution spectroscopic imaging. Magn Reson Med. 2005; 54: 152-8.

16. De Han JH. Assessment of insulin-stimulated gilycogen synthesis by magnetic resonance spectroscopy, Doctoral thesis, University of Nimegen, The Netherlands, 2004; 87-102.

17. Vermathen ?. Kreis $R$, Boesch $C$. Distribution of intramyocellular lipids in human calf muscles as determined by MR spectroscopic imaging. Magn Reson Med. 2004; 51: 253-62.

18. Lexell J, Hentiksson-Larsen $\mathbb{K}$, Sjostrom $M$. Distribution of different fibre types in human skeletal muscles. 2. A study of cross-sections of whole m. vastus lateralis. Acta Pbysiol Scand. $1983 ; 117: 115-22$.

19. van Loon IJ, Schrauwen-Hinderling VB, Koopman R, Wagenmakers Af, Hesselink MK, Schanrt $G$, Kooi ME, Saris WH. Influence of prolonged endurance cycling and recovery diet on intramuscular triglyceride content in trained males. A $\mathrm{m}$ J Physiol Endocrinol Metab. 2003; 285: E804-11.

20. Kuppers H, Verstappen FT, Keizer HA, Geurten P, van Kranenburg G. Variability of aerobic performance in the laboratory and its physiologic correlates. Int J Sports Med. 1985; 6: $197-201$. 
21. DeFronzo RA, Tobin JD, Andres $R$. Glucose clamp technique: a merhod for quanthing insulin secretion and resistance. Aw J Pbysiol. 1979; 237: E214-23.

22. Naressi $A$, Couturier $C$, Dexos JM, Janssen $M$, Mangeat $C$, de Beer $R$, Graveron-Denilly D. Java-based graphical user interface for the MRUI quantication package. Magman. 2001 , 12: $141-52$.

23. Newcomer BR, Boska MD. T1 measurements of 31P metabolites in resing and exercising human gastrocnemius/soleus muscle at 1.5 Tesla. Matgn Reson Med. 1999; 41:486-94.

24. Vanhamme L, van den Boogaart A, Van Huffel S. Improved method for accurate and efficient quantification of MRS data with use of prior knowledge. J Magn Resom. 1997; 129: $35-43$.

25. Boesch C, Slotboom J, Hoppeler H, Kreis R. In wivo determination of intramyocelluar lipids in human muscle by means of localized 1H-MR-spectroscopy. Magn Reson Med. 1997; 37: 484-93.

26. Schick F, Eismann B, Jung WI, Bongers H, Bunse M, Lutz O. Comparison of localized proton NMR signals of skeletal muscle and fat tissue in vivo: two lipid compartments in muscle tissue. Magn Reson Med. 1993; 29: 158-67.

27. Goodpaster $\mathrm{BH}$, Theriault $\mathrm{R}$, Watkins $\mathrm{SC}$, Kelley $\mathrm{DE}$. Intranuscular lipid content is increased in obesity and decreased by weight loss. Metabolism, 2000; 49:467-72.

28. van Loon LJ, Koopman $R$, Manders $R$, van der Weeger W, van Kranenburg GP, Keizer HA. Intramyocellular lipid content in type 2 diabetes patients compared with overweight sedentary men and highly trained endurance athletes. Am J Plysiol Endocrinol Metab. 2004; 287: E558-65.

29. Scheuermann-Freestone $M_{*}$ Madsen PL, Manners D, Blamire AM, Buckingham RE, Styles P, Radda GK, Neubauer S, Clarke K. Abnormal cardiac and skeletal muscle energy metabolism in patients with type 2 diabetes. Circulation. 2003; 107: 3040.6.

30. Cosson E, Paycha F, Tellier P, Sachs RN, Ramadan A, Paries J, Attali $\rrbracket R_{x}$ Valensi P. Lower-limb vascularization in diabetic patients. Assessment by thallium-201 scanning coupled with exercise myocardial scintigraphy. Diabetes Care. 2001; 24: 870-4. 


\section{CHAPTER}

9

\section{GENERAL DISCUSSION}

V.B. Schrauwen-Hinderling, M.K.C. Hesselink, P. Schrauwen, M.E. Kooi, Adapted from the perspective article: Intramyocellular lipid content in human skeletal muscle.

Obesity Research 2006; in press 


\section{GENERAL DISCUSSION}

In 1913 Greene reported that the dark muscle of the King salmon is characterized by "the enormous loading of fat at all stages of the life cycle, but especially at the time the spawning migration begins" and that "the stored fat is gradually eroded during the migration" (1). These observations were followed by quantitative investigations of human muscle. The first intramyocellular lipid. (IMCL) data from biochemical analysis of biopsies from the human quadriceps were published in 1969 by Morgan and colleagues (2). Later, quantitative morphological determination of IMCL was performed by electron microscopy (EM) in the beginning of the 1970's $(3,4)$.

Using EM, individual lipid droplets in myocytes could be visualized in the sarcoplasm, usually in direct contact with mitochondria (5). This direct contact with mitochondria led to the hypothesis that the lipid droplets serve as a fuel for mitochondrial fat oxidation, in situations where rapid supply of fat is needed, such as during exercise. It is long recognized that during endurance exercise, fat oxidation contributes significantly to the energy requirements of skeletal muscle. While fatty acids (FA) stored in adipose tissue as triglycerides first have to undergo lipolysis, be released in the blood and be transported to the active muscle for oxidation, intramyocellular lipid stores would be a readily available substrate source during endurance exercise. Indeed, tracer studies have reported that oxidation of the IMCL stores contribute to the energy used during exercise (6-8), although results are equivocal (9). Therefore, the question to what extent IMCL is used as a substrate source during exercise is still an ongoing debate.

Initially, the interest in the physiological role of IMCL came mainly from the field of exercise physiology. However, this changed dramatically after the finding that IMCL accumulation was associated with insulin resistance (10-12), an important risk factor in the development of T2DM.

\section{Quantification of IMCL content}

Several techniques are available to determine IMCL content, all with their pro and cons (see Chapter 2 for a more detailed description of the different methods). Biochemical analysis of biopsy specimens has been most extensively used, however, this method is susceptible to contamination of adipose tissue that is often interspersed with muscle fibers. Other techniques can separate adipose tissue from muscle cells (EM, histochemistry), but still require biopsy material. On the other hand, non-invasive techniques are available to detect IMCL (MRI, CT), but are generally limited by the fact that a true separation of IMCL and EMCL cannot be achieved. ${ }^{1} \mathrm{H}-\mathrm{MRS}$ is the only non-invasive modality that is able to separate IMCL and EMCL signals and with which IMCL quantification on the same volume can be performed e.g. before and after an intervention. Therefore, in this thesis, we quantified IMCL content by ${ }^{1} \mathrm{H}-\mathrm{MRS}$. 


\section{IMCL as an intracellular source of fuel}

Early isotope studies (8) indicated that during exercise not all the oxidized fat could be accounted for by oxidation of plasma FFA, leading to the suggestion that the lipid droplets inside muscle cells serve as important fuel during exercise. Especially during prolonged exercise IMCL is thought to be an important fuel source and the oxidation of IMCL might have a sparing effect on glycogen oxidation. Whether IMCL are used during exercise can be determined by comparing IMCL content in muscle before and after exercise. In the present thesis we showed using 'H-MRS that IMCL content is decreased after prolonged cycling exercise (Chapter 3 and 7 ), indicating that IMCL can indeed be used as an energy source during physical activity.

Earlier data from biochemical analysis are equivocal on the elfect of acute exercise with some laboratories reporting a decrease in $\mathrm{MCL}$ content (13-19) while others did not (20-24). This discrepancy may be due to the high variability of the biochemical IMCL determination, especially in untrained subjects, where more adipose tissue can contaminate the IMCL determination (25). In contrast to biochemical analysis, EM data showed that IMCL decreased by $42 \%$ in the gastrocnemius muscle after completion of a marathon race (26) and IMCL were nearly depleted after a $100 \mathrm{~km}$ run in seven well-trained subjects (27). These results are in line with the present thesis and other recent ${ }^{1} \mathrm{H}-\mathrm{MRS}$ results, showing a consistent decrease in IMCL content after acute exercise (3, 28-35)). Only a high intensity interval protocol reported no decrease of IMCL content after exercise when ${ }^{1} \mathrm{H}-\mathrm{MRS}$ was employed (36). The latter is not surprising as during high intensity interval protocols carbohydrate is the main fuel oxidized. In summary, there is little doubt that IMCL are indeed oxidized during endurance exercise and can serve as a readily available energy source during exercise.

\section{Fat content of different muscles}

Most studies examining IMCL content have been limited to a few muscle groups. With 'H-MRS especially the muscles of the calf have been extensively studied. In the call, the highest fat contents have been found in the medial part of the soleus muscle and lower values (by a factor of 2-3) in the tibialis anterior and -posterior (37) and the gastrocnemius muscle (38). This matches the different fiber type distribution of these muscles and their substrate use. The soleus muscle is a more oxidative muscle relying more on fat oxidation than the ribialis and gastrocnemius muscles. Likewise, the soleus muscle has a high percentage (about $88 \%$ ) (39), while the gastrocnemius muscle has a lower percentage (about 50\%) of type 1 fibers (39). The fiber composition of the tibialis anterior muscle is intermediate (about 70\% of type 1 fibers) (39). EM (40) and histochemistry (oil red $O)(41,42)$ indeed showed that oxidative type 1 fibers are characterized by a 
higher fat content than glycolytic type 2 fibers. In addition, oxidative type 1 fibers contain more mitochondria, suggesting that the intramyocellular lipid droplets can serve as a rapidly available source of energy for mitochondrial oxidation. In Chapter 7 , we showed that differences in IMCL content are not only present between different muscle groups, but also inside one single muscle group. In the vastus lateralis muscle we found a large regional variation in IMCL content. Analogous to the different IMCL content in different muscle groups, this variation is most likely explained by inhomogeneous distribution of type 1 and type 2 fibers within the vastus lateralis muscle.

\section{Replenishment after exercise}

In order to use $\mathrm{MMCL}$ during repeated exercise bouts $\mathrm{MCL}$ needs to be replenished in the post-exercise state. Analogous to a high carbohydrate diet speeding up the replenishment of glycogen stores, we examined whether the replenishment of IMCL stores is faster on a high-fat diet. In Chapter 6, we reported that in healthy male arhletes the replenishment of IMCL content on a moderate-fat diet ( $39 \mathrm{E} \% \mathrm{fat}$ ) was complete $48 \mathrm{~h}$ after exercise, while IMCL content on a typical athletes' diet $(24 \mathrm{E} \%$ fat) did not recover in $48 \mathrm{~h}$. Our observations are well in line with results from earlier studies that used diets with larger variation in fat content.

IMCL content assessed with biochemical methods during the 24 hours following an exercise bout on either a high-fat ( $68 \%$ of the Energy as fat (E\% fat)) or a lowfat ( $5 \mathrm{E} \%$ fat) diet showed an increase in $\mathrm{MMCL}$ content on the high-fat diet, while it remained unchanged on the low-fat diet (24). The investigation with ${ }^{1} \mathrm{H}$ MRS of the time-course of IMCL recovery after an exercise-induced decrease in IMCL revealed that the IMCL content returned to a level higher than at baseline (supercompensation of $30-45 \%$ ) after $30 \mathrm{~h}$ on a high-fat diet ( $55 \mathrm{E} \% \mathrm{fat}$ ), while on a low-fat diet ( $15 \mathrm{E} \%$ fat) the IMCL content did not recover within $30 \mathrm{~h} \mathrm{(43).}$ Also in female runners, IMCL content was restored to baseline $22 \mathrm{~h}$ after running exercise on a moderate fat diet ( $35 \mathrm{E} \%$ fat) with a supercompensation of IMCL content on the moderate fat diet after $70 \mathrm{~h}$. In contrast, on a low-fat diet (10 E\% fat), IMCL content did not recover in the $70 \mathrm{~h}$ post-exercise (34).

Given that IMCL is used during prolonged exercise, replenishment of IMCL content post-exercise could potentially improve performance. However, when a 120 min time trial was used in order to deplete IMCL stores and was followed by $24 \mathrm{~h}$ with either a high-fat or a high-carbohydrate diet the performance on a subsequent self-paced cycling time trial was lower with the high-fat diet (24). Also in studies focusing on performance after long term adaptation to a high-fat diet, results are equivocal with studies reporting a positive effect (44), a negative effect (45) or no change in performance $(46,47)$, and one study showing no effect on high intensity exercise but a positive effect on submaximal exercise (48). 
Therefore, although IMCL is used during exercise, so far, no strong evidence is awailable that IMCL content is limiting athletic performance. For recent review see Reference (49).

\section{Endurance training}

As discussed above, during exercise both intramyocellular glycogen and lipid stores are used as energy source, dependent on the exercise intensity, and both substrate stores are replenished in the recovery phase post-exercise. With endurance training, glycogen levels are elevated, which promotes fatigue resistance. Analogously to glycogen, it might be expected that IMCL content is increased in the endurance trained state, too.

In Chapter 3, we investigated the response to a two-week training program in young, sedentary male subjects with ${ }^{1} \mathrm{H}-\mathrm{MRS}$ and found a $42 \%$ increase in IMCL content. Likewise, we determined IMCL content in untrained (Chapter 3 ) and in trained subjects (Chapter 7) and found a higher IMCL content in trained subjects.

With biochemical analysis of IMCL, some authors reported increased IMCL content after 4 to 6 weeks of training $(2,50)$, while others reported no change after 12 weeks of training at high intensity (21) or even a decrease in IMCL content (51). These equivocal results are probably again due to the high variability of the biochemical method.

EM revealed 2.5 times higher IMCL content in the vastus lateralis of well-trained orienteers (3) and 2.5 times higher IMCL content in the gastrocnemius muscle of elite rowers compared to controls (52). With 6-8 weeks of endurance training, IMCL content increased up to 3.4 times in the vastus lateralis muscle $(53,54)$. Although almost all studies using EM and involving endurance training reported increased IMCL content after training, the change did not always reach statistical significance $(55,56)$ and one study reports no difference in IMCL content of the gastrocnemius of endurance trained athletes and untrained subjects (57). An increased IMCL content in trained subjects limited to type 1 fibers has been reported in some studies (58) (59), while a fiber-type specific increase in IMCL content in type $2 \mathrm{a}$ and $2 \mathrm{~b}$ fibers was reported by others (40), and a higher IMCL content in trained cross-country runners was limited to type 2 a fibers (60). Similarly to the results from $\mathrm{EM}$, oil red $\mathrm{O}$ stainings report large differences (50$70 \%)$ between trained and untrained subjects $(11,42)$ and increased IMCL content $(+12 \%)$, following a 12-week training period in older subjects (61). Therefore, the EM and the histological data are in line with ${ }^{1} \mathrm{H}-\mathrm{MRS}$ data from us and others, which report higher IMCL content in the trained state (62) (33). Considering the results of EM, light microscopy and ${ }^{1} \mathrm{H}-\mathrm{MRS}$, an increased IMCL content with training is unequivocal. As endurance training also increases the relative amount of type 1 , oxidative muscle fibers, this may partly explain the increase in IMCL $(11,42)$. 


\section{High-fat diets}

The results discussed so far suggest that IMCL functions as a rapidly available energy source to deliver fuel for the mitochondrial ATP formation necessary for muscle contraction. As with glycogen, the levels of these intramuscular substrate stores are influenced by the diet, at least in the recovery phase after exercise. In Chapter 5, we have also examined the effect of high-fat diets per se, independent of prior exercise and in untrained subjects, on IMCL content. We found that IMCL content was increased by $54 \%$ after one week of a high-fat diet. Similarly, with biochemical methods, triglyceride content in skeletal muscle has been reported to increase by $36 \%$ to $90 \%$ after high fat feeding periods ranging from 24 hours to 7 weeks $(24,63-67)$. In line with this, data from EM showed a $130 \%$ increase in IMCL content after 5 weeks of a high-fat diet (68). In other studies, using ${ }^{1} \mathrm{H}$-MRS, the effect of high-fat diets (55-60\% of energy as fat) has been investigated after two to three days $(69,70)$ and also in these studies, an increase (between $48 \%$ and $56 \%$ ) in IMCL content was reported.

The reason for the increase in IMCL on a high-fat diet is not yet clear. It has been shown that a high-fat diet increases fat oxidation which is not due to an increased oxidation of FFA $(65,71)$. This suggests that an increased IMCL (and/or VLDL) oxidation occurs after a high-fat diet, suggesting that the increase in IMCL drives increased IMCL oxidation. Alternatively, it should be noted that when switching to a high-fat diet, fat oxidation only adapts slowly to match fat intake and a positive fat balance occurs. The surplus of fat is mainly stored in adipose tissue, but also in non-adipose tissue such as skeletal muscle. In this respect, the increase in IMCL on a high-fat diet could also simply be seen as an excessive storage of a surplus of circulating fatty acids. Indeed, the increase in IMCL after a week of a high-fat diet as investigated in Chapter 5 was not accompanied by changes in mRNA expression that would point to a stimulated fat oxidation, whereas the training induced increase in IMCL was accompanied by increased gene expression of fat oxidative genes (Chapter 4). These results favor the explanation that the increased IMCL content may simply be due to a positive fat- and energy balance. Also on the long term, a high-fat diet may lead to a positive fat- and energy balance as it has been shown that diets high in fat are generally energy dense and thereby promote overeating. In that respect, it is interesting to note that obese subjects are characterized not only by increased adipose tissue, but generally also by increased plasma lipid concentrations and by high IMCL content and low fat oxidative capacity (72). Additionally, when investigating obese subjects with normal fat oxidation, IMCL content was normal, too (73). This further suggests that the increase in IMCL may be simply due to a mismatch between delivery to, and oxidative capacity of skeletal muscle. In summary, a high-fat diet increases IMCL stores, which may simply be due to a positive fat balance when changing to a high-fat diet. In physically inactive humans consuming a high-energy, high-fat diet, a positive energy- and fat balance 
may occur chronically, resulting in fat accumulation in adipose tissue and probably also in skeletal muscle.

\section{High FFA plasma concentrations}

In accordance with the suggestion above, also other conditions with high FA availability lead to increases in IMCL content. The acute elevation of plasma FFA by infusions results in increased IMCL content $(69,74)$. Also during fasting, lipolysis is stimulated and plasma FFA concentrations are elevated. Interestingly, it has been reported that 72 hours of fasting increased IMCI content (75).

In line with an elevation of IMCL in the presence of high FFA plasma concentrations, we found that exercise that was accompanied by increased plasma FFA resulted in a decrease in IMCL in the exercising legs, but an increase of IMCL content in the inactive, non-exercising muscle (Chapter 7 ). "The increase in IMCL under conditions of high FA availability can simply be the due to a higher supply of fat to the muscle. Alternatively, non-active muscle could act as a buffer for elevated plasma FFA by taking them up from the circulation. High plasma concentrations of FA can harm the endothelial wall and therefore their removal from the circulation is important. Although adipose tissue is readily taking up and storing FA, also muscle tissue seems to fulfill this function if FA availability is high. In this way both the white adipose tissue and the muscle help to prevent or limit elevation of circulating plasma FA levels and the stored IMCL could serve as an energy source when lipid supply is decreasing. However, as we are all aware, in our westernized society with a surplus of dietary energy available, periods of low lipid supply are scarce, resulting in continued high levels of IMCL in non-active muscle tissues.

\section{Association with insulin resistance}

The prevalence of insulin resistance and type 2 diabetes mellitus (T2DM) is increasing rapidly and high energy intake and lack of physical activity in westernized societies are considered major risk factors. The development of insulin resistance coincides with the accumulation of IMCL. With biochemical methods, a correlation of triglyceride content with insulin resistance in Pima Indians was reported (12) and a similar correlation was shown in sedentary subjects with histochemical methods (11) and with 'H-MRS (10). Interestingly, IMCL content has been described as an early marker of the development of insulin resistance. Philipps et al. (76) investigated normoglycemic women and found a negative relation between increased triglyceride content (assessed by histological and biochemical methods) and decreased glycogen synthase activity. Furthermore, histochemically determined high IMCL contents were related to high waist-to-hip ratios and high FFA plasma concentrations. These data suggest that high IMCL content, perhaps due to high plasma FA levels can lead to the 
development of insulin resistance, although the possibility cannot be excluded that insulin resistance leads to the accumulation of IMCL. To investigate early aberrations in metabolism in the pathogenesis of T2DM, a valuable approach is the investigation of healthy subjects with a high risk to develop diabetes in later life, such as family members of parients with type 2 diabetes. With 'H-MRS, Perseghin et al. (77) showed that first-degree relatives of type 2 diabetic patients had higher IMCL content (and were less insulin sensitive) than matched controls. Similarly, the offspring of type 2 diabetic patients was investigated (78) and divided in insulin-sensitive and insulin-resistant subjects. The results showed that the insulin resistant subjects had a higher IMCL content than the insulin sensitive counterparts. The increased IMCL content in insulin resistant but otherwise healthy subjects suggests that the accumulation of IMCL is an early step in the development of T2DM. Also in overt diabetes, IMCL content is severely increased. Early data from biochemical analysis of biopsy samples revealed a six-fold excess of triglyceride content in subjects with T2DM (79). This was confirmed by histochemical methods revealing higher IMCL content in type 2 diabetic subjects, compared to obese or lean controls (11). In accordance, obese subjects who had normal insulin sensitivity were also characterized by normal IMCL content (73) and MMCL content did not differ between obese T2DM patients and BMI-matched controls (Chapter 8 ). Although these data all suggest an important role for IMCL in the development of insulin resistance and type 2 diabetes, the paradoxical observation that endurance trained subjects, who are highly insulin sensitive, have high IMCL levels remains unexplained.

\section{Mechanisms of decreased insulin sensitivity}

The fact that endurance training leads to an increase in IMCL content and improves insulin sensitivity has been described in the literature as the "training paradox" (11). However, as reviewed above IMCL can be increased for two different reasons: 1) a functional increase, whereby IMCL serves as a rapidly available energy source and 2) a pathophysiological increase, whereby increased IMCL is merely due to a continuous over supply of fat. In the former condition, the increase in IMCL can only be functional if at the same time the capacity to liberate these IMCLs and rapidly divert them to oxidation is also increased. Indeed, mRNA concentrations of ACC2 were decreased after two weeks of training, pointing to increased fat oxidative capacity with training (Chapter 4). This is in line with other studies, showing that gene expression of a key component of FA transport (carnitine palmitoyltransferase (CPTI)) and the fat oxidative capacity are also increased in the trained state (80). In the pathophysiological condition, however, the increased IMCL content most likely is not accompanied by such an increased fat oxidative capacity. In Chapter 8 we have therefore compared the muscular oxidative capacity of obese type 2 diabetic patients with non-diabetic control subjects that were matched for BMI. Although 
IMCL levels were similar in both groups, muscular oxidative function was decreased by $-40 \%$ in the diabetic patients. This may indicate that the combination of high $\mathbb{M C L}$ together with low muscular oxidative capacity is required to develop overt type 2 diabetes mellitus. Previously, it has also been suggested that fat oxidative capacity might be more important than IMCL content in determining insulin sensitivity $(11,81)$ and Petersen et al. reported decreased mitochondrial function (oxidative capacity) in the insulin resistant offspring of 'T2DM patients, compared with insulin sensitive controls (82). The consequence of high IMCL levels together with low muscular oxidative capacity may be the accumulation of so-called fatty acid intermediates. It has been suggested that lipid metabolites such as fatty acyl-CoA or DAG are more likely to intervene with insulin signaling than IMCL per se. Diacylglycerol is the intermediate between fatty acyl-CoA that can enter the mitochondria for oxidation, arid triacylglycerol, the form in which lipids are stored in muscle. As outlined above, a functional increase in IMCL as observed with endurance training is accompanied by an increased capacity to divert IMCL to oxidation, and therefore the level of the lipid intermediates will probably stay low. However, in the condition of continuous fat over supply, such as high-fat diet, high plasma FFA levels and obesity, the increased IMCL is not accompanied by a sufficiently increased fat oxidative capacity and therefore not only IMCL but also DAG and fatty acyl-CoA will increase. As mentioned, the latter two have been shown to be able to interfere with insulin signaling (reviewed in (83)).

\section{Concluding remarks}

The physiological function of fat stores in the muscle is to serve as a readily available energy source during exercise. Although physical activity levels in our westernized society are generally very low, this capacity to store fat inside muscle may have conferred an evolutionary advantage to permit physical activity during cycles of feast and famine. In that respect, it was recently suggested that humans' endurance running capacity may have been instrumental in evolution of homo sapiens (84). Nowadays, however, in westernised society the importance of having high IMCL levels may have faded due to the low levels of physical activity and the continuous availability of food. However, the capability to store IMCL is still preserved, and as a consequence, in conditions of high circulating fatty acid levels or high dietary lipid supply, muscle may act as a sink for circulating fatty acids. In these conditions in which IMCLs are not being used for oxidation, IMCLs and their intermediates have a negative impact on insulin signaling and may induce insulin resistance. Therefore, the preserved capacity to store fat in muscle may nowadays have detrimental effects on insulin sensitivity, especially when IMCLs are not being used as substrate. In that respect, the capacity to utilize IMCLs may be more important than the magnitude of IMCL levels per se in determining the negative effects on insulin sensitivity. 


\section{Future perspectives}

In recent years, many studies by us and others have focused on the determination of IMCL content in various conditions and evidence for the above described lipotoxic mechanisms of lipid accumulation in skeletal muscle tissue has become strong. However, only a very limited number of studies have directly quantified lipid intermediates as fatty acid acyl-CoA, DAG and ceramids. The investigation of these intermediates in insulin resistant and insulin sensitive subjects should get more attention in the future. Similarly, not only $\mathrm{MMCL}$ content should be quantified, but future investigations should also aim at determining $\mathbb{I M C L}$ nurnover (e.g. by ingestion or infusion of ${ }^{13} \mathrm{C}$-enriched lipids combined with ${ }^{13} \mathrm{C}$-MRS).

Skeletal muscle is not the only non-adipose tissue that is accumulating FA when their availability is high and lipotoxic mechanisms may also be important in other tissues. Further research is needed to investigate lipid accumulation in tissues such as the liver, the pancreas and the heart. These organs are all important in the pathology of type 2 diabetes mellitus and its co-morbidities and due to lipotoxicity, fat accumulation in these tissues may lead to loss of function. Therefore, the consequences of fat accumulation should be studied in a more integrated way and interventions manipulating fat content in various tissues may open up new ways for prevention and therapy of type 2 diabetes mellitus and its co-morbidities. 


\section{References}

1. Creene CW. The storage of fat in the muscular tissue of the King salmaon and its resorption during the fast of the spawning migration. Bull Bur. Fisferies. 1913; 33: 73-138.

2. Morgan TE, Short FA, Cobb LA. Effect of long-term exercise on skeletal muscle lipid composition. Am J Pbysiol. 1969;216:826.

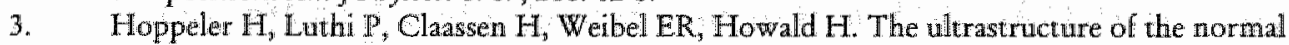
human skeleval muscle. A morphometric analysis on untrained men, women and welltrained orienteers. Plagers Arch. 1973; 344:217-32.

4. Jerusalem $F$, Engel $A G$, Peterson HA. Human muscle fiber fine structure: morphometric data on controls. Newrology. $1975 ; 25: 127-34$

5. Hoppeler H. Exercuse-induced ulrrastructural changes in skeletal muscle. Int I Sports Med. 1986; 7: 187-204.

6. Havel RJ, Carlson LA, Ekelund LG, Holmgren A. Turnover Rate and Oxidation of Different Free Fatty Acids in Man During Exercise. J Appl Physiol. 1964; 19: 613-8.

7. Havel RJ, Perrow B, Jones NL. Uptake and release of free fatry acids and other metabolites in the legs of exercising men. J Appl Pbysiol. 1967; 23: 90-9.

8. Issekutz B, Jr., lissekurz AC, Nash D. Mobilization of energy sources in exercising dogs. J Appl Pbysiol. 1970; $29: 691-7$.

9. Steffensen CH, Roepstorff C, Madsen M, Kiens B. Myocellular triacylglycerol breakdown in females but not in males during exercise. Am J Physiol Endocrinol Metab. 2002; 282: E63442.

10. Krssak M, Fall Petersen K, Dresner A, DiPietro $\mathbb{L}$, Vogel SM, Rothman DL, Roden M, Shulman GI. Intramyocellular lipid concentrations are correlated with insulin sensitivity in humans: a 1H NMR spectroscopy study. Diabetologia. 1999; 42: 113-6.

11. Goodpaster BH, He J, Watkins S, Kelley DE. Skeletal muscle lipid concent and insulin resistance: ewidence for a paradox in endurance-trained athletes. $J$ Clin Endocrinol Metab. 2001; 86: 5755-61.

12. Pan DA, Lillioja S, Kriketos AD, Millner MR, Baur LA, Bogardus C, Jenkins AB, Storlien L.H. Skeletal muscle triglyceride levels are inversely related to insulin action. Diabetes. 1997; 46: 983-8.

13. Carlson LA, Ekelund LG, Froberg SO. Concentration of triglycerides phospholipids and glycogen in skeletal muscle and of free fatty acids and beta-hydroxybutyric acid in blood in man in response to exercise. Eur J Clin Invest. 1971; 1: 248-54.

14. Bergstrom J, Hultman E, Saltin B. Muscle glycogen consumption during cross-country skiing (the Vasa ski race). Int Z Angew Physiol. 1973; 31:71-5.

15. Cleroux J, Van $\mathbb{N g u y e n ~} \mathbb{P}$, Taylor AW, Leenen FH. Effects of beta 1- vs. beta $1+$ beta 2 blockade on exercise endurance and muscle metabolism in humans. J Appl Pbysiol. 1989; 66: 548-54.

16. Costill DL, Gollnuck PD, Jansson ED, Saltin B, Stein EM. Glycogen depletion pattern in human muscle fibres during distance running. Acta Pbysial Scand. 1973; 89: 374-83.

17. Essen B, Jansson E, Henriksson J, Taylor AW, Saltin B. Metabolic characteristics of fibre types in human skeletal muscle. Acta Physiol Scand. 1.975; 95: 153-65.

18. Froberg SO, Mossfeldt F. Effect of prolonged strenuous exercise on the concentration of triglycerides, phospholipuds and glycogen in muscle of man. Acta Pbysiol Scand. 1971; 82: $167-711$.

19. Watt MJ, Heigenhauser GJ, Dyck DJ, Spriet LL. Intramuscular triacylglycerol, glycogen and aceryl group metabolism during $4 \mathrm{~h}$ of moderate exercise in man. J Pbysiol. 2002; 541: 969-78.

20. Essen-Gustavsson $B$, Tesch PA. Glycogen and triglyceride utilization in relation to muscle metabolic characteristics in men performing heavy-resistance exercise. Eur I Appl Pbysiol Occup Plysiol. 1990; 61: 5-10. 
21. Hurley BF, Nenth PM, Martin WH, 3rd, Hagberg JM, Dalsky GP, Holloszy JO. Muscle triglyceride utilization during exercise; effect of training. J Appl Plysol. 1986; 60:5627.

22. Kiens B, Richter EA. Urilization of skeletal muscle triacylglycerol during postexercise recovery in humans. Am I Pbysiol. 1998; 275; E332-7.

23. Roepstorff $C$, Steffensen CH, Madsen M, Stallknecht B, Kanstrup IL, Richter EA, Kiens B. Gender differences in substrate utilization during submaximal exercise in endurance-trained subjects. Am / Pbysiol Endocrinol Metab. 2002; 282: E435-47.

24. Starling RD, Trappe TA, Parcell AC, Kerr CG, Fink WJ, Costill DL. Effects of diet on muscle triglyceride and endurance performance. J Appl Pbysiol. 1997: 82: 1185-9.

25. Watt MJ, Heigenhauser GJ, Spriet LL. Intramuscular triacylglycerol utilization in human skeletal muscle during exercise: is there a controversy? J Appl Plysiol. 2002; 93: 1185-95.

26. Staron RS, Hikida RS, Murray "TF, Hagerman FC, Hagerman MT. Lipid depletion and repletion in skeletal muscle following a marathon. I Newrol Sc: $1989 ; 94: 29-40$.

27. Kayar SR, Hoppeler $\mathrm{H}_{n}$ Howald $\mathrm{H}$, Claassen $\mathrm{H}$, Oberholzer F. Acute effects of endurance exercise on mitochondrial distribution and skeletal muscle morphology. Eny I Appl Pbysiol Occup Pbysial. 1986; 54:578-84.

28. Boesch $\mathrm{C}_{y}$ Slobboom J, Hoppeler $\mathrm{H}$, Kreis $\mathrm{R}$. In vivo determination of intramyocellular lipids in human muscle by means of localized 1H-MR-spectroscopy. Magn Reson Med. 1997; 37: 484-93.

29. Boesch C, Decombaz J, Slotboom J, Rreis R. Observation of intramyocellular lipids by means of 1H magnetic resonance spectroscopy. Proc Natr Soc. 1999; 58: 841-50.

30. Krssak M, Petersen KF, Bergeron R, Price 'T, Laurent D, Rothman DL, Roden $M$, Shulman GI. Intramuscular glycogen and intramyocellular lipid utilization during prolonged exercise and recovery in man: a $13 \mathrm{C}$ and $1 \mathrm{H}$ nuclear magnetic resonance spectroscopy study. / Clin Endocrinol Metab. 2000; 85: 748-54.

31. Rico-Sanz J, Moosavi M, Thomas EL, McCarthy J, Coutts GA, Saeed N, Bell JD. In vivo evaluation of the effects of continuous exercise on skeletal nuscle triglycerides in trained humans. Lipids. 2000; 35: 1313-8.

32. Brechtel K, Niess AM, Machann J, Rett K, Schick F, Claussen CD, Dickhuth HH, Haering HU, Jacob S. Unilisation of intramyocellular lipids (IMCLs) during exercise as assessed by proton magnetic resonance spectroscopy (1H-MRS). Horm Metab Res. 2001; 33: 63-6.

33. Decombaz J, Schmitt B, Ith M, Decarli B, Diem P, Kreis R, Hoppeler $\mathbb{H}$, Boesch C. Postexercise fat intake repletes intramyocellular lipids but no faster in trained than in sedentary subjects. Am f Physiol Regul Integr Comp Physiol. 2001; 281: R760-9.

34. Larson-Meyer DE, Newcomer BR, Hunter GR. Influence of endurance running and recovery diet on intramyocellular lipid content in women: a $1 \mathrm{H}$ NMR study. Am J Physiol Endocrinal Metab. 2002; 282: E95-E106.

35. White LJ, Robergs RA, Sibbitt WL, Jr., Ferguson MA, McCoy S, Brooks WM. Effects of intermittent cycle exercise on intramyocellular lipid use and recovery. Lipids. 2003; 38: 9 13.

36. Rico-Sanz J, Hajnal JV, Thomas EL, Merisova S, Ala-Korpela M, Bell JD. Intracellular and extracellular skeletall muscle triglyceride metabolism during alternating intensicy exercise in humans. J Pbysiol (Lond). 1998; 510: 615-22.

37. Hwang JH, Pan JW, Heydari S, Hetherington HP, Stein DT. Regional differences in intramyocellular lipids in humans observed by in vivo 1 H-MR spectroscopic imaging. $J$ Appl Physiol. 2001; 90: 1267-74.

38. Vermathea $P, K$ reis $\mathbb{R}$, Boesch $C$. Distribution of intramyocellular lipids in human calf muscles as devermined by MR spectroscopic imaging. Magn Reson Med. 2004; 51:253-62.

39. Johnson MA. Polgar J, Weightman D, Appleton D. Data on the distribution of fibre types in thirty-six human muscles. An autopsy study. J Newrol Sci. 1973; 18:111-29.

40. Howald $\mathrm{H}$, Hoppeler $\mathbb{H}$, Claassen $\mathrm{H}$, Mathieu $O$, Straub $R$. Influences of endurance training on the ulltrastructural composition of the different muscle fiber types in humans. Pfugers Axch. 1985; 403: 369-76. 


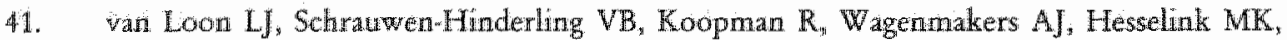
Schare $G, K$ Kooi ME, Saris WH. Influence of prolonged endurance cycling and recovery diet on intramuscular triglyceride content in trained males. Am J Physiol Endocrintol Metab. 2003; 285: E804-11.

42. Wan Loon U, Koopman $R$, Manders $\mathbb{R}$, van der Weegen W, van Kranenburg GP, Keizer IA. Intramyoctllular lipid content in type 2 diabetes patients compared widh overweight sedentary men and highly trained endurance athletes. Am J Pbysiol Endocrinol Metab. 2004: 287: $15558-65$.

43. Decombaz J, Fleith $M$, Hoppeler $H_{3}$ Kreis $R$, Boesch $C$. Effect of diet on the replenishment of intramyocellular lipids after exercise. Ewr J Nutr. 2000; 39: 244-7.

44. Lambert EV, Speechly DP, Dennis SC, Noakes TD. Enhanced endurance in trained cyclists during moderate intensity exercise following 2 weeks adaptation to a high fat diet. Enor J Appl Pbysiol Occup Plyssiol. 1994; 69: 287-93.

45. O'Keefe KA, Keith RE, Willson GD, Blessing DL. Dietary carbohydrate intake and endurance exercise performance of trained female cyclists. Nutrition Research. 1989; 9: 819830.

46. Phinney SD, Bistrian BR, Evans WJ, Gervino E, Blackburn GL. The human metabolic response to chronic ketosis without calonic restriction: preservation of stubmaximal exercise capability with reduced carbohydrate oxidation. Metabolism. 1983; 32: 769-76.

47. Goedecke JH, Christie C, Wilson G, Dennis SC, Noakes TD, Hopkins WG, Lambert EV. Metabolic adaptations to a high-far diet in endurance cyclists. Metabolism. 1999; 48: 1509-17.

48. Rowlands DS, Hopkins WG. Effects of high-fat and high-carbohydrate diets on metabolism and performance in cycling. Metabolism. 2002; 51: 678.90.

49. Burke LM, Kiens B, Ivy JL. Carbohydrates and fat for training and recowery. / Sports Sci. 2004; 22: 15-30.

50. Phillips SM, Green HI, Tarnopolsky MA, Heigenhauser GJ, Grant SM. Progressive effect of endurance training on metabolic adaptations in working skeletal muscle. Am J Plysiol. $1996 ; 270: \mathrm{E} 265 ; 2$.

51. Bergnan $B C$, Butterfield GE, Wolfel EE, Casazza GA, Lopaschuk GD, Brooks GA. Evaluation of exercise and training on musclle lipid metabolism. Am J Pbysiol. 1999; 276: $\mathbb{E} 106-17$.

52. Trendafilov B, Tanuschev M. Morphometrische Untersuchungen an Skelettmuskeln von Wettkaempfern im Rudern. Med Sport. 1981; 21:264-8.

53. Kiessling KH, Pilstrom L, Bylund AC, Saltin B, Pieh! K. Enzyme acrivities and morphometry in skeletal muscle of middle-aged men after training. Scand J Clix Lab Invest. 1974; 33:63-9.

54. Hoppeler H, Howald H, Conley K, Lindstedx SL, Claassen H, Vock P, weilbel ER. Endurance reaining in humans: aerobic capacity and structure of skeletal muscle. I Appl Pbysiol. 1985; 59: 320-7.

55. Orlander J, Aniansson A. Effect of physical training on skeletal muscle metabolism and ultrastructure in 70 to 75-year-old men. Acta Pbysiol Scand. 1980; 109: 149-54.

56. Rosler K, Hoppeler H, Conley KE, Claassen H, Gehr P, Howald H. Transfer effects in endurance exercise. Adaptations in trained and untrained muscles. Eur J Appl Pbystol Occap Plyysiol. 1985; 54: 355-62.

57. Alway SE, MacDougall JD, Sale DG, Sutton JR, McComas AJ. Functional and structural adtaptations in skeletal muscle of trained achlletes. J Appl Physiol. 1988; 64: 1114-20.

58. Prince FP, Hikida RS, Hagerman FC, Staron RS, Allen. WH. A morphometric analysis of human muscle fibers with relation to fiber types and adaptations to exercise. I Neurol Sct. $1981 ; 49: 165-79$.

59. Staron RS, Hikida RS, Hagerman FC, Dudley GA, Murray TF. Human skeletal muscle fiber type adaptability to various worklloads. J Histochem Cytochem. 1984; 32: 146-52.

60. Friden J, Sjostrom M, Ekblom B. Muscle fibre type characteristics in endurance trained and untrained individuals. EuW / Appl Physiol Occup Physiot. 1984; 52: 266-71. 
61. Pruchnic R, Katsiaras A, He J, Winters C, Kelley DE, Goodpaster BH. Exaroise Training Increases Intrannyocellular Lipid and Oxidative Capacity in Older Adults. Am / Physiol Endocrinol Aetall. 2004;

62. Thamer $C$, Machann J, Bachmann $O$, Haap M, Dahl D, Wierek B, Tschritter $O$, Niess $A$, Brechtel K, Fritsche A, Claussen $C$, Jacob S, Schick F, Haring MU, Stumvoll M. Intramyocellular lipids: anthropometric determinants and relationships with maximal aerobic capacity and insulin sensitivity. / Clin Endocrinol Metab. 2003; 88: 1785-91.

63. Helge JW, Wulff B, Kiens B. Impact of a fat-rich diet on endurance in man: rolle of dre dietary period. Med Sci Sports Exerc. 1998; 30: 456-61.

64. Helge JW, Watt PW, Richter EA, Rennie MJ, Kiens B. Fat utilization during exercise: adaptation to a fat-rich diet increases utilization of plasma fatry acids and very low density lipoprotein-triacylglycerol in humans. / Physiol. 2001; 537: 1009-20.

65. Zderic TW, Davidson CJ, Schenk S, Byerley LO, Coyle EF. High-Fat Diet Elevates Resting Intramuscular Triglyceride Concentration and Whole-Body Lipolysis During Exercise. Am JPhysiol Endocrinal Metal. 2003;

66. Kiens B, Essen-Gustavsson B, Gad P, Lithell H. Lipoprotein lipase activity and intramuscular triglycetide stores after long-term high-fat and high-carbohydrate diets in physically trained men. Clin Physiol. 1987; 7: 1-9.

67. Jansson E, Kaijser L. Effect of diet on muscle glycogen and blood glucose utilization during a short-term exercise in man. Acta Pbysiol Scand. 1982; 115:341-7.

68. Vogr M, Puntschart A, Howald H, Mueller B, Mannhart C, Gfeller-Tuescher L, Mullis P, Hoppeler H. Effects of dietary fat on muscle substrates, metabolism, and performance in athletes. Med Sci Sports Exerc. 2003; 35: 952-60.

69. Bachmann OP, Dahl DB, Brechtel K, Machann J, Haap M, Maier T, Loviscach M, Stumvoll $M$, Claussen CD, Schick F, Haring HU, Jacob S. Effects of intravenous and dietary lipid challenge on intranyocellular lipid content and the relation with insulin sensitivity in humans. Diabetes. 2001; $50: 2579-84$.

70. Johnson NA, Stannard SR, Mehilski K, Trenell MI, Sachinwalla T, Thompson CH, Thompson MW. Intrannyocellular triacylglycerol in prolonged cycling with high-and lowcarbohydrate availability. J Appl Physiol. 2003; 94: 1365-1372.

71. Schrauwen P, Wagenmakers AJ, van Marken Lichtenbelt WD, Saris WH, Westerterp KR. Increase in fat oxidation on high-fat diet is accompanied by an increase in triglyceridederived fatty acid oxidation. Diabetes. 2000; 49:640-6.

72. Goodpaster BH, Theriault R, Watkins SC, Kelley DE. Intramuscular lipid content is increased in obesity and decreased by weight loss. Metabolism. 2000; 49: 467.72.

73. Perseghin $G$, Scifo P, Danna M, Battezzati A, Benedini S, Meneghini E, Dell Maschio $A_{*}$ Luzi $\mathrm{L}$. Normal insulin sensitivity and IMCL content in overweight humans are associared with higher fasting lipid oxidation. Am J Physiol Endocrinol Metab. 2002; 283; 1556-64.

74. Boden $G$, Lebed B, Schatz M, Homko C, Lemieux S. Effects of acute changes of plasma free fatty acids on intramyocellular fat content and insulin resistance in healny subjects. Diabetes. 2001; 50: 16127 .

75. Stannard SR, Thompson MW, Fairbairm K, Huard B, Sachinwalla T, Thompson CH. Fasting for $72 \mathrm{~h}$ increases intramyocellular lipid content in nondiabetic, physically fit men.. A m I Physiol Endocrinol Metab. 2002; 283: E1185-E1191.

76. Phillips DI, Caddy $S$, llic V. Fielding BA, Frayn KN, Borthwick AC, Taylor R. Intranuscular triglyceride and muscle insulin sensitivity: evidence for a relationship in nondiabetic subjects. Metabolism. 1996; 45:947-50.

77. Perseghin $G$, Scifo P, De Cobelli F, Pagliato E, Battezzati A, Arcelloni C, Vanzulli A, Testolin G, Pozza G, Del Maschio A, Luzi L. Intranyocellular triglyceride content is a determinant of in viro insulin resistance in humans: a $1 \mathrm{H}-13 \mathrm{C}$ nuclear magnetic resonance spectroscopy assessment in offspring of type 2 diabetic parents. Diabetes. 1999; 48: 1600-6.

78. Jacob S, Machanı J, Rett K, Brechtel K, Volk A, Renn W, Maerker E, Mathlaei S, Schick $\mathrm{F}$, Claussen $\mathrm{CD}$, Haring HU. Association of increased intramyocellular lipid content with 
insulin resistance in lean nondiabetic offspring of type 2 diabetic subjects. Diabetes. 1999 ; 48: 1113-9.

79. Faholt K, Jensen I, Lindkaer Jensen S, Mortensen $H$, Volund A, Heding LG, Noerskov Petersen $P$, Falholt W. Carbohydrate and lipid metabolism of skeletal muscle in type 2 diabetic patients. Diabet Med. 1988; $5: 27-31$.

80. Tunstall RJ, Mehan KA, Wadley GD, Collier GR, Bonen A, Hargreawes M, CameronSmith D. Exercise training increases lipid metabolism gene expression in human skeletal muscle. Am J Pbysiol Endacrinol Metab. 2002; 283: $\mathbb{1} 66-72$.

81. Bruce CR, Andersoin MJ, Carey AL, Newman DG, Bonen A, Kriketos AD, Cooney GJ, Hawley JA. Muscle oxidative capacity is a better predictor of insulin sensitivity than lipid status. J Clin Endocrinol Metab. 2003; 88: 5444-51.

82. Petersen $K F^{*}$, Dufour S, Befroy $D$, Garcia $R$, Shulman GI. Impaired mitochondrial activity in the insulim-resistant offspring of patients with type 2 diabetes. $N$ Engl J Med. 2004; 350 : 66471 .

83. Shulman GI. Cellular mechanisms of insulin resistance. J Clin Invest. 2000; 106: 171-6.

84. Bramble DM, Lieberman DE. Endurance running and the evolution of Homo. Nature. $2004 ; 432: 345-52$. 


\section{SUMMARY}

Although most fat in the human body is stored in adipose tissue, a small fraction is located inside skeletal muscle cells in the form of lipid droplets in the sarcoplasm (intramyocellular lipid, IMCL). This thesis focuses on the investigation of intramyocellular lipid content under various circumstances as measured by proton Magnetic Resonance Spectroscopy ('H-MRS). With this technique, measurements can be performed repeatedly in the same volume of muscle and in a non-invasive way.

The elevated IMCL content in endurance trained subjects and the location of IMCL droplets near the mitochondria, led to the suggestion that IMCL can serve as an intramuscular energy source during prolonged exercise. Remarkably, it was found that IMCL content was also elevated in type 2 diabetes mellitus and that IMCL content correlated with insulin resistance. Insulin resistance is an important risk factor for developing type 2 diabetes mellitus. These findings suggest that IMCL may be involved in the development of insulin resistance and type 2 diabetes. In that respect, it seems paradoxical that IMCL content is also elevated in endurance trained athletes, who are very insulin sensitive.

Long-term endurance training is accompanied by a lot of physiological adaptations that can increase insulin sensitivity (e.g. increased perfusion, increased fat-free mass and change in fiber type) and these adaptations might overcompensate a negative influence of IMCL on insulin sensitivity. Therefore, we investigated the effect of a two-week training program on $\mathrm{MCL}$ content and insulin sensitivity in Chapter 3. After such a short-term training intervention, long-term adaptations of endurance training can be ruled out. After a training period of two weeks, we found that IMCL content was increased by $42 \%$ and this was not accompanied by a decrease in insulin sensitivity. On the contrary, all markers of insulin sensitivity pointed towards an improvement in insulin sensitivity, albeit not statistically significant. The finding that such a short term training intervention leads to an increase in both IMCL content and insulin sensitivity, provides support to the notion that IMCL content per se cannot be the culprit in hampering insulin sensitivity. In fact, IMCL might serve as an important energy source during prolonged exercise, as we showed in the same study, that IMCL content decreased by $14 \%$ in the vastus lateralis muscle during a three-hour cycling protocol.

To investigate the molecular adaptations in skeletal muscle that accompanied the training-induced increase in IMCL content described in Chapter 3, expression of marker genes of fat- and carbohydrate metabolism were investigated in biopsy specimens obtained in the same study (Chapter 4). A decreased expression of ACC2 mRNA (-29\%) was found. As ACC2 is converting acetyl-CoA to malonyl-CoA, which in turn inhibits fatty acid transport into mitochondria, the 
decrease in ACC2 mRNA is interpreted as an adaptation that leads to increased fat oxidative capacity. From these findings we concluded that molecular adaptations in muscle to improve fat oxidative capacity accompany the increase in IMCL content with training even though whole body fat oxidation during exercise; as measured by indirect calorimetry, was not (yet) improved after two weeks of training. This may suggest that the increase of IMCL with training serves to fuel the muscle during physical activity.

In Chapter 5 we showed that IMCL content can be elevated to a similar extent $(+54 \%)$ by consuming a high-fat diet for one week as with two weeks of endurance training. However, in this situation molecular adaptations of the investigated genes differed from the training-induced changes. Namely, ACC2 mRNA levels tended to be increased after the intervention $(+33 \%)$, rather than decreased. Therefore, ACC2 mRNA expression after a high-fat diet did not point to an increased fat oxidative capacity. These results suggest that the increase in IMCL content after a high-fat diet may serve a different goal compared with the increase in IMCL after training: in the latter case, the increase in IMCL is functional and provides more intramuscular substrate, whereas with high-fat feeding the increase may simply be a passive response to the positive fat balance that occurs when switching to a high fat diet.

While the increase in IMCL content after a high-fat diet may not seem favorable in sedentary subjects, it could well be an advantage for athletes who are subjected to extreme endurance exercise, where substrate can limit performance. The decrease of IMCL content during exercise points out a role of this energy store in physical activity and fast replenishment of IMCL content may therefore be an advantage in subsequent exercise. Whether the fat percentage of the diet influences the rate of recovery of IMCL content after exercise in endurance trained athletes was investigated in Chapter 6 . We found that on a moderate-fat diet ( $39 \mathrm{EN} \%$ fat) IMCL content was completely replenished within 48 hours, while this was not the case on a low fat diet ( $24 \mathrm{EN} \%$ fat). Therefore, these results indicate that a diet with more fat does indeed accelerate the repletion of IMCL after exercise. However, it remains to be shown whether the increased IMCL content can improve performance.

The decrease in IMCL content in active muscle during exercise shows that IMCL oxidation contributes substantially to fat oxidation during exercise, although the largest contribution comes from plasma free fatty acids (FFA). During exercise, adipose tissue lipolysis is stimulated to provide FFA to the working muscle. The release of FFA from adipose tissue usually exceeds fat oxidative capacity of the working muscle, leading to increases in FFA plasma concentrations. The majority of the surplus of FA will be re-esterified in adipose tissue, but since liver and muscle are also able to store fat, part of the circulating fatty acids may be re- 
esterified in these tissues. In Chapter 7, we investigated the IMCL content in the active vastus lateralis muscle and the (almost) inactive biceps brachii muscle before and after cycling exercise, which increased plasma faity acid levels substantially. Again, we found that IMCL content in the vastus lateralis muscle decreased by $20 \%$ after exercise, while $\mathrm{MCL}$ content increased by $38 \%$ in the non-exercising biceps brachii muscle. These results indicate that prolonged endurance exercise with its concomitant increase in plasma FFA concentration can result in a net increase in MCL content in less active muscle.

As stated above, there is strong evidence that not IMCL per se is hampering insulin sensitivity, but that the correlation between IMCL content and insulin resistance may represent an indirect relationship. Family members of patients with type 2 diabetes mellitus have an increased risk of developing type 2 diabetes mellitus later in life and are therefore an interesting population to study early developments of the disease. It was found that, next to elevated IMCL content and decreased insulin sensitivity, this population is also characterized by a decreased mitochondrial function, resulting in reduced muscular oxidative capacity. To obtain more insight in the role of IMCL content and oxidative capacity in type 2 diabetes, we investigated both parameters in the vastus lateralis muscle of diabetic subjects and healthy, BMI-matched controls in Chapter 8 . We found that IMCL content was similar, while skeletal muscle oxidative capacity was decreased in type 2 diabetic subjects. Interestingly, oxidative capacity correlated negatively with plasma glucose concentration in diabetic subjects, showing that the decrease in oxidative capacity was related to the degree of illness. These results suggest an important role for oxidative capacity in the pathogenesis of type 2 diabetes mellitus. Recently, it has been suggested that a low oxidative capacity may lead to the accumulation of lipid intermediates that may directly interfere with insulin signaling. This may explain why high levels of IMCL are associated with insulin resistance under conditions, when oxidative capacity is low (type 2 diabetes), whereas under conditions of high oxidative capacity (endurance training), high levels of IMCL do not hamper instlin sensitivity.

In conclusion, the results of the present thesis confirm that IMCL is an important energy source during prolonged exercise. IMCL content can be modulated acutely by factors such as dietary fat content, training status and plasma FFA concentrations. Our results support the view that IMCL content can be increased either to provide more intramuscular energy substrate, as is the case with endurance training, or simply as a consequence of hight fat availability, as it is the case on a high-fat diet and with high FFA plasma concentrations. In conditions where high levels of IMCL are not accompanied by high oxidative capacity, lipid intermediates may accumulate, thereby explaining the relationship 
between $\mathrm{MCL}$ and insulin resistance. In that respect, a low oxidative capacity may be involved in the development of type 2 diabetes mellitus. 


\section{NEDERLANDSE SAMENVATTING}

In het menselijk lichaam wordt vet vooral in het vetweefsel opgeslagen. In skeletspier bevindt een kleine hoeveelheid wet zich echter ook in de vorm van kleine vetdruppels in de spiercellen (intramyocellulaire lipiden, IMCL). Het IMCL gehalte werd in dit proefschrift met de non-invasieve methode proton magnetische resonantie spectroscopie ('H-MRS) gekwantificeerd. Een voordeel van deze niet-invasieve techniek is dat het IMCL gehalte herhaaldelijk kan worden gemeten in dezelfde spier, zodat veranderingen in de tijd, ten gevolge van interventies, kunnen worden bestudeerd. Een ander voordeel van deze methode is dat, in vergelijking met spierbiopten, een groter spiervolume kan worden bestudeerd.

Magnetische resonantie spectroscopie maakt gebruik van een magnetische eigenschap van atoomkernen, die beïnvloed wordt door de chemische ongeving van de kern. Zo zullen b.v. protonen van vet een ander signalal geven dan protonen van creatine zodat deze moleculen kunnen worden geidentificeerd. Verder is er een signaalverschil tussen vet in kleine vetdruppels in een waterige omgeving in spiercellen (IMCL) en vet dat zich in vetweefsel in een vet-rijke omgeving rondom de spierbundels bevindt (extramyocellulair lipid, EMCL). Het vermogen van MRS om het lipidesignaal van IMCL en EMCL te onderscheiden maakt specifieke kwantificatie van IMCL met deze methode mogelijk. IMCL kan zowel worden gekwantificeerd binnen één zorgvuldig gekozen volume van een paar $\mathrm{ml}$ (=voxel) (single voxel MRS) of in honderden voxels tegelijkertijd (magnetic resoncance spectroscopic imaging, MRSI). Verschillen in IMCL gehalte binnen een spier of tussen spiergroepen kunnen m.b.v. deze laatste methode in één meting worden onderzocht. Beide methoden werden in dit proefschrift toegepast.

In plaats van het MR signaal van protonen kan ook het signaal van fosfor kernen ( $\left.{ }^{1} \mathrm{P}\right)$ worden gemeten. In de spier kan op deze manier PCr, ATP en Pi worden gekwantificeerd voor, tijdens en na inspanning. Het PCr gehalte daalt an het begin van inspanning en hersteld snel weer na het stoppen van inspanning. De verandering van het $\mathrm{PCr}$ gehalte gedurende en na inspanning geeft informatie over het oxidatieve vermogen van de onderzochte spier.

In dit proefschrift werd onderzocht hoe het gehalte van IMCL onder diverse omstandigheden veranderd en of de verandering gepaard gaat met veranderingen in andere fysiologische parameters, zoals insulinegevoeligheid of oxidatieve capaciteit. Op deze manier werd getracht inzicht te krijgen in de rol van IMCL, enerzijds als energiebron bij inspanning en anderzijds bij het ontstaan van ouderdomssuikerziekte.

Uit voorgaand onderzoek is al bekend dat het IMCL gehalte verhoogd is in duurgetrainde sporters en dat de IMCL druppels zich in de buurt van 
mitochondrièn, de energiecentrales van de cellen, bevinden. Deze bevindingen leidden tot de suggestie dat IMCL als een intracellulaire energiebron voor langdurige inspanning, wanneer veel vet wordt verbrand, dient. Opmerkelijk was echter de bevinding dat patiënten met type 2 diabetes mellitus (ouderdomssuikerziekte) ook gekarakteriseerd worden door een verhoogd IMCL gehalte. Bovendien correleert het IMCL gehalte sterk met de mate van insuline resistentie. Deze bevindingen wijzen erop dat $\mathrm{MMCL}$ een rol zou kunnen spelen in de ontwikkeling van insuline resistentie en type 2 diabetes. Deze bevinding is opmerkelijk omdat het IMCL gehalte ook werhoogd is in duurgetrainde sporters, die juist heel erg gevoelig voor insuline zijn.

Een mogelijke verklaring voor deze paradox is dat jarenlange duurtraining leidt tot andere fysiologische aanpassingen die de insulinegevoeligheid kunnen verhogen (bijwoorbeeld: verbeterde spierdoorbloeding, meer spiermassa en een verandering in het type spiervezels). Het is daarom zeer goed mogelijk dat deze aanpassingen compenseren voor de mogelijke negatieve invloed wan een verhoogd IMCL gehalte op de insuline gevoeligheid. Om deze mogelijkheid te toetsen hebben we in hoofstuk 3 het effect van een duurtrainingsprogramma van 2 weken op het IMCL gehalte en de insulinegevoeligheid in ongetrainde proefpersonen onderzocht. Twee weken duurtraining is te kort om de bovengenoemde lange-termijn aanpassingen te bewerkstelligen. We vonden dat twee weken duurtraining leidde tot een toename van het IMCL gehalte van $42 \%$ en de toename in IMCL gehalte ging niet gepaard met een afname van de insulinegevoeligheid; alle indirecte parameters wezen eerder op een toegenomen insuline gevoeligheid. Deze bevinding duidt er op dat het IMCL gehalte per se geen negatief effect heeft op de insuline gevoeligheid. Aangezien duurtraining leidt tot een toename van het IMCL gehalte ligt het meer voor de hand dat IMCL dient als een belangrijke energiebron tijdens inspanning. Deze suggestie wordt ondersteund door de bevinding dat in bovengenoemde studie het IMCL gehalte in de vastus lateralis, één van de quadriceps spieren die intensief gebruikt wordt tijdens het fietsen, met $14 \%$ afnam tijdens een fietsinspanning van drie uur.

Om te onderzoeken welke moleculaire aanpassingen gepaard gaan met de training-geinduceerde toename in IMCL gehalte beschreven in hoofdstuk 3, werd in skeletspierbiopten de mRNA expressie bepald van genen betrokken bij het vet-en lsoolhydraatmetabolisme (hoofdstuk 4). mRNA expressie van ACC2 bleek significant verlaagd (29\%) na twee weken duurtraining. ACC2 is betrokken bij de omzetting van acetyl-CoA naar malonyl-CoA, wat een sterke remmer van het mitochondriële vetzuurtransport is. Een afname van ACC2 wordt daarom ook gezien als een aanpassing die leidt tot een toename van de capaciteit om vetten te verbranden. Ondanks het feit dat op lichaamniveau nog geen toegenomen vetverbranding werd gemeten, lijkt de trainingsgeïnduceerde toename in IMCL gehalte gepaard te gaan met een toename van de capaciteit van 
de spier om vet te verbranden, wat opnieuw suggereert dat MMCL na training dient als energiebron voor de spier tijdens inspanning.

In hoofdstuk 5 hebben we het effect van één week vetrijke voeding op het IMCL gehalte onderzocht en gevonden dat dit leidt tot een vergelijkbare stijging in MCL gehalte $(+54 \%)$ als twee weken duurtraining. Opnieuw werden de moleculaire aanpassingen in de skeletspier onderzocht: in tegenstelling tot de daling in ACC2 na training, ging de toename in $\mathrm{MCL}$ gehalte door verrijke voeding gepaard met een tendens tot een toename in ACC2 mRNA $(+33 \%)$, wat duidt op een afname in capaciteit om vetten te verbranden. De toename in IMCL na een vetrijke voeding lijkt daarom een andere reden te hebben dan de toename in IMCL gehalte na duurtraining: in het laatste geval lijkt de toename van IMCL. te dienen als extra energiebron voor de spier tijdens inspanning, terwijl na een vetrijke voeding de toename van $\mathrm{MCL}$ gehalte mogelijk een simpele passieve reactie is op de positieve vetbalans (vetinname groter dan vetverbranding) die ontstaat bij het consumeren van vetrijke voeding. Het overschot aan vet wordt simpelweg (ook) opgeslagen in de spier.

De toename van het IMCL gehalte als gevolg van het consumeren van een vetrijke voeding is mogelijk een schadelijke consequentie van een te hoge vetinname. Toch kan het verhogen van het IMCL gehalte door vetrijke voeding misschien gunstig zijn voor duursporters, zodat zij meer energievoorraad hebben voor langdurige inspanningen. Het feit dat het IMCL gehalte afneemt na duurinspanning (hoofdstuk 3) duidt er op dat het gunstig kan zijn om deze voorraad na inspanning weer snel an te vullen, zodat bij een volgende inspanning weer voldoende substraat voorradig is. Daarom onderzochten we in hoofdstuk 6 of we de snelheid waarmee IMCL aangevuld kan worden na inspanning konden verhogen door het vetgehalte van de voeding te verhogen. We vonden dat de consumptie van een voeding met een 'normaal' vetgehalte (39 energie\% vet) leidde tot een volledig herstel van het IMCL gehalte binnen 48 uur na inspanning, terwiil het IMCL gehalte niet volledig tot het uitgangsniveau was hersteld indien een vetarme, voor duursporters gebruikelijke, voeding (24 energie\% vet) werd geconsumeerd. Deze resultaten tonen dus inderdaad aan dat het vetgehalte van de voeding de snelheid warmee IMCL aangevuld kan worden na inspanning positief beinvloedt. Of hogere IMCL voorraden ook inderdaad leiden tot een verbeterde duurprestatie moet echter nog verder worden onderzocht.

De afname in het IMCL gehalte in actieve spieren tijdens inspanning duidt er op dat IMCL bijdragen aan de totale vetverbranding tijdens inspanning. Toch is bekend dat de grootste bijdrage aan de vetverbranding in de spier geleverd wordt door de vetzuren die in het bloed circuleren. Tijdens inspanning wordt de afbraak van vet in het vetweefsel gestimuleerd, waardoor de concentratie 
circulerende vetzuren toeneemt, zodat de spier meer vetzuren voor vetverbranding kan opnemen. De toename in circulerende vetzuren overschrijdt echter de mate warin de vetzuren kunnen worden verbrand, waardoor de vetzuurconcentratie in het bloed tijdens inspanning blijft stijgen. Het merendeel van het overschot an circulerende vetzuren zal opnieuw worden opgenomen in het vetweefsel en aldaar worden opgeslagen. Echter, omdat ook de lever en spier in staat zijn om vetten op te nemen en op te slaan, is het mogelijk dat ook deze weefsels een deel van het overschot aan circulerende vetzuren opslaat. In hoofdstuk 7 hebben we het IMCL gehalte gemeten voor en na inspanning in een actieve (vastus lateralis) en een inactieve (biceps brachii) spier. Tijdens inspanning nam de concentratie circulerende vetzuren inderdaad sterk toe, terwijl het IMCL gehalte in de actieve spier daalde met ongeveer $20 \%$. In de inactieve spier nam het MCL gehalte echter toe met $38 \%$ na inspanning, vermoedelijk door passieve opname van de circulerende vetzuren. Deze resultaten tonen aan dat duurinspanning kan leiden tot een netto toename van IMCI in inactieve spieren.

Zoals eerder opgemerkt is er een sterke correlatie tussen het IMCL gehalte en de mate van insuline resistentie. Echter, er zijn ook sterke aanwijzingen dat niet het IMCL gehalte per se een negatief effect heeft op de insuline gevoeligheid. Eerstelijnsverwanten van patiënten met type 2 diabetes mellitus hebben een sterk verhoogd risico dat zij op hogere leeftijd ook deze ziekte krijgen. Om deze reden wordt deze populatie veelvuldig gebruikt om de vroege ontwikkeling van type 2 diabetes mellitus te bestuderen. In deze populatie werd onder andere gevonden dat de insuline gevoeligheid al verlaagd is, het IMCL gehalte verhoogd en het mitochondriële functioneren in de spier verstoord. Een verminderd mitochondrieel functioneren zal leiden tot een verminderde oxidatieve capaciteit van de skeletspier. Uit deze studies kan echter niet geconcludeerd worden of het verhoogde IMCL gehalte of het verminderde mitochondrieel functioneren gerelateerd is an het ontstaan van insuline resistentie en type 2 diabetes mellitus. Daarom hebben we in hoofdstuk 8 beide parameters gemeten in de vastus lateralis van patiënten met type 2 diabetes en in gezonde controles met een gelijke mate van overgewicht. Het bleek dat het MMCL gehalte identiek was in beide groepen mar dat de oxidatieve capaciteit van de spier verlaagd was in patienten met type 2 diabetes mellitus. Bovendien was de oxidatieve capaciteit sterk negatief gecorraleerd met het glucose gehalte van het bloed, wat er op duidt dat de daling van de oxidatieve capaciteit gerelateerd was aan de ernst van de ziekte. Deze resultaten suggereren dat de oxidatieve capaciteit mogelijk belangrijker is bij het ontstaan van type 2 diabetes dan IMCL gehalte per se. Recentelijk is gesuggereerd dat een lage oxidatieve capaciteit van de spier, samen met hoge IMCL gehaltes, kan leiden tot de stapeling van vetzuurintermediairen, welke een direct (negatief) effect op de cellulaire insuline signalering kunnen hebben. Mogelijkerwijs, leidt een hoog IMCL gehalte alleen rot insuline resistentie indien dit gepaard gat met een lage oxidatieve capaciteit (zoals bij 
type 2 diabetes), waardoor de vetzuurintermediairen in de spiercel stapelen, terwijl een hoog IMCL gehalte in combinatie met een hoge oxidatieve capaciteit (zoals bij duurtraining) geen negatief effect op de insuline gevoeligheid zal hebben.

In conclusie, de resultaten van dit proefschrift bevestigen dat IMCL een belangrijke energiebron tijdens durinspanning is. Het IMCL gehalte wordt beïnloed door omgevingsfactoren zoals het vetgehalte van de voeding, de mate van getraindheid en interventies die de concentratie circulerende vetzuren verhogen. De toename in IMCL gehalte door deze factoren kan enerzijds tot doel hebben om extra intramusculaire energievoorraden te verkriigen (zoals bij) duurtraining), anderzijds kan het een simpel gevolg zijn van een te hoog vetaanbod aan de spier (zoals bij vetrijke voeding of bij hoge vetzuurconcentraties in het bloed). Indien het hoge IMCL gehalte niet gepaard gaat met een hoge capaciteit om vetten te verbranden zullen vetzuurintermediairen mogelijk opstapelen in de spiercel, waardoor insuline resistentie kan ontstaan. Een verminderde oxidatieve capaciteit lijkt daarom ook betrokken bij het ontstaan van type 2 diabetes mellitus. 


\section{DANKWOORD}

Heel veel mensen hebben aan dit proefschrift bijgedragen en ik wil dit proefschrift dan ook graag afsluiten met een woord van dank.

Allereerst wil ik Eline, mijn dagelijkse begeleidster bedanken. Eline, je had de MMCL mering al opgezet, zodat ik meteen met experimenten aan de slag kon. Gedurende mijn hele aio-periode was je een geweldige begeleidster, ik kon altijd met van alles bij je terecht en je maakte altijd tijd voor me vrij. Ik heb veel van je geleerd en kijk uit naar de vervolgonderzoeken, die we hebben gepland.

Mijn promotoren Prof Jos van Engelshoven en Prof Klaas Nicolay wil ik ook heel hartelijk danken. Prof van Engelshoven, u heeft met een echt hart voor onderzoek altijd weer moeilijkheden opgelost en dit onderzoek mogelijk gemaakt. Klaas, de gespreken met jou waren altijd waardevol en we hebben veel van je expertise kunnen profiteren.

De beoordeelingscommissie wil ik graag bedanken voor het doorlezen en beoordelen van mijn proefschrift.

Ik wil ook graag alle collega-onderzoekers van de afdeling Radiologie bedanken voor de gezellige sfeer. Ik had het erg naar mijn zin en jullie waren altijd heel behulpzaam. In het bijzonder wil ik mijn diverse kamergenoten bedanken: Vincent, Marc L, Marianne, Quido, Dave en Robbert, ik vond het erg gezellig met jullie! En Marianne, ik vind het heel erg leuk dat je ook paranimph wilt zijn! Ik hoop ook dat we binnenkort weer eens het tennis racket op kunnen pakken! Jaap, je bent onze andere spectro-aio en hebt me meer dan eens kunnen helpen als ik vast zat, bedankt! Marc $G$, je hebt mijn computer problemen altijd opgelost, heel erg bedankt!

Alle MRI laboranten will ik bedanken voor alle hulp met mijn "rare spectroproblemen" en voor de hulp als ik de scanner ruimte vanwege zwangerschap niet binnen mocht en vanuit de deur moeilijke instructies gaf. Eveline, Henk, Etienne en Axel heb ik bijzonder vaak lastig gevallen, maar jullie hebben me altijd uitstekend geholpen. Bedankt!

Fons wist altijd een antwoord op de statistische vragen, heel erg bedankt! Mijn dank gaat ook naar alle andere collega's van de afdeling, die me op allerlei manieren altijd weer hebben geholpen. Ine, zonder jou zou dit boekje er niet zo mooi uitzien. Heel erg bedankt voor het lay-outen!

De samenwerking met de vakgroepen Humane Biologie en Bewegingswetenschappen was heel belangrijk voor de experimenten beschreven in dit proefschrift. Alleen door de goede samenwerking kon dit proefschrift met fysiologische artikelen gerealiseerd worden. Deze samenwerking heeft me ook de mogelijkheid gegeven om in het moleculair biologisch lab te werken en op die manier een extra facet aan dit proefschrift toe te voegen.

Patrick en Matthijs, jullie werden gaande weg steeds nauwer betrokken en hebben dan ook hoe langer hoe meer de rol van "fysiologische" begeleiders waar 
genomen. Ik wil jullie bedanken voor jullie inzet en interesse, ik kon veel van jullie leren en verheug me er op om ook in de toekomst samen te werken.

Bij de bepalingen in her lab was ik niet ver gekomen zonder de geduldige instructies en grote hulp van Esther en Gert, die ik bij deze heel hartelijk wil bedanken.

Luc en Rene, gelukkig schrikten jullie niet terug voor metingen 's avonds laat en in het weekend! Ik wil jullie heel erg bedanken voor jullie inzet en de prettige samenwerking.

Marco en Janna waren onmisbaar bij hoofdstuk acht, in het bijzonder wil ik jullie bedanken voor jullie hulp bij het scannen toen ik zwanger was. En ook met jou, Marco, zal ik in de toekomst samenwerken, waar ik naar uit kijk.

Natuurlijk hebben ook andere collega's van Humane Biologie en Bewegingswetenschappen me altijd weer verder geholpen, mijn dank daarvoor!

Verschillende stagiaires hebben ook mee gewerkt aan dit proefschrift en ik wil graag Marjon Jacobs, Christine Nabuurs, Janna van Diepen, Niels Boon en Steven Constandse bedanken voor hun bijdrage.

Ik wil ook graag Henk de Feyter, Jeanine Prompers en Jeroen Jeneson uit Eindhoven bedanken woor de interessante gesprekken en bijeenkomsten. Henk, jou wil ik nog in het bijzonder bedanken voor je inbreng bij het maken van de ergometer. Ook Hans Savelberg heeft meegewerkt aan de ontwikkeling van de ergometer alsmede het medebegeleiden van onze stagiaire Marjon: mijn dank daarvoor!

Annemie, Mariëlle, Harry, Alex en Eva van pulmonologie wil ik ook graag bedanken voor hun inzer bij het toepassen van ${ }^{31} \mathrm{P}$-spectroscopie bij patiënten.

Paul Laeven en collega's van de instrumentele dienst hebben de ergometer gemaakt en altijd hun best gedaan als iets met spoed gerepareerd moest worden. Hartelijk dank!

Graag wil ik ook alle proefpersonen bedanken, die aan de studies hebben mee gedaan zonder wie ik geen van de experimenten had kunnen doen. Ook iedereen die voor me in de scanner heeft gelegen om een sequentie of een spoel te testen wil ik heel hartelijk danlken. Vaak was het 's avonds en meestal duurde het langer dan gepland...

Ook bij de mensen uit mijn privé leven wil ik even stil blijven staan en de gelegenheid nemen om mijn familie in Zwitserland, in het bijzonder mijn ouders te bedanken. Liebes Mami, Lieber Papi, Ihr habt mich mit unglaublichem Vertrauen unterstuezt und sicherlich nicht nur leichten Herzens, aber immer wohlwollend habt Thr meinen Weg hier in Holland mitverfolgt. Holland ist zwar weir weg, aber wie Papi sagt, Amerika waere viel weiter...

Lieber Chrigi und liebe Regula, obwohl ich wenig von mir hoeren lasse und Thr auch vielbeschaeftig seid, kann das unserem speziellen Geschwisterband nichts anhaben! Es ist soweit, auch Eure Babyschwester hat ihr Buechlein fertig! Und 
Dir, Regula, moechte ich noch ganz besonders dafuer danken, dass Du mir als "Paranimph" beistehen moechtest.

Auch alle Freunde in der Schweiz, die mir meine Schreib-und Telefonierfaulheir nie uebel genommen haben, will ich ganz herzlich danken: Nuschi, Babsy, Fluri, Martine, Miri, und Moni, ich denke viel an Euch und hoffentlich bis bald wieder mal!

Mijn schoonfamilie heeft me hier in Nederland wortels gegeven en ik wil ze daarvoor heel hartelijk danken. In het bijzonder wil ik Liza en Cor bedanken, jullie stonden altijd meteen klaar als we vanwege congressen, zieke kinderen of iets anders moeilijk zaten, hartelijk dank daarvoor!

Ja, Par, je werd eerder al genoemd, maar je steun was natuurlijk veel belangrijker dan alleen de professionele samenwerking. Je hebt altijd in me geloofd. Met veel begrip, en misschien nog belangrijker, soms met onbegrip heb je me de dingen weer laten relativeren. Lieve Pat, ondanks dat ik Zwitserland soms mis, heb ik geen seconde spijt gehad om hier naartoe te komen. Je weet het, he, je bent het voor me!

Max en Sara, jullie zijn natuurlijk het mooiste wat ons kon overkomen. Vermoedelijk beseffen jullie helemaal niet hoeveel vreugde jullie met jullie zo eigen karaktertjes in mijn leven hebben gebracht en door jullie piekerde ik nooit lang als het op het werk even tegen zat.

Het dankwoord is al lang en toch ben ik zeker mensen vergeten, ik hoop dat jullie het me niet aanrekenen. Bedankt allemaal! 


\section{CURRICULUM VITAE}

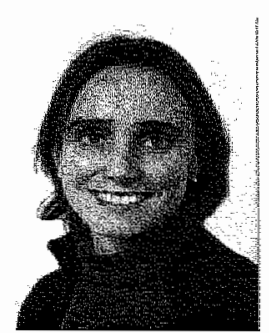

Vera Bettina Schrauwen-Hinderling was born on July 15,1973 in Affoltern a.A., Switzerland. After graduating secundary school at the Gymnasium in Oberwil (BL), Switzerland, she studied Biology (with specialization in chemistry) at the ETH in Zuerich, Switzerland (1993-98). She specialized further by following a one-year postgraduate course with a degree in Human Nutrition at the ETH Zuerich, Switzerland (19981999). In 2000 she was involved in a research project focussing on satiety signals in humans and rats at the Institute of Animal Sciences at the ETH with collaborations with the department of Human Biology at Maastricht University. In January 2001, she started her PhD project at the department of Radiology at the Maastricht University Hospital. In 2001 she was awarded with the NASO travel award to attend the congress of the European Association of the Study of Obesity (EASO) in Vienna and with a travel award for young scientists to attend the international workshop on non-invasive investigation of muscle function in Marseille. In 2005, she was awarded with a scholarship for talented PhD students (Kootstra Fellowship) from the faculty of Medicine of Maastricht University. Presently, she is working part-time as a post-doctoral student at the Department of Radiology at the Maastricht University Hospital and part-time as an assistant professor at the Department of Human Biology of Maastricht University. 
List of Publications (full papers):

Auerbach D, Bantle S, Keller S, Hinderling V, Leu M, Ehler E, Perriard JC. Different domains of the $\mathrm{M}$-band protein myomesin are involved in myosin binding and M-band targeting. Mol Biol Cell 1999;10:1297-308.

Schrauwen P, Hinderling V, Hesselink MK, Schaart G, Kornips E, Saris WH, Westerterp-Plantenga M, Langhans W. Etomoxir-induced increase in UCP3 supports a role of uncoupling protein 3 as a mitochondrial fatty acid anion exporter. Faseb J 2002;16:1688-90.

Hinderling VB, Schrauwen P, Langhans W, Westerterp-Plantenga MS. The effect of etomoxir on 24 -h substrate oxidation and satiety in humans. Am J Clin Nutr 2002;76:141-7.

Schrauwen-Hinderling VB, Schrauwen P, Hesselink MK, van Engelshoven JM, Nicolay $\mathrm{K}$, Saris WH, Kessels AG, Kooi ME. The increase in intramyocellular lipid content is a very early response to training. J Clin Endocrinol Metab $2003 ; 88: 1610-6$.

Schrauwen-Hinderling VB, wan Loon LJ, Koopman R, Nicolay K, Saris WH, Kooi ME. Intramyocellular lipid content is increased alter exercise in nonexercising human skeletal muscle. J Appl Physiol 2003;95:2328-32.

van Loon LJ, Schrauwen-Hinderling VB, Koopman R, Wagenmakers AJ, Hesselink MK, Schaart G, Kooi ME, Saris WH. Influence of prolonged endurance cycling and recovery diet on intramuscular triglyceride content in trained males. Am J Physiol Endocrinol Metab 2003;285:E804-11.

Schrauwen-Hinderling VB, Kooi ME, Hesselink MK, Moonen-Kornips E, Schart G, Mustard KJ, Hardie DG, Saris WH, Nicolay $K$, Schrauwen P. Intramyocellular lipid content and molecular adaptations in response to a oneweek high-fat diet. Obesity Research 2005;13:2088-94.

Schrauwen-Hinderling VB, Hesselink MK, Moonen-Kornips E, Schaart G, Kooi ME, Saris WH, Schrauwen P. Short term training is accompanied by a down regulation of ACC2 mRNA in skeletal muscle. Int J Sports Med, in press.

Schrauwen-Hinderling VB, Hesselink MK, Schrauwen P, Kooi ME. Intramyocellular lipid (IMCL) content in human skeletal muscle. Perspective. Obesity Research, in press. 
Schrauwen-Hinderling VB, Kooi ME, Hesselink MK, Jeneson JA, Backes W, van Echteld CJ, van Engelshoven JM, Mensink M, Schrauwen P.

Impaired in vivo mitochondrial function but similar intramyocellular lipid content in patients with type 2 diabetes mellitus compared to BMI-matched controls. Submitted for publication. 